\title{
PREVISÃO DE PREÇOS NA PECUĀRIA DE CORTE DO ESTADO DE SĀO PAULO
}

ANA LÚCIA KASSOUF

Dissertação apresentada ā Escola Superior de Agricultura "Luiz de Queiroz", da Universidade de São Paulo, para obtenção do título de Mestre en Agronomia. Area de Concentração: Economia Agrária.

\author{
PIRACICABA \\ ESTADO DE SÃO PAULO - BRASIL \\ Abril de 1988
}


Reservo esta pāgina para expressar especial agradecimento ao professor, orientador e amigo Rodolfo Hoffmann com quem aprendi muito, näo sō nas suas excelentes aulas e sua brilhante e firme orientação, mas também pela sua personalidade e simplicidade que me deram uma grande lição de vida.

Na verdade, por mais que escreva, serā pouco para externar minha gratidāo.

Diante disso, a você Rodolfo, o meu muito obrigada. 
Aos meus pais

Ibrahim e Maria Alice

OFEREÇO

Ao meu marido

João Martines

DEDICO 


\section{AGRADECIMENTOS}

Aos professores membros da banca Dr. Geraldo Sant'Ana de Camargo Barros, Dr. Manuel Foll edo e Dr. Pedro Valentim Marques pelas críticas e sugestões.

A todos os professores e funcionários do Departamento de Economia e Sociologia Rural da ESALQ, que direta ou indiretamente colaboraram para a realização desta pesquisa.

Ao Centro de Informática na Agricultura (CIAGRI) por ter proporcionado a utilização dos microcomputadores, indispensāveis na realização desta dissertação e a seus funcionārios que muito me auxiliaram e ensinaram.

A Bolsa de Mercadorias de São Paulo pelo apoio financeiro, em especial a Dra. Irene foldenberg pelo fornecimento de dados e pelo empenho e interesse nesta pesquisa.

Ao Boletim Preços Agrícolas Pecuāria de Corte, em especial a João Gomes Martines Fọ, por ter proporcionado todas as facilidades na obtenção dos dados e nos contatos com especialistas do mercado de carne.

Ao colega Abel Ciro M. Igreja e a todos os outros que me ajudaram e incentivaram.

As bibliotecārias do Departamento de Economia e Sociologia Rural, Angēlica e Luciane.

Ao CNPq e CAPES pelo apoio financeiro. 
SUMARRIO

Pāg ina

LISTA DE TABELAS $\ldots \ldots \ldots \ldots \ldots \ldots \ldots \ldots \ldots \ldots \ldots \ldots \ldots \ldots \ldots \ldots$

LISTA DE FIGURAS $\ldots \ldots \ldots \ldots \ldots \ldots \ldots \ldots \ldots \ldots \ldots \ldots \ldots \ldots \ldots \ldots \ldots \ldots \ldots \ldots$

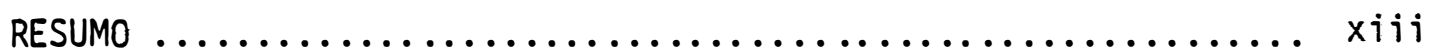

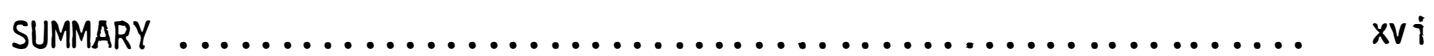

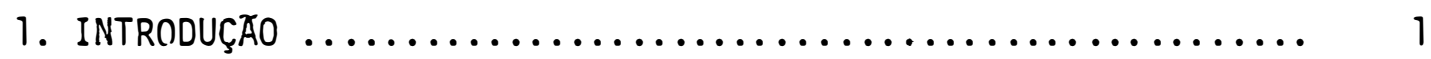

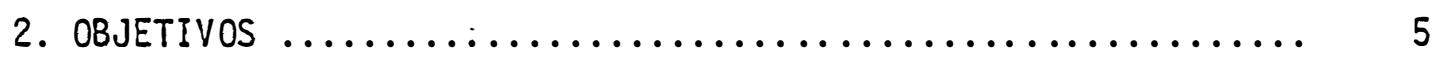

3. REVISAOO DE LITERATURA $\ldots \ldots \ldots \ldots \ldots \ldots \ldots \ldots \ldots \ldots \ldots \ldots \ldots \ldots \ldots \ldots \ldots \ldots \ldots \ldots$

3.1. Método de Anālise Harmōnica .................... 6

3.2. Método de Box e Jenkins (Modelos ARIMA) ............. 7

3.3. Outros Mētodos .......................... 10

4. MATERIAL E METODOS $\ldots \ldots \ldots \ldots \ldots \ldots \ldots \ldots \ldots \ldots \ldots \ldots \ldots \ldots \ldots$

4.1. Os Dados Utilizados ....................... 12

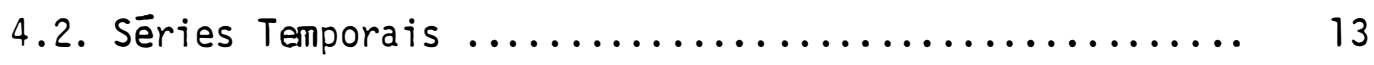

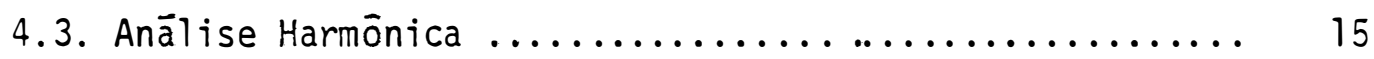

4.4. Métodos de Box e Jenkins (Modelos ARIMA) ............ 19

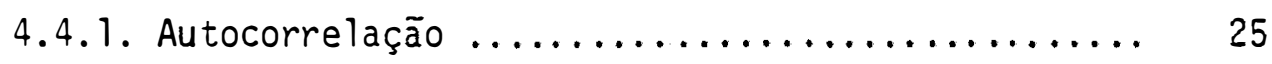

4.4.2. Autocorrelação parcial .................. 29

4.4.3. Testes para verificar se o modelo $\bar{e}$

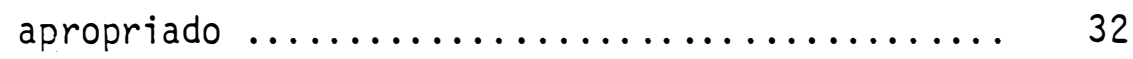

4.4.4. Formas do Modelo ARIMA ................ 35

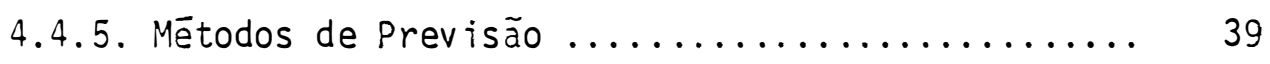

4.4.6. Atualização das previsões .............. 44 
5. RESULTADOS E DISCUSSAO $\ldots \ldots \ldots \ldots \ldots \ldots \ldots \ldots \ldots \ldots \ldots \ldots$

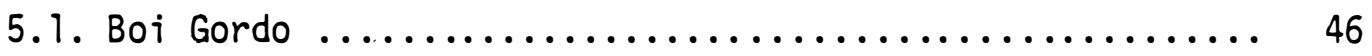

5.1.1. Modelo ARIMA de Box e Jenkins ............. 46

5.1.2. Modelo Harmōnico .................... 53

5.1.3. Modelos Mistos ....................... 54

5.1.4. Fatores modificadores de preços $\ldots \ldots \ldots \ldots . \ldots 6$

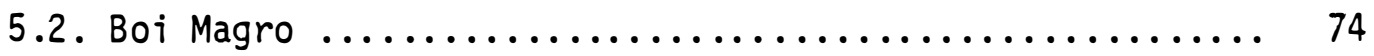

5.3. Bezerro ................................. 81

6. CONCLUSOES $\ldots \ldots \ldots \ldots \ldots \ldots \ldots \ldots \ldots \ldots \ldots \ldots \ldots \ldots \ldots \ldots$

REFERENCIAS BIBLIOGRAFICAS $\ldots \ldots \ldots \ldots \ldots \ldots \ldots \ldots \ldots \ldots \ldots \ldots \ldots$

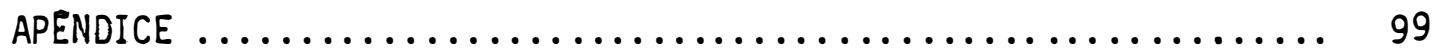




\section{LISTA DE TABELAS}

Tabela nọ

Păgina

5.1. Estimativas dos parämetros obtidas de alguns modelos SARIMA testados na sērie dos logarítmos dos preços mensais da arroba do boi gordo no período de janeiro de 1970 a dezembro de 1986

5.2. Equação obtida do modelo misto cam $A R(2)$ para a sērie de preços reais mensais da arroba do boi gordo no período de janeiro de 1980 a dezembro de 1986

5.3. Previsões de preços reais da arroba do boi gordo, observações obtidas nos mercados fisicos e a ter mo, para 1987, e valor do erro quadrātico médio

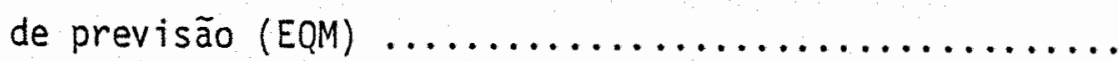

5.4. Equação obtida do modelo mis to com $\operatorname{ARMA}(1,1) \mathrm{pa-}$ ra a sērie de preços reais mensais da arroba do boi gordo no período de janeiro de 1980 a dezem

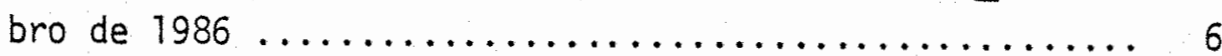

5.5. Previsōes de preços reais da arroba do boi gordo obtidas do modelo mis to com $A R(2)$, observações fornecidas nos mercados físico e a temo para o período de 1981 a 1987 e valores do erro quadrā-

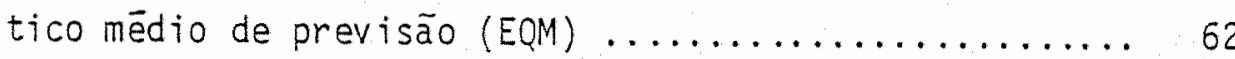

5.6. Variação do Produto Interno Bruto brasileiro no

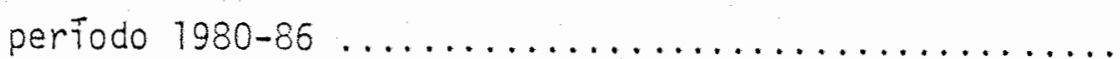


5.7. Equação obtida do modelo misto com $A R(2)$ para a sērie de preços reais mensais do boi magro no pe riodo de janeiro de 1974 a dezembro de $1980 \ldots \ldots \ldots \ldots 77$

5.8. Equação obtida do modelo misto com $\operatorname{AR}(2)$ para a sērie de preços reais mensais do boi magro no pe ríodo de janeiro de 1980 a dezembro de 1986

5.9. Previsões de preços do boi magro obtidas pelo modelo misto com $A R(2)$ e preços do mercado físico para 1981 e 1987

5.10. Equação obtida do modelo misto can $\operatorname{AR}(2)$ para a sērie de preços reais mensais do bezerro no período de janeiro de 1974 a dezembro de $1980 \ldots \ldots \ldots \ldots . .85$

5.11. Equação obtida do modelo misto com $A R(2)$ para a série de preços reais mensais do bezerro no período de janeiro de 1980 a dezembro de $1986 \ldots \ldots \ldots \ldots 86$

5.12. Previsões de preços reais do bezerro e observaçōes do mercado físico para 1987 e 1987 
LISTA DE FIGURAS

Figura nọ

Pägina

4.1. Onda senoidal $\ldots \ldots \ldots \ldots \ldots \ldots \ldots \ldots \ldots \ldots \ldots \ldots \ldots \ldots$

4.2. Representação do MHS no círculo trigonomētrico ....... 16

4.3. Exemplo de função de autocorrelação extraĩda de Box e Jenkins (1976)

4.4. Exemplos de autocorrelações $\left(r_{k}\right)$ e autocorrelaçōes parciais amostrais $\left(\bar{\phi}_{k k}\right)$ para modelos $\operatorname{AR}(1)$, MA(1) e ARMA $(1,1)$. Extraído de MORETTIN e TOLOI

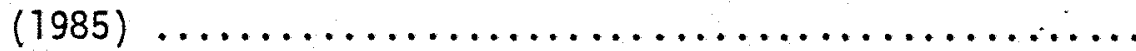

5.1. Grāfico dos preços reais mensais da arroba do boi gordo no período de 1970 a 1987

5.2. Primeiras 48 autocorrelações da sērie do $\log$ do preço do boi gordo, apōs efetuar a $1^{a}$ diferença

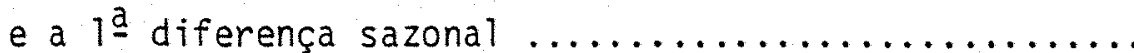

5.3. Primeiras 48 autocorrelaçōes parciais da sērie do $\log$ do preço do boi gordo, após efetuar a $\rceil^{a}$ diferença e a 1 a diferença sazonal $\ldots . . \ldots \ldots \ldots \ldots \ldots$

5.4. Estimativas das autocorrelaçōes dos residuos do modelo SARIMA $(0,1,1)(0,1,1), 12 \ldots \ldots \ldots \ldots \ldots \ldots$

5.5. Previsões de 84 meses ( 7 anos) obtidas a partir do mës 205 (jan.de 1987) pelo modelo SARIMA $(0,1,1)(0,1,1)_{12}$ 
Figura no

5.6. Comparação entre as previsões de preços da arroba do boi gordo obtidas do modelo misto com $A R(2)$, do mercado a termo e observações do mercado físico

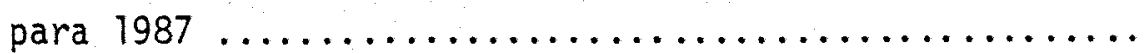

5.7. Comparação entre as previsões de preços da arroba do boi gordo obtidas do modelo misto com ARMA $(1,1)$, do mercado a termo e observaçōes do mercado físico para 1987

5.8. Comparações entre as previsões de preços da arro ba do boi gordo obtidas pelo modelo misto com $A R(2)$, pelo mercado a termo e observações do mer

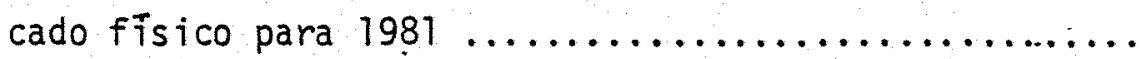

5.9. Comparações entre as previsões de preços da arro ba do boi gordo obtidas pelo modelo misto com $A R(2)$, pelo mercado a termo e observações do mer

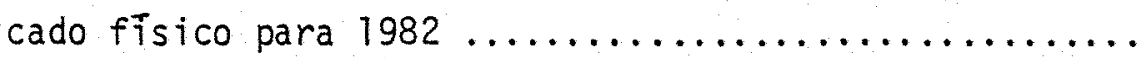

5.10. Comparações entre as previsões de preços da arro ba do boi gordo obtidas pelo modelo misto com $A R(2)$, pelo mercado a termo, e observações do

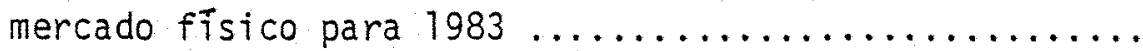

5.11. Comparações entre as previsões de preços da arro ba do boi gordo obtidas pelo modelo misto com $A R(2)$, pelo mercado a termo, e observações do mercado físico para $1984 \ldots \ldots \ldots \ldots \ldots \ldots \ldots \ldots \ldots$ 
Figura nọ

5.12. Comparações entre as previsões de preços da arro ba do boi gordo obtidas pelo modelo misto com $A R(2)$, pelo mercado a termo e observações do mer

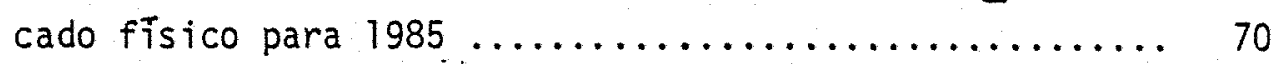

5.13. Comparações entre as previsões de preços da arro ba do boi gordo obtidas pelo modelo misto com $A R(2)$, pelo mercado a termo e observações do mer cado físico para 1986

5.14. Comparações entre as previsões de preços da arro ba do boi gordo obtidas pelo modelo misto com $A R(2)$, pelo mercado a termo e observações do mer

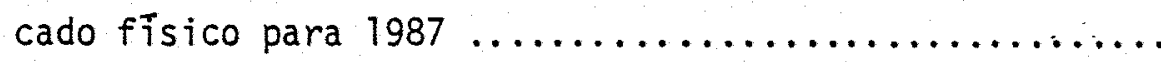

5.15. Gräfico dos preços reais mensais do boi magro no periodo de janeiro de 1970 a agosto de 1987

5.16. Comparações entre as previsões de preços do boi magro obtidas pelo modeto misto com $A R(2)$ e observações do mercado físico para 1981

5.17. Comparações entre as previsões de preços do boi magro obtidas pelo modelo mis to com $\operatorname{AR}(2)$ e observações do mercado físico para $1987 \ldots \ldots \ldots \ldots \ldots \ldots$

5.18. Gräfico dos preços reais mensais do bezerro no periodo de janeiro de 1970 a agosto de $1987 \ldots \ldots \ldots$. 
Figura nọ

Pāgina

5.19. Comparações entre as previsões de preços do bezerro obtidas da regressão com boi magro e observações do mercado físico para 1981

5.20. Comparações entre as previsões de preços do bezerro obtidas da regressão com boi magro e observaçōes do mercado físico para 1987 ..............

5.21. Comparações entre as previsões de preços do bezerro obtidas do modelo misto com AR(2) e obser vações do mercado físico para 1981

5.22. Comparações entre as previsões de preços do bezerro obtidas do modelo misto com $\operatorname{AR}(2)$ e obser vações do mercado físico para $1987 \ldots \ldots \ldots \ldots \ldots \ldots$ 
PREVISAO DE PREÇOS NA PECUARIA DE CORTE DO

ESTADO DE SÃO PAULO

Ana Lūcia Kassouf

Orientador: Prof. Rodolfo Hoffmann

RESUMO

Sēries de preços reais mensais do bezerro, boi magro e da arroba do boi gordo, no período de janeiro de 1970 a dezembro de 1986 , foram analisadas, observando-se as variaçōes existentes e ajustando-se modelos do tipo ARIMA, Harmōnico e mistos, a fim de obter previsões de preços.

Estas séries temporais são compostas por uma tendēncia li near de crescimento dos preços, variaçōes cíclicas estacionais, caracterizadas por periodos de safra e entressafra dentro do ano, e plurianuais, com período em torno de 6 anos, resultante dos abates de matrizes em ēpo cas de preços baixos, alën de variações irregulares.

Aplicando-se o mëtodo de Box e Jenkins à sērie dos logarítmos dos preços da arroba do boi gordo, no período de janeiro de 1970 a dezembro de 1986, foi obtido como melhor modelo um SARIMA $(0,1,1)$ $(0,1,1)_{12}$. Entretanto, este não forneceu boas previsões, não conseguindo captar os ciclos de 6 anos. 
0 modelo harmōnico, aplicado à mesma sērie e no mesmo pe ríodo, conseguiu prever valores razoāveis, porēm, as melhores previsões de preços foram obtidas ao se utilizar modelos mistos com $\operatorname{AR}(2)$ e com ARMA $(1,1)$, ou seja, contendo componentes do modelo harmōnico associados aos do ARIMA.

Todos estes modelos forneceram previsões mensais de preços da arroba do boi gordo para o ano de 1987, as quais foram comparadas, atravēs do erro quadrātico mēdio de previsão, aos preços do mercado físico. Preços obtidos em negociações no mercado a termo do boi gor do da Bolsa de Mercadorias de São Paulo também foram comparados aos pre ços do mercado físico, para a verificação do seu desempenho.

Os resultados mostraram ser o modelo mis to com $A R(2) \quad 0$ que forneceu melhores previsões, vindo en seguida o modelo misto com ARMA $(1,1)$, as previsões do mercado a termo, o modelo harmónico e por ül timo o $\operatorname{SARIMA}(0,1,1) \times(0,1,1)_{12}$.

0 modelo misto com $A R(2)$ foi ajustado à sērie de preços da arroba do boi gordo num periodo mais longo, prevendo preços para 1981 até 1987, ano a ano. Estas previsões de preços, assim como as fornecidas pelo mercado a termo, foram comparadas aos preços do mercado físico. Observou-se que no mercado a termo as previsōes foram melhores em 5 dos 7 anos; en 1982 e 1983 as previsões do modelo misto com $\operatorname{AR}(2)$ foram superiores.

Este resultado nos levou a concluir que as previsões de preços obtidas na Bolsa de Mercadorias de São Paulo são muito boas e refletem os preços do mercado físico. 
As sēries de preços do bezerro e boi magro, foi, tambēm, ajustado o modelo com $\operatorname{AR}(2)$, para obtenção de previsões para 1981 e 1987. Devido à semeihança entre essas sēries, foram obtidas previsões de preços do bezerro atravēs de uma regressão com base nos preços do boi magro. 
Ana Lücia Kassouf

Adviser: Prof. Rodolfo Hoffmann

SUMMARY

Monthly real prices of calf, feeder cattle as well as of fat steer, from january, 1970 up to december, 1986, were analysed. ARIMA, Harmonic and mixed models were fitted, in order to make prices forecasts.

In general, time series can be decomposed in the following itens: a) linear trend, b) seasonal variations, c) a long term cycle (with about six years period, which reflects cows slaughtering when prices are low and fat steers retention in the upward phasis of the cycle) and d) random variations.

The Box and Jenkins processes were adjusted to the logarithm of fat steer prices, fram january, 1970 to december, 1986. The SARIMA $(0,1,1) \times(0,1,1) 12$ model was chosen as the bestone. However, this model was not helpful in forecasting since it failed to capture long term cycles. 
The harmonic model fitted to the same time series resulted in better estimates. However the best prices forecasts were obtained by using the mixed models with $\operatorname{AR}(2)$ and $\operatorname{ARMA}(1,1)$. Each one of these models is a combination of the harmonic and ARIMA models.

A11 of the models provided monthly forecast estimates for prices of fat steer in 1987. These were compared with the prices really practiced under market conditions through the mean square error of forecasting. Futures market prices at the São Paulo Board of Trade were also compared with the actual market prices, in order to verify their performance.

The results showed that the $A R(2)$ mixed model provided the best forecasts, followed by $\operatorname{ARMA}(1,1)$ mixed model, the harmonic model and finally $\operatorname{SARIMA}(0,1,1) \times(0,1,1) 12$. The futures market prices performed between the $\operatorname{ARM}(1,1)$ mixed model and harmonic model.

The $A R(2)$ mixed model was fitted to a longer series of fat steer prices and was used to forecast prices from 1981 up to 1987, annually. These results and the futures market prices were compared with the actual market prices. Futures market predictions performed better in five out of the seven years considered. Better forecasts for 1982 and 1983 were obtained by $A R(2)$ mixed model.

Such results led us to conclude that the price forecasts obtained from the São Paulo Board of Trade are satisfactory and reflect the actual market prices. 
The $A R(2)$ mixed model was also adjusted to the time series of calf and feeder cattle in order to obtain forecast estimates in 1981 and 1.987. Due to the simmilarity between those time series, the price forecasts for calf were obtained through a regression of calf prices on feeder cattle prices. 
1. INTRODUÇAOO

Os mercados de produtos agrīcolas são, muitas vezes, competitivos, ou seja, existe um grande número de vendedores e de compradores com informações sobre o mercado, negociando mercadorias razoavelmente homogèneas (ver, por exemplo, Brandt, 1980). Tambēm ē frequente a situação em que um grande nümero de produtores agrīcolas se defrontam com um número relativamente reduzido de compradores, especialmente quando o produto agrícola é a matéria prima de uma agroindüstria.

A pulverização da produção agropecuäria faz com que os produtores do setor sejam, de maneira geral, passivos $\bar{a}$ formação dos preços, sujeitando-se ao preço estabelecido no mercado.

Por outro lado, é importante o carāter biolōgico da produção agrícola e sua dependência das condiçōes climāticas, o que faz com que a produção planejada seja, em geral, bastante diferente da efetivamente obtida. 
Essas circunstāncias determinam grande instabilidade nos preços agrícolas, em comparação com os preços de produtos e serviços não-agrícolas. Isso mostra a importāncia de se dispor. de um método estatístico para prever, da melhor maneira possível, os preços futuros, que são elementos essenciais para tomar decisōes na produção e na comercialização dos produtos.

O mercado de carne bovina nacional possui características peculiares, apresentando ciclos que se repetem com certa regularidade, com períodos de alta e baixa dos preços, o que torna as tēcnicas de previsão de grande importāncia na orientação dos agentes desse mercado.

A formação destes ciclos jā foi descrità por vārios autores, entre eles: Dias (1972), Mascolo (1980) e Garcia (1984). Os ciclos plurianuais decorrem basicamente das expectativas das cotaçōes do boi gordo no futuro. Se a tendência do preço do boi gordo for declinante e o pecuarista projetā-la para o futuro, nāo haverā estímulo para a produção e retenção de matrizes. Os produtores, necessitando cobrir seus custos e estando os preços baixos, levarão um maior nüméro de animais ao abate, incluindo as matrizes, o que acentuarā a tendēncia de baixa nos preços pelo excesso de oferta. Contudo, esta matança indiscriminada de animais acarretarā em algum tempo escassez de boi gordo, - que farā reverter a tendéncia, com alta nos preços. Havendo uma expectativa futura desta alta, a produção é estimulada e matrizes e be zerros serāo retidos, reduzindo ainda mais a oferta de animais para aba te, acentuando a tendéncia altista dos preços. Entretanto, futuramente 
esta retenção de animais ocasionarā excesso de oferta e consequente declînio nos preços, dando início a nova fase de queda nos preços, e assim sucessivamente.

Alēm desta variação cíclica plurianual, hā tambēm as variações estacionais dentro de um mesmo ano, que decorrem da sazonalidade da produção forrageira. No caso da criação extensiva de gado no Estado de São Pauto, na entrada do periodo das āguas (setembro-outubro), a produção forrageira aumenta, fazendo com que os produtores retenham o gado para obter maior peso, reduzindo com isto a oferta. Ao conträrio, na entrada do período seco (abril-maio) a oferta de boi aumenta, pois o gado é vendido para evitar perdas de peso e prejuízo na venda.

O mercado de carne bovina no Brasil, além de apresentar oscilações nos preços decorrentes de ciclos normais de produção, sofre constantes intervenções goverṇamenta is que acarretam grandes variações dentro da série histōrica e dificultam a obtenção de previsões de preços, uma vez que a uniformidade do comportamento dos preços ao longo do tempo è drasticamente afetada.

0 conhecimento do ciclo pecuário e das variações nos preços é de grande importāncia para os agentes do mercado bovino que trabalham com expectativas, como ē o caso das negociações futuras de boi gordo e garrote realizadas no Mercado a Termo da Bolsa de Mercadorias de São Pauto. Nesse mercado, indivíduos com a posse física da mercadoria podem se assegurar contra oscilaçōes de preços utilizando o mecanismo de "hedge", atravēs da compra ou venda de contratos com datas de vencimento futuro, como descrevem Andrade (1985) e Tsunechiro (1983). 
A ocorrēncia de um período de alta dos preços prejudica os consumidores, diminuindo seu poder de compra e consequentemente 0 consumo per capita de carne. Por outro lado, o periodo de baixa acarreta drāsticas consequências à pecuäria de corte brasileira e descapitaliza o setor. As politicas governamentais visando amenizar essas oscilações de preços poderiam ser mais efetivas se houvesse uma maneira de prever a evolução dos preços com uma precisão razoāvel. 
2. OBJETIVOS

0 objetivo desta pesquisa $\bar{e}$ analisar as variações dos pre ços do bezerro, boi magro e da arroba do boi gordo no estado de São Pau10, levando em consideração a tendēncia, as variações cíclicas, estacionais e plurianuais e as irregularidades que podem ocorrer dentro de uma sērie temporal.

Serão comparados os modelos de Anālise Harmōnica e ARIMA de Box e Jenkins, ajustando-os às séries para obtenção de previsões de preços. Previamente será feita uma exposição sobre aspectos bāsicos da teoria relativa a estes modelos.

Para as très categorias, boi gordo, boi magro e bezerro, as previsões obtidas serão comparadas aos preços do mercado físico, para que se possa avaliar a capacidade preditiva do modelo utilizado.

Preços do boi gordo, estabelecidos en negociações no mercado a termo da Bolsa de Mercadorias de São Paulo, serão comparados aos obtidos através dos modelos estatísticos e tambëm aos do mercado físico, visando estudar o desempenho deste mercado quanto à obtenção de boas pre visões. 


\section{REVISAOO DE LITERATURA}

\subsection{Mētodo de Anāl ise Harmônica}

GARCIA (1984) estudou as variações ciclicas e de tendēncia dos preços anuais (1950-1982), das principais categorias de gado comercializado no Pantanal Matogrossense, comparando-as com as variaçōes de outras regiões pecuārias do paīs. A tendēncia mostrou-se linear, enquan to as oscilaçōes em torno dessa tendēncia, estimadas pelo modelo harmōnico, mostraram a existēncia de um ciclo pecuārio de 8 anos para o boi magro no Pantanal Matogrossense e de 7 anos para o boi gordo no Estado de São Paulo.

Este autor utilizou um modelo harmōnico contendo apenas dois componentes, com períodos de 7 e 8 anos, e atravēs do indice de Doran e Quilkey selecionou aquele que apresentava a maior porcentagem da variação explicada pela regressão.

Assim como GARCIA (1984), värios outros autores, citados a seguir, utilizaram a anāitise harmōnica para o ajustamenteo de 
modelos e estudos de ciclos, porém raramente esta técnica foi utilizada para previsão de preços, que ē o intuito deste trabalho.

SILVEIRA JUNIOR (1979) utilizou modelos de Anālise Harmōnica para estudar o crescimento de bovinos da raça Ibagē e para fazer previsão do peso de abate, levando em consideração a variação estacional do peso do animal.

Atravēs de regressão mültipla com funçäo harmōnica OKAWA (1985) analisou preços e quantidades comercializadas de sardinha no mer cado atacadista de Säo Paulo: Os resultados obtidos permitiram considerar a anālise harmōnica um instrumento de grande utilidade no esclarecimento de fenōmenos cíclicos do mercado de sardinha.

COELHO (1980) empregou a anālise harmōnica a dados de produção de citros, enquanto AMARAL (1968) utilizou-a em dados de precipitaçōes pluviomētricas e DUARTE (1974) no estudo de curva epidemiolögica da ferrugem alaranjada do cafeeiro na Zona da Mata, MG.

\subsection{Método de Box e Jenkins (Modelos ARIMA).}

A técnica de Box e Jenkins é considerada recente, por muitos autores, em comparação aos modelos estatisticos tradicionais. Diante de tal fato, a bibliografia, no que se refere $\bar{a}$ aplicabilidade desta técnica em problemas prāticos e de economia agrícola é escassa, principalmente no Brasil. Isto incentivou-nos a estudar o desempenho dos modelos ARIMA aplicando-os ao estudo das variações de preços da pecuäria de corte no Estado de São Paulo. 
A seguir estäo relacionados alguns trabalhos sobre essa tēcnica.

SCHMITZ e WATTS (1970) utilizaram o modelo ARIMA e a tēcnica de alisamento exponencial para obter previsöes da produção de trigo em quatro grandes paīses exportadores - Estados Unidos, Canadā, Austrāilia e Argentina - no perīodo 1950-1966. O objetivo foi obter pre visões mais precisas comparando as duas tēcnicas utilizadas. Para os Estados Unidos, o modelo ARIMA mostrou-se melhor enquanto que no Canadā, Austrālia e Argentina o método de alisamento exponencial foi superior. Desta forma, os autores concluem que o mëtodo de previsão a ser escolhido depende das condiçōes do problema e dos dados a serem utilizados, sendo portanto específico para cada caso. Alēm disso, salientam 0 fato de os modelos estruturais, is to $\bar{e}$, aqueles que contēm variāveis econômicas de nada superarem, nas previsōes, os modelos estatísticos que utilizam apenas a sērie temporal a ser projetada.

PINO (1980) aplica a técnica de Box e Jenkins às sēries de preços e produção de leite e cafē no Estado de São Paulo, dando ēnfa se $\bar{a}$ anālise de intervenção. Suas conclusões sugerem que os modelos ARIMA são bastante gerais e fornecem previsões precisas. As 1 imitações estão na fase de identificação do modelo, que segundo o autor, exige ex periēncia e perspicācia do pesquisador, a tëm da necessidade do uso de computadores, podendo ocorrer limitações por detalhes de programação.

BRANDT e BESSLER (1981) analisaram trés diferentes métodos individuais de previsão: econométrico, ARIMA e opiniāo de especialistas, além de métodos combinados, para uma sērie de preços de 
suínos nos Estados Unidos, no periodo 1976-1980. Os resultados mostraram ser o modelo ARIMA o melhor mētodo individual para previsāo; porēm, métodos combinados superaram o modelo ARIMA.

LEUTHOLD et alii, citados por BRANDT e BESSLER (1981), compararam modelos econométricos aos modelos ARIMA, para obtenção de previsões de preços em uma sērie temporal de preços diārios de suínos, concluindo que o modelo economëtrico apresentou-se um pouco melhor com relação ao modelo ARIMA.

JUST e RAUSSER (1981) examinaram a performance de vārios modelos econométricos utilizados por firmas americanas para previsão de preços de milho, trigo, farelo de soja, ōleo de soja, soja, algodão, boi em pē e suínos, no período 1976-1978, utilizando preços do mercado futuro como padrão de comparação. Os resultados sugerem que os preços do mercado futuro são preferiveis para o farelo de soja e o ōleo de soja, enquanto que algumas previsōes econométricas são preferíveis para boi gordo e suinos, mostrando-se inconclusivos os resultados para os demais produtos.

Diversos mētodos para previsão de sēries temporais foram comparados por GONÇALVES (1983), entre eles: de Suavização, "Naive", Auto Regressivos e Box e Jenkins. Esses modelos foram utilizados na anālise de dados climatolōgicos, especificamente, a sērie de precipitações pluviais mensais no Municipio de Pindorama, SP, de janeiro de 1950 a abril de 1981. Os resultados permitiram concluir que o modelo ARIMA de Box e Jenkins foi o que mostrou melhor desempenho. 
MASCOLO e SOUZA (1983) aplicaram a técnica de Box e Jenkins à sērie de preços mensais, reais da arroba do boi gordo recebidos pelos pecuaristas do Estado de São Paulo, no perióodo de janeiro de 1975 a dezembro de 1982, selecionando os modelos: $\operatorname{SARIMA}(0,1,1)$ $(0,1,1)_{12}$ e SARIMA $(0,1,0)(0,1,1)_{12}$

\subsection{Outros Mētodos}

DIAS (1972) e MASCOLO (1980) analisaram a pecuāria de corte no Brasil, adaptando um modelo de programação linear dināmica desenvolvido por Josë L. Carvalho na Universidade de Chicago. Estes estudos seguem uma outra linha em relaçāo à utilizada no presente trabaTho, uma vez que utilizaram da anālise estrutural, ou seja, diversos indices econōmicos são avaliados, assim como decisōes que o pecuarista pode tomar em relação ao seu rebanho (por exemplo, o número de bois, novithas e matrizes a vender para abate e número de novithas incorporadas ao estoque reprodutor) são levadas em conta. Os autores reconhecem como grande problema no desenvolvimento da pesquisa a dificuldade na obtenção de dados, necessitando impor inümeras restriçōes e estabelecer com certo grau de arbitrariedade, alguns coeficientes.

Nesta mesma anāiise, MASCOLO (1980) subdividiu em três fases distintas a estrutura de mercado da pecuäria de corte no Brasil, sendo elas: produção, processamento e distribuição. Considerou, dentro da produção, as fases de cria, recria e engorda como sendo caracterizadas por um sistema competitivo de mercado, juntamente com a fase de 
distribuição, realizada por açougues e supermercados. Jā na etapa de processamento, representada pelos frigoríficos, foi constatada a existēncia de um sistema oligopsonista com relação aos produtores e oligopolista em relação aos varejistas. 
4. MATERIAL E METODOS

\subsection{Os Dados Utilizados}

As sēries de preços mensais do bezerro, do boi magro e da arroba do boi gordo foram obtidas do Instituto de Economia Agrícola - IEA e representam valores nominais médios recebidos pelos pecuaristas, ponderados para vārias regiōes de produção do Estado de São Pau 10, no período de janeiro de 1970 a agosto de 1987 . De março a dezembro de 1986, entretanto, devido ao congelamento de preços decretado pelo governo e a cobrança de ágios, os preços fornecidos pelo IEA apresentaram-se defasados em relação aos preços realmente realizados no mercado. Optou-se, então, pela utilização, neste periodo, de dados obtidos de levantamentos diārios realizados pelo CEPEA/FEALQ (Fundação de Estudos Agrärios "Luiz de Queiroz").

Os preços nominais mensais foram deflacionados pelo Indice Geral de Preços - Disponibilidade Interna, da Fundação Getūlio Vargas, com base em março de 1986 . Todo o estudo foi realizado com as séries de preços reais mensais do bezerro, do boi magro e da arroba do boi gordo. 
Os preços do Mercado a Termo foram fornecidos pela Bolsa de Mercadorias de São Paulo, onde as cotaçōes, no caso do boi gordo, são feitas somente nos meses pares do ano. Foram utilizados os preços médios estabelecidos em dezembro do ano anterior ao da previsão, cujas cotações referem-se aos meses de fevereiro, abril, junho, agosto, outubro e dezembro do ano seguinte. Esses preços tambëm foram deflacionados da forma descrita anteriormente.

Para a realização dos cālculos, foram experimentados os se guintes programas para microcomputadores da linha PC/XT: Statistical Graphics System (STATGRAPHICS), The System for Statistics (SYSTAT) e Regression Analysis for Time Series (RATS).

Atravës da comparação dos resultados de exemplos, extraídos do livro de Box e Jenkins (1976), concluiu-se que, para a utilização dos modelos SARIMA, o melhor em termos de precisão, facilidade e rapidez foi o STATGRAPHICS, que foi, então, utilizado para ajustar esse tipo de modelo. O programa RATS trouxe problemas no uso dos componentes sazonais e no processo de convergência. Entretanto, os modelos harmōnicos e mistos foram obtidos atraves do RATS pois somente ele apresentou a possibilidade de incluir variāveis externas ao modelo ARIMA.

\subsection{Séries Temporais}

As sēries temporais, segundo GREENBERG e WEBSTER (1983), possuem certas peculiaridades que levaram à criação de mëtodos especiałs para sua anāitise. São elas: 
- importāncia da ordenação temporal dos valores da série;

- valores de variāveis num determinado tempo serem dependentes de valores de variāveis num tempo anterior, is to $\bar{e}$, presença de alta correlação entre "lags", devido a componentes sazonais;

- uma série temporal de comprimento t não corresponder a t diferentes observações de uma variāvel aleatōria, mas sim, a uma única observação ou realização parcial de um processo estocāstico.

Conceitualmente uma sērie temporal $z_{t} \operatorname{com} t=1,2, \ldots, n$, pode ser dividida em quatro componentes: tendēncia, variação estacional, variação cíclica e variação aleatōria.

Considerando um modelo multiplicativo obtemos:

$$
z_{t}=T_{t} \cdot E_{t} \cdot C_{t} \cdot a_{t}
$$

ou

$$
\log z_{t}=\log T_{t}+\log E_{t}+\log c_{t}+\log a_{t}
$$

onde, a tendēncia $\left(T_{t}\right)$ retrata o comportamento da sērie em um longo período de tempo, podendo ser: crescente, decrescente ou constante. A variação estacional ou sazonal $\left(E_{t}\right)$ mostra as flutuações ocorridas dentro de um ano, em função, basicamente, dos periodos de safra e entressafra da produção agropecuāria. A variação cíclica plurianual $\left(C_{t}\right)$ exibe movimentos com periodos variāveis e maiores que um ano e as variações aleatōias $\left(a_{t}\right)$ mostram as oscilações irregulares causadas por fenômenos climäticos excepcionais, intervençōes governamentais, etc, 


\subsection{Anāitise Harmōnica}

A anālise harmōnica tem sua origem no estudo dos fenōmenos ondulatōrios da física. 0 exemplo bäsico ê o movimento harmōnico simples.

A Figura 4.1. abaixo representa uma onda senoidal, cuja equaçäo é:

$$
Y_{t}=A \cos \left(\omega t-\dot{\xi}_{0}\right)
$$

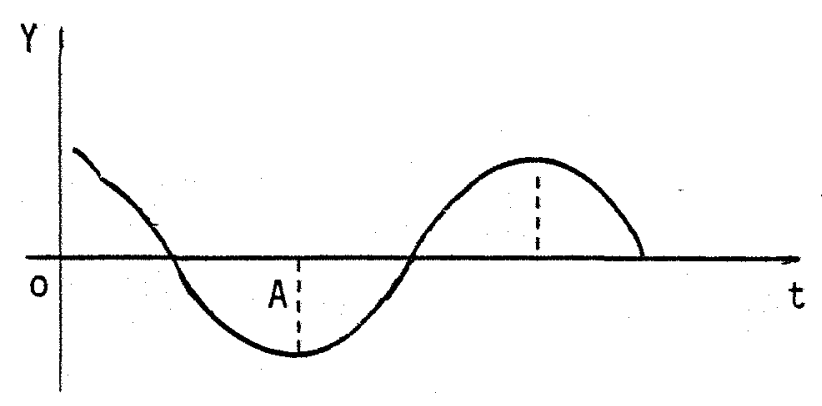

Figura 4.1. Onda senoidal

onde:

$$
\begin{aligned}
A & =\text { semi-amplitude da onda; } \\
-\xi_{0}= & \text { fase inicial } \\
\omega= & \text { velocidade angular ou pulsação } \\
& \omega=\frac{2 \pi}{T}=2 \pi \cdot f(T=\text { perĩodo; } f=\text { frequēncia }) ; \\
t= & \text { tempo. }
\end{aligned}
$$

A Figura 4.2. ilustra a relação entre o āngulo $\omega t-\xi_{0}$ e o valor de $Y_{t}$. 


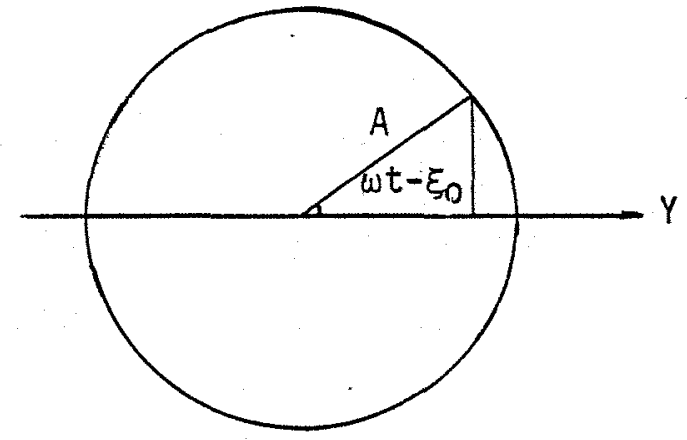

Figura 4.2. Representação do MHS no círculo trigonométrico

Lembrando que $0 \cos (a-b)=\cos a \cos b+\operatorname{sen} a \operatorname{sen} b$, a equação (4.1) pode ser escrita como:

$Y_{t}=A\left(\cos \omega t \cos \xi_{0}+\operatorname{sen} \omega t \operatorname{sen} \xi_{0}\right)$

Podemos escrever:

$A \cos \xi_{0}=a$

$A \operatorname{sen} \xi_{0}=b$

Substituindo-se (4.3) e (4.4) na equação (4.2), obtemos :

$$
Y_{t}=a \cos \omega t+b \operatorname{sen} \omega t
$$

ou ainda,

$$
Y_{t}=a \cos \frac{2 \pi}{T} t+b \operatorname{sen} \frac{2 \pi}{T} t
$$

Elevando ao quadrado e somando as equações (4.3) e (4.4) resulta: 


$$
\begin{aligned}
& A^{2} \cos ^{2} \xi_{0}+A^{2} \operatorname{sen}^{2} \xi_{0}=a^{2}+b^{2} \\
& A^{2}\left(\cos ^{2} \xi_{0}+\operatorname{sen}^{2} \xi_{0}\right)=a^{2}+b^{2} \\
& A=\sqrt{a^{2}+b^{2}}
\end{aligned}
$$

Dividindo (4.4) por (4.3) encontramos:

$\operatorname{tg} \xi_{0}=\frac{b}{a} \therefore \xi_{0}=\operatorname{arctg} \frac{b}{a}$

Conhecidos os valores de a e b, a relação (4.6) permite determinar $\xi_{0}$, levando-se em consideração os sinais de $\underline{a}$ e $\underline{b}$.

E claro que, em geral, as variações cíclicas de uma série temporal com período $T$ não terão a forma de uma senóide e, consequentemente, não serão bem representadas por apenas um componente harmô nico com período $T$. Para obter uma função cíclica com forma mais fle xîvel são incluĩdos no modelo os componentes harmônicos com períodos iguais a vārios submūitiplos de $T$.

Então, dados os valores da sērie $z_{t}$, tem-se:

$$
Z_{t}=\alpha+\sum_{i=1}^{T / 2} Y_{i t}
$$

ou

$$
z_{t}=\alpha+\sum_{i=1}^{T / 2} A_{i} \cos \left(\omega i t-\xi_{0 i}\right)
$$

ou

$$
Z_{t}=\alpha+\sum_{i=1}^{T / 2} A_{i} \cos \left[(2 \pi i t / T)-\xi_{0 i}\right]
$$

ou

$$
z_{t}=a+\sum_{i=1}^{T / 2-1}\left(a_{i} \cos \omega i t+b_{i} \operatorname{sen} \omega i t\right)+a_{T / 2} \cos (\omega t T / 2)
$$


Note-se que o termo sen(wtT/2) não aparece nesta ūltima expressão porq̣ue, como $\omega=2 \pi / T$, seu valor será sempre zero.

Neste trabalho, além do componente cíclico explicado pelo modelo harmōnico, è necessārio tambèm representarmos a tendēncia, que serā dada por um polinômio:

$$
z_{t}=c_{0}+c_{1} t+c_{2} t^{2}+\ldots+c_{m} t^{m}
$$

onde:

$$
\begin{aligned}
& z_{t}=\text { preço no mês } t \\
& t=\text { tempo } \\
& c_{j}=\text { parâmetros da regressão } \\
& m=\text { grau do polinômio. }
\end{aligned}
$$

Desta forma, o modelo a ser estudado serā composto pela tendência, mais a combinação linear de harmōnicos, da seguinte forma: $z_{t}=c_{0}+c_{1} t+\ldots+c_{m} t^{m}+\sum_{i=1}^{T / 2-1}\left[a_{i} \cos (2 \pi i t / T)+b_{i} \operatorname{sen}(2 \pi i t / T)\right]+a_{T / 2} \cos \pi t$ Esse modelo ē uma regressão mūltipla de $z_{t}$ contra $t, t^{2}, \ldots, t^{m}, \cos (2 \pi i t / T)$ e sen $(2 \pi i t / T)$. Os parämetros podem, então, ser estimados pelo método de minimos quadrados da maneira usual. Vale ressaltar que na prätica não é preciso incluir todos os $T / 2$ componentes harmōnicos.

As variações estaciona is tambēm podem ser estimadas através de um modelo de regressão linear mültipla com 11 variāveis binärias $s_{i t}($ com $i=1, \ldots, 11)$, de maneira que $s_{i t}=1$ para o més de ordem $i+1$ e $S_{i t}=0$ para os demais meses. 0 modelo fica 


$$
z_{t}=\alpha+\sum_{i=1}^{11} B_{i} S_{i t},
$$

onde a representa o valor da variävel em janeiro. Note que esse mode10 tem 12 parämetros e que o modelo harmōnico com todos os submültiplos possiveis do período de 12 meses tambēm tem 12 parâmetros ( $\mu, 5$ coeficientes de termos com seno e 6 coeficientes de termos com co-seno). $\mathrm{Na}$ realidade o uso de variāveis binārias e o modelo harmōnico são. equivalentes, isto $\bar{e}$, "explicam" a mesma parcela das variações de $z_{t}$. Os parâmetros do modelo com variāveis binārias são de interpretação mais sim ples, mostrando diretamente a variação estacional dos preços.

Maiores detalhes sobre a Anālise Harmōnica podem ser obtidos em Doran e Quilkey, 1972; Morettin, 1979 e Chatfield, 1984.

\subsection{Método de Box e Jenkins (Modelos ARIMA)}

Para facilitar a explanação dessa metodologia, inicialmente serão analisados os modelos auto-regressivos (AR) e de mēdias mōveis (MA). Posteriormente serão apresentados os modelos ARMA e ARIMA (modelos auto-regressivos, integrados, de mëdias möveis).

Preliminamente são definidos alguns operadores que facilitam a manipulação desses modelos.

Considere a série temporal $Z_{t}, t=1, \ldots, n$.

Utilizando o operador (B) de translação para o passado (Backward), podemos escrever

$$
B Z_{t}=Z_{t-1}
$$


e, em geral,

$$
B^{m} Z_{t}=Z_{t-m}
$$

Analogamente, utilizando o operador $(F)$ de translação para o futuro (Forward), temos

$$
\begin{aligned}
& F^{m} z_{t}=z_{t+m} \\
& 0 \text { operador diferença }(\Delta) \text { e o operador soma }(S) \text { são ca- }
\end{aligned}
$$
racterizados pelas expressöes a seguir:

$$
\begin{aligned}
& \Delta Z_{t}=Z_{t}-Z_{t-1}=(1-B) Z_{t} \\
& \Delta z_{t}=(1-B)^{d} z_{t} \\
& s Z_{t}=\left(1+B+B^{2}+\ldots\right) Z_{t}=(1-B)^{-1} z_{t} .
\end{aligned}
$$

Se a variāvel $Z_{t} \bar{e}$ formada por um processo auto-regressivo de ordem $p$, indicado por $A R(p)$, temos

$$
\bar{z}_{t}=\phi_{1} \bar{z}_{t-1}+\phi_{2} \bar{z}_{t-2}+\ldots+\phi_{p} \bar{z}_{t-p}+a_{t}
$$

onde, sendo u a mēdia da sērie,

$$
\begin{aligned}
& \bar{z}_{t}=z_{t}-\mu \\
& \phi_{1}, \phi_{2}, \ldots, \phi_{p} \text { são parämetros }
\end{aligned}
$$

e

$$
a_{t} \bar{e} \text { o erro aleatörio com } E\left(a_{t}\right)=0, \quad V\left(a_{t}\right)=\sigma_{a}^{2} \text { e }
$$
$E\left(a_{t} a_{t+h}\right)=0$ para $h \neq 0$. Um elemento aleatörio com essas características è denominado ruĩdo branco. 
A expressão (4.7) pode ser escrita:

$\phi(B) \tilde{z}_{t}=a_{t}$,

onde

$\phi(B)=1-\phi_{1} B-\phi_{2} B^{2}-\cdots-\phi_{p} B^{p}$

Consideremos o caso particular de um AR (1), ou seja:

$\tilde{z}_{t}=\phi_{1} \quad \tilde{z}_{t-1}+a_{t}$

ou

$$
\left(1-\phi_{1} B\right) \tilde{z}_{t}=a_{t}
$$

ou, ainda,

$$
\begin{gathered}
\bar{z}_{t}=\left(1-\phi_{1} B\right)^{-1} a_{t}=\left(1+\phi_{1} B+\phi_{1}^{2} B^{2}+\ldots\right) a_{t}=a_{t}+\phi_{1} a_{t-1}+\phi_{1}^{2} a_{t-2}+\ldots \\
\text { Uma vez que } a_{t} \bar{e} \text { um ruído branco, segue-se que } \\
v\left(\bar{z}_{t}\right)=\left(1+\phi_{1}^{2}+\phi_{1}^{4}+\ldots\right) \sigma_{a}^{2}
\end{gathered}
$$

Essa expressão mostra que a variāncia de $\bar{Z}_{t}$ sōe finita se $\left|\phi_{1}\right|<1$. Dizemos, então, que o processo auto-regressivo ē estacionärio. Verifica-se, então, que o AR(1) sōo è estacionārio quando $\left|\phi_{1}\right|<1$. Considerando $\phi(B)=1-\phi_{1} B$ como um polinömio em $B$, nota-se que a raiz da equação $\phi(B)=0 \bar{e} 1 / \phi_{1}$. Se $\left|\phi_{1}\right|<1$, essa raiz serā, em mōdulo, maior que 1. Portanto, um $A R(1)$ é estacionārio somente se a raiz de $\phi(B)=0$ for, em mōdulo, maior que 1. Pode-se demonstrar que um $A R(p)$ é estacionärio somente se todas as $p$ raízes de $\phi(B)=0$ tiverem mödulos maiores que 1 . 
Consideremos em seguida, uma variāvel $z_{t}$ gerada por um processo de médias mōveis de ordem $q$, indicado por $\operatorname{MA}(q)$. Nesse caso:

$$
\tilde{z}_{t}=a_{t}-\theta_{1} a_{t-1}-\theta_{2} a_{t-2}-\cdots-\theta_{q} a_{t-q},
$$

onde

$$
\theta_{1}, \dot{\theta}_{2}, \ldots, \theta_{q} \text { são parāmetros. }
$$

\section{Fazendo}

$$
\theta(B)=1-\theta_{1} B-\theta_{2} B^{2}-\ldots-\theta_{q} B^{q}
$$

o modelo fica

$$
\begin{aligned}
& \tilde{z}_{t}=\theta(B) a_{t} \\
& \text { No caso particular do MA(1) temos } \\
& \tilde{z}_{t}=\left(1-\theta_{1} B\right) a_{t}
\end{aligned}
$$

segue-se que

$$
a_{t}=\left(1-\theta_{1} B\right)^{-1} \tilde{z}_{t}
$$

ou

$$
\begin{aligned}
& a_{t}=\left(1+\theta_{1} B+\theta_{1}^{2} B^{2}+\ldots\right) \tilde{z}_{t} \\
& \text { Os coeficientes. } 1, \theta_{1}, \theta_{1}^{2}, \ldots \text { dessa expressão formam }
\end{aligned}
$$
uma sequência convergente somente se $\left|\theta_{1}\right|<1$. Nesse caso dizemos que o. MA(1) é invertivel, e ele é equivalente a um processo auto-regressivo de ordem infinita.

$$
\text { Considerando } \theta(B)=1-\theta, B \text { como um polinōmio em } B \text {, ve- }
$$
rifica-se que a raiz de $\theta(B)=0 \cdot \bar{e} 1 / \theta_{1}$. Se $\left|\theta_{1}\right|<1$ essa raiz serä, 
em mōdulo, maior que 1. Portanto, um processo MA(1) è invertīvel se a raiz de $\theta(B)=0$ tiver mödulo maior que 1 . Em geral, pode-se demonstrar que um $M A(q) \bar{e}$ invertivel se todas as $q$ raizes de $\theta(B)=0$ tiverem mōdulo maior que 1 .

Combinando-se os dois processos, AR e MA, obtēm-se um modelo auto-regressivo de mëdia mövel ARMA $(p, q)$, onde os valores correntes da sērie temporal dependem dos valores passados da sērie e dos erros correntes e passados.

$$
\bar{z}_{t}=\phi_{1} \bar{z}_{t-1}+\ldots+\phi_{p} \bar{z}_{t-p}+a_{t}-\theta_{1} a_{t-1}-\ldots-\theta_{q} a_{t-q}
$$

Na forma compacta, temos:

$$
\phi(B) \bar{z}_{t}=\theta(B) a_{t}
$$

Os modelos apresentados atē aqui exigem estacionaridade das sēries temporais, isto è, a sērie se desenvolve no tempo aleatoriamente em torno de uma mëdia constante, refletindo alguma forma de equi lîbrio estāve1. Quando nos deparamos com sēries nāo estacionārias, porém homogêneas, ou seja, sem apresentar comportamento explosivo, podemos obter uma série estacionāria atravēs de diferenças entre valores consecutivos, is to $\bar{e}$, calculando-se $w_{t}=\Delta{ }^{d} z_{t}$. Diante da nova série $w_{t}$, o modelo ARMA visto anteriormente poderä ser ajustado aos dados, ou seja, temos

$$
\begin{aligned}
& \phi(B) w_{t}=\theta(B) a_{t} \\
& \text { Uma vez que } w_{t}=\Delta z_{t}=(1-B) d_{z_{t}} \text {, obtemos } \\
& \phi(B) \Delta z_{t}=\theta(B) a_{t}
\end{aligned}
$$


que é a representação geral de um modelo auto-regressivo, integrado, de mëdias möveis, indicado por ARIMA $(p, d, q)$.

Quando uma sërie temporal apresenta autocorrelação nos resĩduos, ou correlação significativa em "lags" de baixa ordem, o ajustamento ē feito atravēs do modelo ARIMA. Porēm, quando se observa correlações entre "lags" mūltiplos de um determinado período $\underline{s}$, devemos ajustar aos dados um modelo ARIMA sazonal (SARIMA).

Considerando um comportamento sazonal com periodo igual a $\underline{s}$, podemos escrever 0 modelo $\operatorname{SARIMA}(p, d, q) \times(P, D, Q)_{s}$ como:

$$
\phi(B) \Phi\left(B^{S}\right)\left(1-B^{S}\right)^{D}(1-B)^{d} Z_{t}=\theta(B) \theta\left(B^{s}\right) a_{t},
$$

onde

$$
\Phi\left(B^{S}\right)=1-\Phi{ }_{1} B^{S}-\Phi_{2} B^{2 S}-\ldots-\Phi_{p} B^{P S}
$$

$\bar{e}$ o operador auto-regressivo sazonal de ordem $P$, estacionärio;

$$
\theta\left(B^{S}\right)=1-\theta_{1} B^{S}-\ldots-\theta_{Q} B^{Q S}
$$

$\bar{e}$ o operador de médias mōveis sazonal de ordem $Q$, invertível, e $\left(1-B^{S}\right)^{D}=\Delta^{D} \bar{e} O$ operador diferença sazonal, onde $D$ representa $O$ nümero de "diferenças sazonais".

Apōs a apresentaçāo dos diferentes modelos, vamos descrever a metodologia para o seu ajustamento a uma série temporal.

Inicialmente, o modelo deverā ser identificado. Esta fase é considerada crïtica, segundo MORETTIN e TOLOI (1985), pois vārios pesquisadores podem identificar modelos diferentes para a mesma sé rie temporal. 
0 procedimento baseia-se na anālise das estimativas das autocorrelações e autocorrelações parciais.

\subsubsection{Autocorrelação}

A autocovariāncia de "lag" $k$, definida como a covariān cia entre $z_{t}$ e $z_{t+k}$, $\bar{e}$ dada por:

$$
\begin{aligned}
& \gamma_{k}=\operatorname{cov}\left[z_{t}, z_{t+k}\right]=E\left[\left(z_{t}-\mu\right)\left(z_{t+k}-\mu\right)\right] \\
& E \text { claro que } \gamma_{0}=\sigma_{z}^{2}
\end{aligned}
$$

A autocorrelação de "lag" k $\bar{e}$

$$
\rho_{k}=\frac{E\left[\left(z_{t}-\mu\right)\left(z_{t+k}-\mu\right)\right]}{\left.\sqrt{E\left[\left(z_{t}-\mu\right)^{2}\right] E\left[\left(z_{t+k}-\mu\right)^{2}\right.}\right]}=\frac{E\left[\left(z_{t}-\mu\right)\left(z_{t+k}-\mu\right)\right]}{\sigma_{z}^{2}},
$$

jā que para um processo estacionārio a variância $\sigma_{Z}^{2}=\gamma_{0} \bar{e}$ a mesma no tempo $t+k$ e no tempo $t$.

Então a autocorrelação de "lag" k ē:

$$
\rho_{k}=\frac{\gamma_{k}}{\gamma_{0}}
$$

E claro que, com $k=0$, temos $p_{0}=1$.

Para obtermos a função de autocovariāncia, basta colocar em gräfico os valores de $\gamma_{k}$ em função dos "lags" $k$. Da mesma for ma, para obter a função de autocorrelação, basta colocar os valores de $o_{k}$ em função dos "lags" $k$, como exemplificado na figura 4.3. a seguir. 


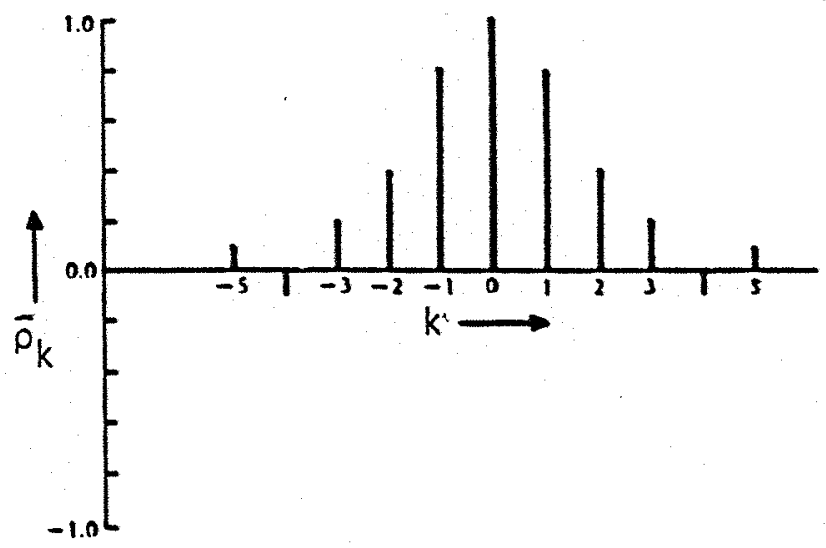

Figura 4.3. Exemplo de função de autocorrelação extraĩda de Box e Jenkins (1976)

Nota-se que o grāfico è simētrico. Portanto podemos considerar apenas valores a partir do "lag" 0 . A representação grāfica da função de autocorrelação e denominada correlograma.

Na prätica, evidentemente, não conhecemos os verdadeiros valores das autocorrelaçōes, e utilizamos as respectivas estimati vas.

As estimativas das autocovariāncias $\left(\gamma_{k}\right)$ säo dadas por: $\bar{\gamma}_{k}=c_{k}=\frac{1}{N} \sum_{t=1}^{N-k}\left(z_{t}-\bar{z}\right)\left(z_{t+k}-\bar{z}\right)$ para $k=0,1, \ldots$

e as estimativas das autocorrelações $\left(\rho_{k}\right)$ por:

$$
\bar{p}_{k}=r_{k}=\frac{c_{k}}{c_{0}}
$$

A funçäo de autocorrelação $\bar{e}$ importante para verificar se uma sērie è estacionäria. Se a sērie é estacionāria, a função de autocorrelação aproxima-se rapidamente de zero. Se isso não ocorrer, devem ser calculadas as diferenças de valores consecutivos da série, sucessivamente, até obter estacionaridade. 
As funções de autocorrelação dos processos $\operatorname{AR}(p), \operatorname{MA}(q)$ e ARMA $(p, q)$ possuem determinadas características de grande importãn cia na identificação do modelo. Elas estão descritas a seguir e na Figura 4.4 são apresentados os casos mais simples.

a) para um processo $A R(p)$ a função de autocorrelação decai de acordo com exponenciais e/ou senōides amortecidas, sendo infinita em extensão;
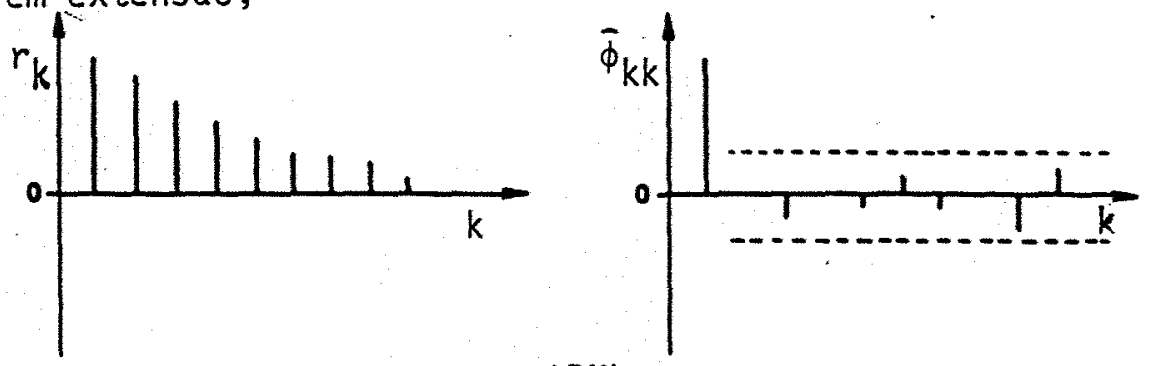

AR(1)
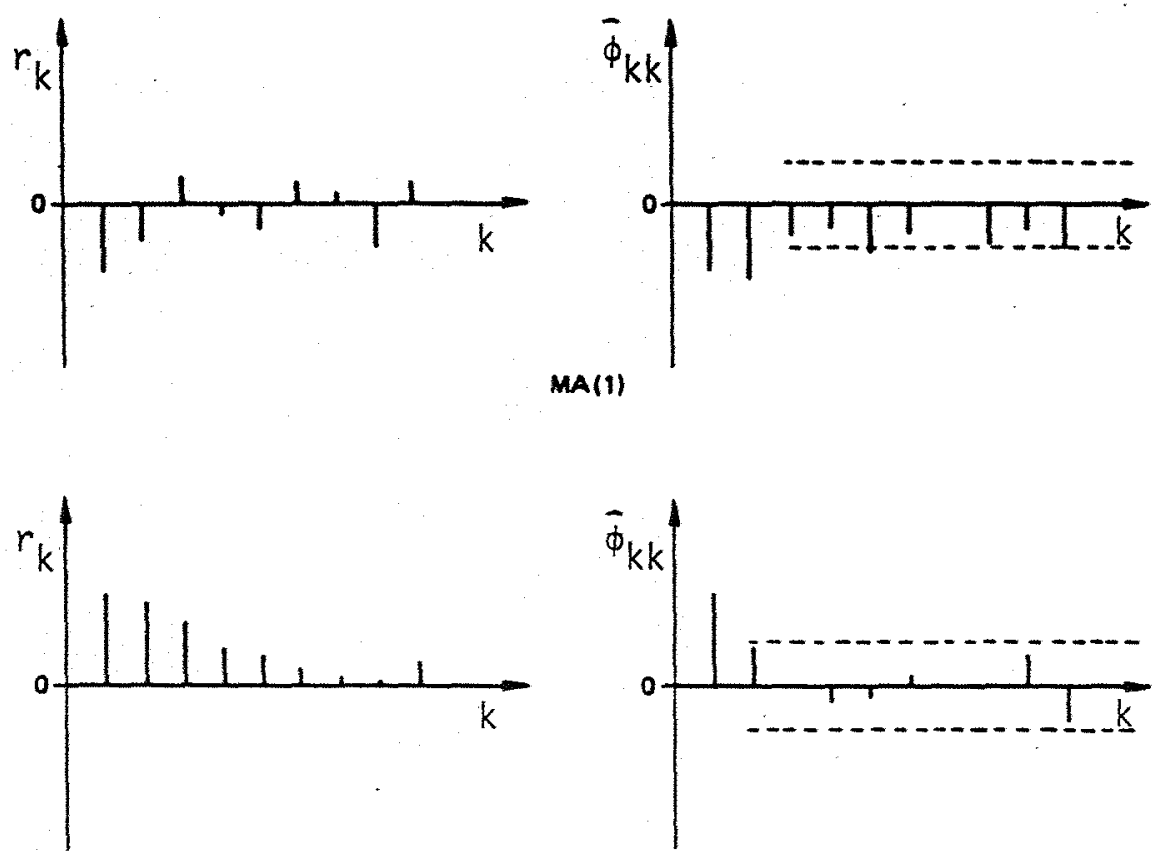

ARMA (1, 1)

Figura 4.4. Exemplos de autocorrelaçōes $\left(r_{k}\right)$ e autocorrelações parciais amostrais $\left(\hat{\phi}_{k k}\right)$ para modelos $\operatorname{AR}(1), \operatorname{MA}(1)$ e $\operatorname{ARMA}(1,1)$. Extraído de MORETTIN e TOLOI (1985). 
b) para um processo $M A(q)$ a função de autocorrelação é finita, no sentido de que apōs o "lag" q todas as autocorrelações são iguais a zero;

c) para um processo ARMA $(p, q)$ a função de autocorrelação é infinita em extensão, e decai de acordo com exponenciais e/ ou senōides amortecidas apōs o "lag" q-p.

Para caracterizar a função de autocorrelação serā necessārio testar se os valores de $\rho_{k}$ são zero alëm de um certo "lag". Para efetuar esse teste, dado por BARTLETT (ver Box e Jenkins, 1976), obtêm-se inicialmente a estimativa do desvio padrão da autocorrelação estimada $\left(r_{k}\right)$, que ē aproximadamente dado por

$$
\begin{aligned}
& \bar{\sigma}\left(r_{k}\right)=\sqrt{\frac{1}{N}\left(1+2 \sum_{v=1}^{q} r_{v}^{2}\right)}, k>q \text {, onde } k=" 1 a g " \\
& \text { Esta förmula para } k=1 \text { resume-se em } \bar{\sigma}\left(r_{k}\right)=\sqrt{\frac{1}{N}},
\end{aligned}
$$

pois considera-se uma série totalmente aleatōria, em que todas as autocorrelaçōes $r_{v}$ são iguais a zero. Jā para $k=2$, testaremos a hipótese $\rho_{2}=0$, atribuindo um valor diferente de zero a $r_{1}$ e zero aos demais $r$. Para $k=3$ os valores de $r_{1}$ e $r_{2}$ serão diferentes de zero e os demais iguais a zero, etc.

Na prätica podemos considerar $\rho_{k}$ como sendo significativamente diferente de zero se $\left|r_{k}\right|>2 \cdot \bar{\sigma}\left(r_{k}\right), k>q$.

Visando facilitar o processo de identificação, Box e Jenkins (1976) propõem a utilização da função de autocorrelação parcial. 


\subsubsection{Autocorrelação parcial}

Consideremos um mode 10 AR de ordem $p$, ou seja:

$\tilde{z}_{t}=\phi_{1} \bar{z}_{t-1}+\phi_{2} \tilde{z}_{t-2}+\ldots+\phi_{p} \tilde{z}_{t-p}+a_{t}$

Multiplicando por $\tilde{z}_{t-k}$ e aplicando esperança, obtemos:

$\gamma_{k}=\phi_{1} \gamma_{k-1}+\phi_{2} \gamma_{k-2}+\ldots+\phi_{p} \gamma_{k-p} \quad k>0$

pois

$E\left[\bar{z}_{t-k} a_{t}\right]=0$ quando $k>0$

Dividindo (4.8) por $\gamma_{0}$, teremos:

$\rho_{k}=\phi_{1} \rho_{k-1}+\phi_{2} \rho_{k-2}+\ldots+\phi_{p} \rho_{k-p} \quad k>0$

Indicando por $\phi_{k j} \circ j-\bar{e} s i m o$ coeficiente de um processo AR (k), então $\phi_{k k}$ serā o ültimo coeficiente. De acordo com (4.9) podemos escrever:

$$
\rho_{j}=\phi_{k 1} \rho_{j-1}+\phi_{k 2} \rho_{j-2}+\ldots+\phi_{k k} \rho_{j-k} \quad j=1,2, \ldots, k
$$

Estas $k$ equaçōes para $j=1$ atē $k$, denominadas equaçōes de YULE-WALKER podem ser escritas na seguinte forma matricial:

$$
\left(\begin{array}{ccccc}
1 & \rho_{1} & \rho_{2} & \cdots & \rho_{k-1} \\
\rho_{1} & 1 & \rho_{1} & \cdots & \rho_{k-2} \\
\cdot & \ddots & \cdot & & \\
\rho_{k-1} & \dot{\rho}_{k-2} & \rho_{k-3} & \cdots & 1
\end{array}\right] \cdot\left(\begin{array}{l}
\phi_{k 1} \\
\phi_{k 2} \\
\dot{\phi_{k k}}
\end{array}\right)=\left(\begin{array}{l}
\rho_{1} \\
\rho_{2} \\
\vdots \\
\rho_{k}
\end{array}\right)
$$


Resolvendo sucessivamente estas equações para $k=1,2,3, \ldots$, alēm de outros coeficientes, obteremos $\phi_{k k}$, que são as autocorrelações parciais.

$$
\begin{aligned}
& \phi_{11}=\rho_{1} \\
& \phi_{22}=\frac{\left|\begin{array}{ll}
1 & \rho_{1} \\
\rho_{1} & \rho_{2}
\end{array}\right|}{\left|\begin{array}{ll}
1 & \rho_{1} \\
\rho_{1} & 1
\end{array}\right|}=\frac{\rho_{2}-\rho_{1}^{2}}{1-\rho_{1}^{2}}
\end{aligned}
$$

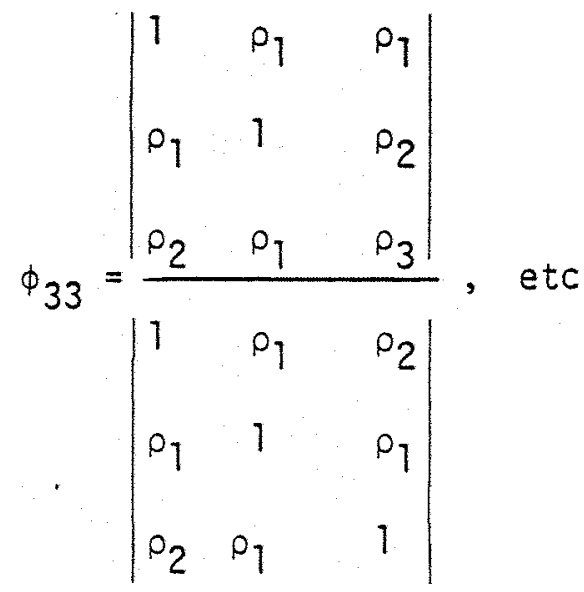

Demonstra-se que $\phi_{k k} \bar{e}$ a autocorrelaçäo parcial entre as variāveis $z_{t} \in z_{t-k}$, dadas as variāveis intermediärias $z_{t-1}, \ldots, z_{t-k+1}$

Para se obter a estimativa da autocorrelação parcial $\oint_{k k}$, basta substituir $\rho_{k}$ pelas suas estimativas $r_{k}$. 
Para a identificação do modelo atravēs da função de autocorrelação parcial, devemos observar as seguintes características descritas abaixo e ilustradas na figura 4.4.

a) um processo $A R(p)$ tem função de autocorrelação parcial $\phi_{k k} \neq 0$ para $k \leqslant p$ e $\phi_{k k}=0$, para $k>p$;

b) um processo $M A(q)$ tem função de autocorrelação par cial que se comporta de maneira similar à função de autocorrelação de um processo $A R(P)$, ou seja, é dominada por exponenciais e/ou senōides amortecidas;

c) um processo ARMA $(p, q)$ tem função de autocorrelação parcial que se comporta como a função de autocorrelação parcial de um processo MA puro.

QUENOUILLE, citado em Box e Jenkins (1976), mostra que para um processo $A R(p)$ as estimativas das autocorrelações parciais de ordem $p+1, p+2, \ldots$, são aproximadamente independentemente distribuĩdas e a estimativa do respectivo desvio padrão ē dada por:

$$
\tilde{\sigma}\left[\bar{\phi}_{k k}\right]=\frac{1}{\sqrt{N}}, k>p
$$

Evidentemente, isso pode ser usado para testar a significāncia das estimativas das autocorrelações parciais. Da mesma forma que para as autocorrelações, consideramos $\phi_{k k} \neq 0$ se $\left|\hat{\phi}_{k k}\right|>2 \cdot \tilde{\sigma}\left[\hat{\phi}_{k k} \mid\right.$ para $k>p$. 
Apōs a identificação do modelo, o prōximo passo consiste em se estimar os parämetros. Este procedimento abrange duas par tes: cālculo das estimativas iniciais e cālculo das estimativas finais do modelo especificado.

Pelo fato dos métodos de estimação dos parâmetros serem complexos, envolvendo a resolução de sistemas de equações não-lineares por processos iterativos, eles não serão apresentados neste es tudo. Para maiores informações ver Box e Jenkins (1976).

Tendo sido identificado o modelo e estimados os seus parâmetros, resta sabermos se ele é realmente apropriado para a série analisada. Para isto, serão apresentados alguns testes que auxiliarão a checagem e obtenção do melhor modelo.

\subsubsection{Testes para verificar se o modelo è apropriado}

4.4.3.1. Tes te do Superajustamento

Consiste em se ajustar modelos com parâmetros adicionais, testando a significāncia destes parāmetros incluīdos e verificando se hā redução significativa na variância residual.

Este método ē ütil quando sabemos "a priori" em que direção pode estar ocorrendo a inadequação do modelo. 
4.4.3.2. Teste de autocorrelação residual

Suponha um modelo

$\phi(B) w_{t}=\theta(B) a_{t}$

onde

$$
w_{t}=\Delta d_{t}
$$

Tendo sido estimados os parāmetros $\phi$ e $\theta$, podemos escre-

ver:

$$
\overline{\mathrm{a}}_{t}=\bar{\theta}^{-1}(B) \quad \bar{\phi}(B) w_{t}
$$

onde

$\bar{a}_{t}$ são os resĩduos estimados.

Supondo que a forma do modelo utilizado $\bar{e}$ correta e os verdadeiros valores de $\phi$ e $\theta$ são conhecidos, então, pára valores de $k$ pequenos em comparação com $n$, e $n$ grande, as estimativas das autocorrelaçōes $r_{k}(a)$ dos $a_{t}$ são não-correlacionadas e com distribuição aproximadamente normal com média zero e desvio padrão $1 / \sqrt{n}$. Poderemos, então, utilizar este fato para testar aproximadamente se as autocorrelações são significativamente diferentes de zero.

Na prātica os valores dos parāmetros são todos estimativas e o teste consiste em comparar $r_{k}(\bar{a})$ com os limites $\pm 2 / \sqrt{n}$.

Em certos casos foi demonstrado que, para valores de $k$ pequenos $(k=1$ ou 2$)$ o desvio padrão de $r_{k}(\vec{a}) \vec{e}$ substancialmente menor do que $1 / \sqrt{n}$. Nesses casos os limites $\pm 2 \sqrt{n}$ levam a subestimar a signi ficância dos valores de $r_{k}(\hat{a})$ (ver Box e Jenkins, 1976, p.290-291).

Os valores $r_{k}(\hat{a})$ são obtidos pela seguinte fómula: 


$$
r_{k}(\bar{a})=\frac{\sum_{t=k+1}^{n} \bar{a}_{t} \bar{a}_{t-k}}{\sum_{t=1}^{n} \bar{a}_{t}^{2}}
$$

\subsubsection{Teste de Box-Pierce (Q)}

0 teste de Box-Pierce $\bar{e}$ baseado nas primeiras $K$ autocorrelações dos $\bar{a}_{t}$, isto $\bar{e}$, nos valores de $r_{k}(\bar{a})$ para $(k=1,2, \ldots, k)$. Para um processo ARIMA $(p, d, q)$, demonstra-se que, se o modelo ajustado ē apropriado, então $Q=n \sum_{k=1}^{K} r_{k}^{2}(\bar{a})$ tem distribuição de quiquadrado $\left(x^{2}\right)$ com $(k-p-q)$ graus de liberdade.

Na prätica podemos utilizar as primeiras 20 ou 25 autocorrelaçōes, considerando o modelo como bem ajustado para valores de $Q<x^{2}(K-p-q)$.

\subsubsection{Teste de correlação cruzada}

Esse teste baseia-se na correlação cruzada entre valores passados da sērie e o valor presente do resíduo. Um modelo adequado tera $a_{t} e z_{t-k}$ independentes para $k \geqslant 1$ e portanto a $\operatorname{cov}\left\{a_{t}, z_{t-k}\right\}=0$ para $k \geqslant 1$. Torna-se necessärio, portanto, examinarmos a função de correlação cruzada $\left(\tilde{s}_{k}\right)$, para valores estimados do resīduo $\bar{a}_{t}$ :

$$
\bar{s}_{k}=\frac{\sum_{t=k+1}^{n} \bar{a}_{t}\left(z_{t-k}-\bar{z}\right)}{\sqrt{\sum_{t=1}^{n} \bar{a}_{t}^{2} \sum_{t=1}^{n}\left(z_{t}-\bar{z}\right)^{2}}} k=1,2, \ldots
$$


Considera-se que $\bar{s}_{k} \bar{e}$ significativamente diferente de zero se $\left|\bar{s}_{k}\right|>2 / \sqrt{n}$.

Analisando as autocorrelaçōes $r_{k}(\bar{a})$, teremos idéia sobre novos termos de mēdia mōvel que deverão ser incluídos no modelo. Por exemplo, se $\left|r_{6}(\bar{a})\right|>2 / \sqrt{n}$, um termo $\theta_{6}{ }^{a} t-6$ deverā ser incluĩdo no modelo.

Se $\left|\vec{s}_{k}\right|>2 / \sqrt{n}$, isso indica que novos termos auto-regressivos devem ser incluĩdos no modelo.

Procederemos tentativamente desta forma, atē que nenhum dos $\bar{s}_{k}$ e $r_{k}(\bar{a})$ se apresente mais significativo.

A prōxima etapa consiste na apresentação do modelo de previsão dos valores futuros da sērie, que è a principal finalidade da construção de modelos ARIMA.

\subsubsection{Formas do Mode 10 ARIMA}

Inicialmente são apresentadas as 3 formas alternativas do Modelo ARIMA, que serão utilizadas posteriormente.

I. Expressão de $Z_{t}$ en função de valores prēvios da sērie e de valores prévios e correntes de $a_{t}$.

Vimos que o modeto ARIMA $(p, d, q)$ pode ser indicado por

$$
\phi(B)(7-B)^{d} Z_{t}=\theta(B) a_{t}
$$




$$
\phi(B)(1-B)^{d}=1-\xi_{1} B-\xi_{2} B^{2}-\ldots-\xi_{p+d} B^{p+d}=\xi(B)
$$

Então o modelo ARIMA pode ser escrito como

$$
\xi(B) Z_{t}=\theta(B) a_{t}
$$

ou

$$
z_{t}=\xi_{1} z_{t-1}+\ldots+\xi_{p+d} z_{t-p-d}+a_{t}-\theta_{1} a_{t-1}-\ldots-\theta_{q} a_{t-q}
$$

Essa expressão mostra $Z_{t}$ como função de valores anteriores da série, do valor de $a_{t}$ e de valores anteriores do ruijdo bran co. E uma forma ūtil para calcular previsões.

No caso particular do APIMA $(1,1,1)$ temos:

$$
\begin{aligned}
& \left(1-\phi_{1} B\right)(1-B) z_{t}=\left(1-\theta_{1} B\right) a_{t} \\
& {\left[1-\left(1+\phi_{1}\right) B+\phi_{1} B^{2}\right] z_{t}=\left(1-\theta_{1} B\right) a_{t}} \\
& z_{t}=\left(1+\phi_{1}\right) z_{t-1}-\phi_{1} z_{t-2}+a_{t}-\theta_{1} a_{t-1}
\end{aligned}
$$

Comparando essa expressão com (4.11), verifica-se que

$$
\begin{aligned}
& \xi_{1}=1+\phi_{1} . \\
& \xi_{2}=-\phi_{1}
\end{aligned}
$$

II. Expressão de $Z_{t}$ em função dos valores atual e prēvios de $a_{t}$ 


$$
z_{t}=a_{t}+\psi_{1} a_{t-1}+\psi_{2} a_{t-2}+\cdots
$$

ou

$$
z_{t}=a_{t}+\sum_{j=1}^{\infty} \psi_{j} a_{t-j}
$$

ou ainda

$$
z_{t}=\psi(B) a_{t}
$$

onde

$$
\psi(B)=1+\psi_{1} B+\psi_{2} B^{2}+\ldots
$$

Multiplicando ambos os lados de (4.12) por $\xi(B)$, obtemos:

$$
\xi(B) \cdot Z_{t}=\xi(B) \psi(B) a_{t}
$$

Comparando $(4.10)$ e $(4.13)$ verifica-se que

$$
\xi(B) \psi(B)=\theta(B)
$$

ou

$$
\left(1-\xi_{1} B-\ldots-\xi_{p+d^{B}}{ }^{p+d}\right)\left(1+\psi_{1} B+\psi_{2} B^{2}+\ldots\right)=\left(1-\theta_{1} B-\ldots-\theta_{q} B^{q}\right)
$$

Os pesos $\psi_{j}$ podem ser obtidos identificando-se os coeficientes de $B, B^{2}, \ldots$. Desta maneira obtemos

$$
\begin{aligned}
\psi_{1} & =\xi_{1}-\theta_{1} \\
\psi_{2} & =\xi_{1} \psi_{1}+\xi_{2}-\theta_{2} \\
\vdots & \\
\psi_{j} & =\xi_{1} \psi_{j-1}+\ldots+\xi_{p+d} \psi_{j-p-d}-\theta_{j}
\end{aligned}
$$


onde

$$
\psi_{0}=1 \text { e } \psi_{j}=0 \text { para } j<0
$$

e

$$
\theta_{j}=0 \text { para } j>q .
$$

III. Expressão de $Z_{t}$ em função de valores prēvios de $z_{t}$ e do valor atual de $a_{t}$.

De (4.12), admitindo a invertibilidade do modelo, obte mos:

$$
\psi^{-1} \text { (B) } z_{t}=a_{t}
$$

ou

$$
\pi(B) Z_{t}=\left(1-\Sigma \pi_{j} B^{j}\right) Z_{t}=a_{t}
$$

Portanto, o modelo serā:

$z_{t}=\pi_{1} z_{t-1}+\pi_{2} z_{t-2}+\ldots+a_{t}$

De (4.15) segue-se que

$a_{t}=\pi(B) Z_{t}$

Substituindo esse resultado em (4.10), obtemos:

$$
\begin{aligned}
& \xi(B) Z_{t}=\theta(B) \pi(B) Z_{t} \\
& \xi(B)=\theta(B) \pi(B) \\
& \left(1-\xi_{1} B-\ldots-\xi_{p+d} B^{p+d}\right)=\left(1-\theta_{1} B-\ldots-\theta_{q} B^{q}\right)\left(1-\pi_{1} B-\pi_{2} B^{2}-\ldots\right)
\end{aligned}
$$


4.4.5. Mëtodos de Previsão

Supondo conhecidos os valores $\ldots, z_{t-2}, z_{t-1}, z_{t}$ ate o instante $t$, denominado origem das previsões, nosso objetivo é prever valores $z_{t+\ell}$ com $\ell \geqslant 1$.

Rescrevendo as 3 formas do modelo ARIMA vistas anteriormente com $t+l$ ao invés de $t$, temos:

I. Equação de diferenças

$$
z_{t+\ell}=\xi_{1} z_{t+\ell-1}+\ldots+\xi_{p+d} z_{t+\ell-p-d}-\theta_{1} a_{t+\ell-1}-\ldots-\theta_{q} a_{t+\ell-q}+a_{t+\ell}
$$

II. Choques aleatōrios

$$
z_{t+\ell}=\sum_{j=-\infty}^{t+\ell} \psi_{t+\ell-j} a_{j}=\sum_{j=0}^{\infty} \psi_{j} a_{t+l-j}, \text { com } \psi_{0}=1
$$

III. Forma invertida

$$
z_{t+\ell}=\sum_{j=1}^{\infty} \pi_{j} z_{t+l-j}+a_{t+\ell}
$$

A previsão de origen $t$ e horizonte $\ell$, isto $\bar{e}$, a previsão de $z_{t+\ell}$, serā denotada por $\bar{z}_{t}(\ell)$.

Tendo origem $t$, a previsão de $z_{t+\ell}$ pode ser considerada como uma função linear das observações $z_{t}, z_{t-1}, z_{t-2} \ldots$ e portanto serā também uma função linear dos choques $a_{t}, a_{t-1}, a_{t-2} \ldots$.

Vamos supor que a melhor previsão $\bar{e}$ dada por: 


$$
\bar{z}_{t}(\ell)=\psi_{\ell}^{* a} t+\psi_{l+1}^{*} a_{t-1}+\psi_{l+2^{a} t-2}^{*} \cdots=\sum_{j=0}^{\infty} \psi_{l+j}^{*} a_{t-j}
$$

Queremos determinar os pesos $\psi_{j}^{*}$ que minimizem 0 erro quadrātico mēdio de previsão.

Usando (4.17) temos que:

$$
E\left[z_{t+l}-\bar{z}_{t}(l)\right]^{2}=E\left[\sum_{j=0}^{\infty} \psi_{j} a_{t+l-j}-\sum_{j=0}^{\infty} \psi_{\ell+j}^{*} a_{t-j}\right]^{2}
$$

Observando que:

$$
\sum_{j=0}^{\infty} \psi_{j} a_{t+l-j}=\sum_{j=-l}^{\infty} \psi_{l+j} a_{t-j}
$$

podemos escrever o erro de previsão como:

$$
\begin{aligned}
e_{t}(l)=z_{t+\ell} & -\bar{z}_{t}(\ell)=\psi_{0} a_{t+\ell}+\psi_{1} a_{t+\ell-1}+\ldots+ \\
& +\psi_{\ell-1} a_{t+1}+\sum_{j=0}^{\infty}\left(\psi_{\ell+j}-\psi_{\ell+j}^{*}\right) a_{t-j}
\end{aligned}
$$

Então, lembrando que $a_{t} \bar{e}$ um ruĩdo branco, obtemos:

$$
E\left[e_{t}(l)\right]^{2}=\left(1+\psi_{T}^{2}+\ldots+\psi_{l-1}^{2}\right) \sigma_{a}^{2}+\sum_{j=0}^{\infty}\left(\psi_{l+j}-\psi_{l+j}^{*}\right)^{2} \sigma_{a}^{2}
$$

Conclu ímos portanto que $E\left[e_{t}(\ell)\right]^{2}$ è minimizada, se:

$$
\psi_{\ell+j}^{*}=\psi_{\ell+j}
$$

Então a previsão de erro quadrático mēdio minimo é:

$$
\bar{z}_{t}(l)=\psi_{l^{a}}+\psi_{l+1^{a} t-1}+\psi_{l+2^{a} t-2}+\ldots
$$


De acordo com (4.17), temos:

$$
\begin{aligned}
z_{t+\ell} & =\left(a_{t+\ell}+\psi_{1} a_{t+\ell-1}+\ldots+\psi_{\ell-1} a_{t+1}\right)+ \\
& +\left(\psi_{\ell} a_{t}+\psi_{\ell+1} a_{t-1}+\ldots\right)=e_{t}(\ell)+\bar{z}_{t}(\ell) .
\end{aligned}
$$

A esperança condicional de um valor passado, presente ou futuro de uma variāvel, dadas as informações disponiveis atē o ins tante $t$, serā indicada colocando a variāvel entre colchetes. Considerando a expressão anterior, a esperança condicional de $z_{t+\ell}$, conhecidos os valores da sērie atē o tempo $\underline{t} \bar{e}$ dada por:

$$
E\left[z_{t+\ell} \mid z_{t}, z_{t-1}, \ldots\right]=\left[z_{t+\ell}\right]=\psi_{\ell} a_{t}+\psi_{\ell+1} a_{t-1}+\ldots
$$

Comparando $(4.19)$ e $(4.20)$, conclui-se que a previsão $\bar{z}_{t}(\ell) \bar{e}$ igual à esperança condicional de $z_{t+\ell}$ no tempo $t$.

0 erro de previsão fica:

$$
e_{t}(\ell)=a_{t+\ell}+\psi_{1} a_{t+\ell-1}+\ldots+\psi_{\ell-1} a_{t+1}
$$

Desde que:

$$
\left[e_{t}(l)\right]=0
$$

a previsão é imparcial. A variância do erro de previsão è dada por:

$$
\begin{aligned}
& v(l)=\operatorname{var}\left[e_{t}(l)\right]=\left(1+\psi_{1}^{2}+\psi_{2}^{2}+\ldots+\psi_{\ell-1}^{2}\right) \sigma_{a}^{2} \\
& 0 \text { erro de previsão a um passo serāa: } \\
& e_{t}(1)=z_{t+1}-\hat{z}_{t}(1)=a_{t+1}
\end{aligned}
$$


Como $a_{t} \bar{e}$ um ruĩdo branco, segue-se que os erros de pre visão a um passo, para diferentes valores de $\underline{t}$, são não correlacionados.

Iremos agora, escrever a previsão $\overline{\mathrm{Z}}_{t}(l)$ com base nas 3 formas al ternativas do modelo ARIMA vistas anteriormente.

I. Previsão com base na equação de diferenças.

Tomando a equação (4.16) e aplicando esperança condicional, temos:

$$
\begin{aligned}
{\left[z_{t+\ell}\right] } & =\hat{z}_{t}(\ell)=\xi_{1}\left[z_{t+\ell-1}\right]+\ldots+\xi_{p+d}\left[z_{t+\ell-p-d}\right]- \\
& -\theta_{1}\left[a_{t+\ell-1}\right]-\ldots-\theta_{q}\left[a_{t+\ell-q}\right]+\left[a_{t+\ell}\right] \quad-p / \ell \geq 1 .
\end{aligned}
$$

Então as previsões podem ser feitas, utilizando os seguintes fatos:

$$
\begin{array}{ll}
{\left[z_{t+k}\right]=\bar{z}_{t}(k),} & k>0 \\
{\left[z_{t+k}\right]=z_{t+k},} & k \leqslant 0 \\
{\left[a_{t+k}\right]=0,} & k>0 \\
{\left[a_{t+k}\right]=a_{t+k},} & k \leqslant 0 \\
\text { Para calcular } \bar{z}_{t}(l) \text { precisamos dos } \bar{z}_{t}(l-1), \bar{z}_{t}(l-2), \ldots
\end{array}
$$

que são obtidos recursivamente.

Para exemplificar, vamos considerar um modelo ARIMA $(3,1,1)$

$$
\left(1-\phi_{1} B-\phi_{2} B^{2}-\phi_{3} B^{3}\right)(1-B) Z_{t}=\left(1-\theta_{1} B\right) a_{t}
$$


43

Substituindo $t$ por $t+\ell$, obtemos

$$
\left(1-\phi_{1} B-\phi_{2} B^{2}-\phi_{3} B^{3}\right)(1-B) Z_{t+l}=\left(1-\theta_{1} B\right) a_{t+l}
$$

ou

$$
\begin{aligned}
z_{t+\ell}=\left(1+\phi_{1}\right) z_{t+\ell-1} & -\left(\phi_{1}-\phi_{2}\right) z_{t+\ell-2}-\left(\phi_{2}-\phi_{3}\right) z_{t+\ell-3}-\phi_{3} z_{t+\ell-4}+ \\
& +a_{t+\ell}-\theta_{1} a_{t+\ell-1}
\end{aligned}
$$

Então

$$
\begin{aligned}
& \bar{z}_{t}(1)=\left(1+\phi_{1}\right) z_{t}-\left(\phi_{1}-\phi_{2}\right) z_{t-1}-\left(\phi_{2}-\phi_{3}\right) z_{t-2}-\phi_{3} z_{t-3}-\theta_{1} a_{t} \\
& \bar{z}_{t}(2)=\left(1+\phi_{1}\right) \bar{z}_{t}(1)-\left(\phi_{1}-\phi_{2}\right) z_{t}-\left(\phi_{2}-\phi_{3}\right) z_{t-1}-\phi_{3} z_{t-2} \\
& \bar{z}_{t}(3)=\left(1+\phi_{1}\right) \bar{z}_{t}(2)-\left(\phi_{1}-\phi_{2}\right) \bar{z}_{t}(1)-\left(\phi_{2}-\phi_{3}\right) z_{t}-\phi_{3} z_{t-1}
\end{aligned}
$$

Genera lizando:

$$
\begin{aligned}
\bar{z}_{t}(l) & =\left(1+\phi_{1}\right) \bar{z}_{t}(l-1)-\left(\phi_{1}-\phi_{2}\right) \bar{z}_{t}(l-2)-\left(\phi_{2}-\phi_{3}\right) \bar{z}_{t}(l-3)- \\
& -\phi_{3} \bar{z}_{t}(l-4), \quad \text { para } \ell \geqslant 5
\end{aligned}
$$

II. Previsão com base na equação de choques aleatörios.

De (4.17) utilizando esperança condicional, obtemos:

$$
\begin{aligned}
{\left[z_{t+l}\right] } & =\bar{z}_{t}(l)=\psi_{1}\left[a_{t+l-1}\right]+\ldots+\psi_{\ell-1}\left[a_{t+1}\right]+\psi_{\ell}\left[a_{t}\right]+ \\
& +\psi_{\ell+1}\left[a_{t-1}\right]+\ldots+\left[a_{t+l}\right]
\end{aligned}
$$


III. Previsão com base na equação de forma invertida.

De (4.18) utilizando esperança condicional, obtemos:

$$
\left[z_{t+\ell}\right]=\bar{z}_{t}(\ell)=\sum_{j=1}^{\infty} \pi_{j}\left[z_{t+\ell-j}\right]+\left[a_{t+\ell}\right]
$$

4.4.6. Atualização das previsões

Consideremos as previsões de $Z_{t+\ell+1}$ feitas a partir das origens $t+1$ e $t$, da seguinte forma:

$$
\bar{z}_{t+1}(\ell)=\psi_{\ell} a_{t+1}+\psi_{\ell+1} a_{t}+\psi_{l+2} a_{t-1}+\ldots
$$

e

$$
\bar{z}_{t}(\ell+1)=\psi_{l+1} a_{t}+\psi_{\ell+2} a_{t-1}+\ldots
$$

Subtraindo as equaçōes acima, obtemos:

$$
\bar{z}_{t+1}(\ell)=\bar{z}_{t}(\ell+1)+\psi_{\ell^{a}}{ }_{t+1}
$$

Desta forma, poderemos atualizar a previsão $z_{t+\ell+1}$, feita no instante $t$, com base en uma nova observação $z_{t+1}$. ou seja, faremos a previsão de $Z_{t+\ell+1}$ na origem $t+1$, adicionando a $\bar{z}_{t}(\ell+1)$ um mūltiplo do erro de previsão de $z_{t+1}$, dado por (4.21):

$$
a_{t+1}=z_{t+1}-\bar{z}_{t}(1)
$$

Cabe observar que as formulas de previsão apresentadas nessa seção não levam em consideração o fato de que não dispomos dos valores dos parâmetros, mas apenas de suas estimativas. Seguindo um 
procedimento estabelecido por Box e Jenkins, o cālculo dos erros de previsão ignora a nossa incerteza a respeito dos valores dos parâmetros.

Todos os procedimentos vistos anteriormente referem-se aos modelos ARIMA. Para os modelos sazonais (SARIMA) não hā nenhuma dificuldade adicional. Inicialmente teremos que calcular diferenças com "lag" 1 e com "lag" $\underline{s}$, ou seja, teremos que aplicar os operadores $\Delta$ e $\Delta_{S}$ (s-periodo), a fim de produzir estacionaridade; com isto obte mos os valores de $w_{t}=\Delta_{s}^{D} \Delta^{d} Z_{t}=\left(1-B^{s}\right)^{D}(1-B)^{d} Z_{t}$.

Em seguida, observamos as funções de autocorrelação e de autocorrelação parcial amostrais da sērie w nos "lags". 1,2,3... para obter valores de $\mathrm{p}$ e $q$ e nos "lags" s,2s,3s..., para obter valores de $\underline{P}$ e $\underline{Q}$, selecionando-se deste modo, um modelo tentativo.

Os procedimentos subsequentes serão idēnticos aos explicados para o processo ARIMA, porém agora com o modelo inicial SARIMA. 


\section{RESULTADOS E DISCUSSAOO}

\subsection{Boi Gordo}

A Figura 5.1 mostra a sērie de preços reais mensais da arroba do boi gordo. Para a realização dos cālculos, os preços foram transformados em logarítmo, a fim de tornar o efeito sazonal aditivo e estabilizar a variāncia do erro, como descreve CHATFIELD(1984).

\subsubsection{Modelo ARIMA de Box e Jenkins}

Foi utilizada inicialmente a técnica de Box e Jenkins aplicada à sērie dos logaritmos dos preços reais da arroba do boi gor do no período de janeiro de 1970 a dezembro de 1986.

A estacionaridade da sērie foi obtida, isto é, as autocorrelaçōes caîram rapidamente para zero, apōs se efetuar a 1 a $d i-$ ferença e a $1^{\mathrm{a}}$ diferença sazonal.

Em seguida foram obtidas estimativas das autocorrelações e autocorrelações parciais que são apresentadas nas figuras 5.2 
e 5.3, respectivamente. Com base nessas figuras foram escolhidos e testados alguns modelos. Os resultados dos ajustes encontram-se na Tabela 5.1. O SARIMA $(0,1,1)(0,1,1) \frac{12}{12}$ foi considerado o methor, apresentando todas as estimativas de parāmetros significativas.

As estimativas das autocorrelações dos residuos foram obtidas a fim de se testar a adequabilidade do modelo escolhido, e estas não apresentaram valor superior a dois desvios padrões, ou seja, não foram significativas, como pode ser visto na Figura 5.4.

0 teste $Q$ calculado, tomando as 20 primeiras autocorrelações residuais, apresentou-se não-significativo, mostrando, portanto, que o modelo foi apropriado para fins de ajuste.

As previsões obtidas à partir de janeiro de 1987 mostraram que o modelo SARIMA utilizado não foi capaz de projetar as variações cíclicas plurianuais, com perĩodo de 6 anos. Para que 0 modelo capte essas variações cíclicas plurianuais parece ser necessärio, neste caso, que ele contenha termos com defasagem de 72 meses (6 anos). Entretanto, o programa utilizado (STATGRAPHICS) permite so mente a introdução de defasagens de baixa ordem e/ou defasagens relativas a componentes sazonais, assim como, diferenças de ordem 1 ou no mäximo 2, impossibilitando o aparecimento de variāveis com defasagem 72 junto com as de ordem 12 e ordem inferior. E interessante ressaltar, ainda, que de acordo com o método exposto por Box e Jenkins, um componente de média mövel ou auto-regressivo de ordem 72 (equivalente a 6 anos) só deveria ser incluĩdo no modelo se a autocorrelação do 


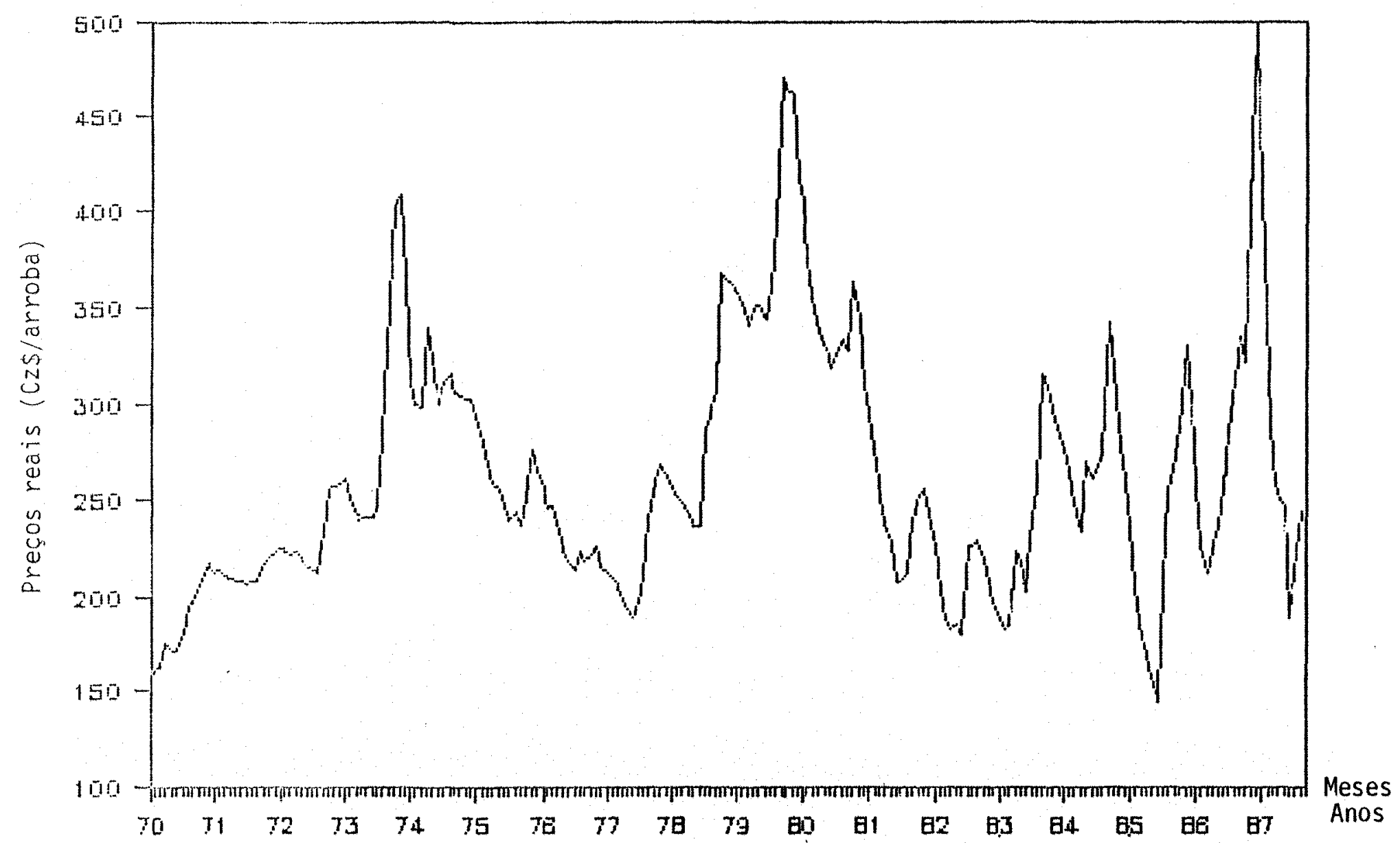

Figura 5.1. Gráfico dos preços reais mensais da arroba do boi gordo no período de 1970 a 1987 


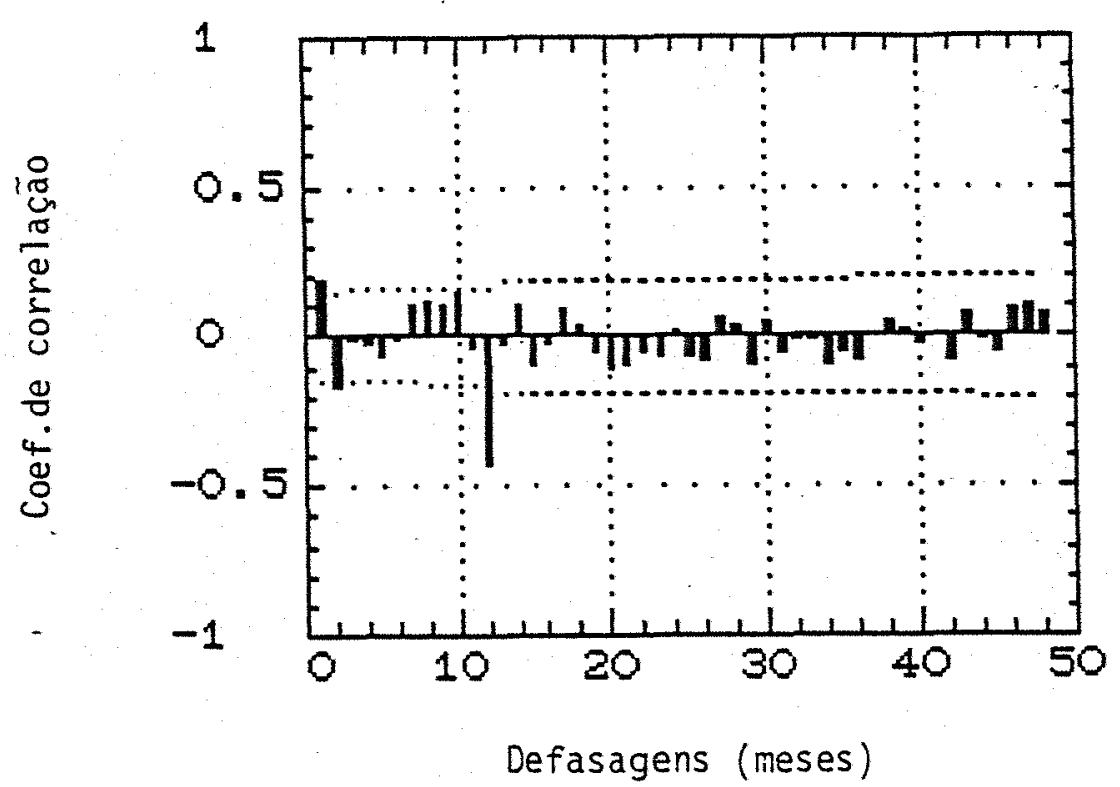

Figura 5.2. Primeiras 48 autocorrelações da série do $\log$ do preço do

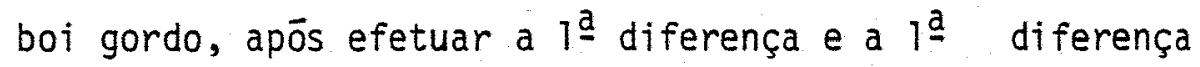
sazonal

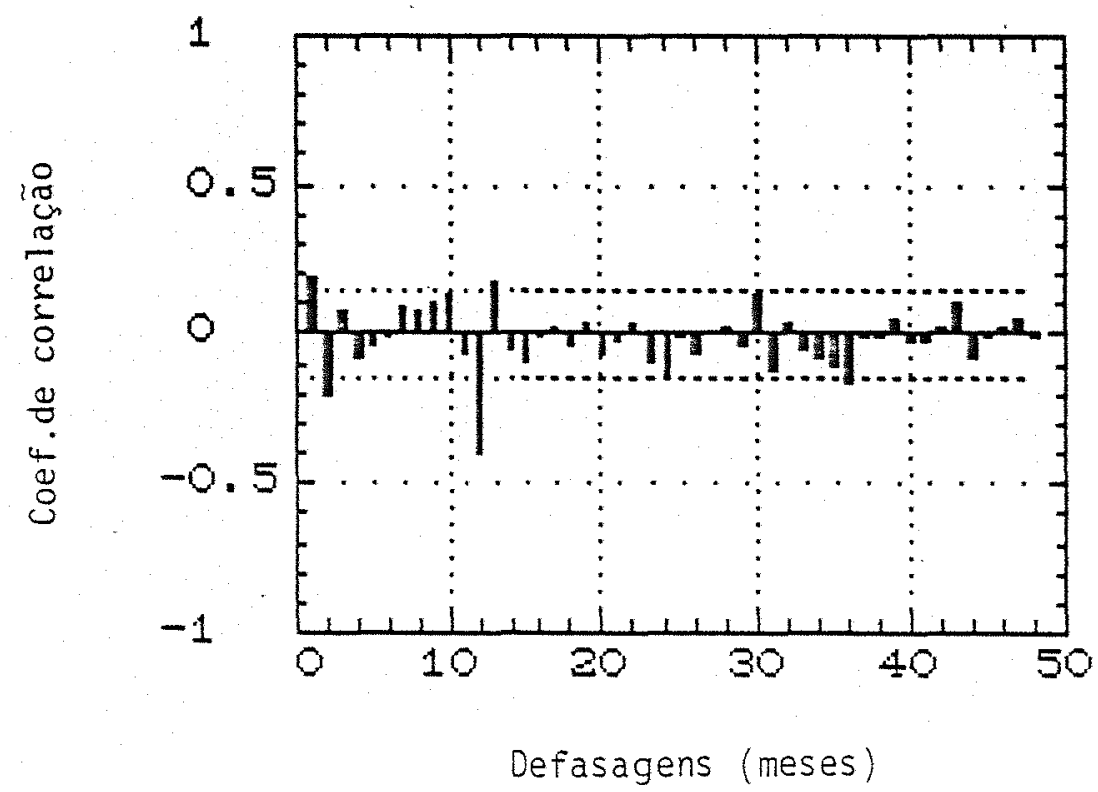

Figura 5.3. Primeiras 48 autocorrelaçōes parciais da sërie do $\log$ do

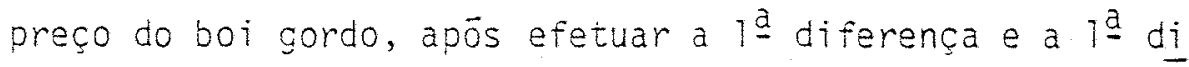
ferença sazonal 
Tabela 5.1. Estimativas dos parāmetros obtidas de alguns modelos SARIMA testados na sērie dos logarítmos dos preços mensais da arroba do boi gordo no período de janeiro de 1970 a dezembro de 1986. Entre parēnteses estão os valores do teste $t$ obtidos para cada estimativa de parâmetro

\begin{tabular}{|c|c|c|c|c|c|c|c|c|}
\hline \multirow{3}{*}{ Modelos SARIMA } & \multicolumn{6}{|c|}{ Estimativas dos parāmetros e respectivas variāveis } & \multirow{3}{*}{$\begin{array}{l}\text { teste } \\
Q(20)\end{array}$} & \multirow{3}{*}{$\begin{array}{l}\text { estimativa da } \\
\text { variancia } \\
\text { do erro }\end{array}$} \\
\hline & $\bar{\phi}_{1}$ & $\overline{\phi_{2}}$ & $\bar{\theta}_{1}$ & $\overline{\bar{\theta}_{2}}$ & $\bar{\Phi}_{1}$ & $\bar{\theta}_{1}$ & & \\
\hline & $z_{t-1}$ & $z_{t-2}$ & $a_{t-1}$ & $a_{t-2}$ & $z_{t-12}$ & $a_{t-12}$ & & \\
\hline$(0,1,0) \times(0,1,1) 12$ & - & - & - & - & - & $\begin{array}{c}.782 \\
(13,67)\end{array}$ & 21,16 & 0,32804 \\
\hline$(0,1,1) \times(0,1,1)_{12}$ & - & - & $\begin{array}{c}-.298 \\
(-4,06)\end{array}$ & - & - & $(14.778$ & 12,01 & 0,84647 \\
\hline$(1,1,1) \times(0,1,1)_{12}$ & $\begin{array}{c}-.182 \\
(-0,82)\end{array}$ & - & $\begin{array}{c}-.468 \\
(-2,28)\end{array}$ & - & - & $\begin{array}{c}.758 \\
(12,96)\end{array}$ & 9,93 & 0,90659 \\
\hline$(1,1,1) \times(1,1,1) 12$ & $\begin{array}{c}-.170 \\
(-0,79)\end{array}$ & - & $\begin{array}{c}-.461 \\
(-2,33)\end{array}$ & - & $\begin{array}{l}-.079 \\
(-0,71)\end{array}$ & $\begin{array}{c}.719 \\
(8,64)\end{array}$ & 9,36 & 0,89799 \\
\hline$(1,1,2) \times(1,1,1) 12$ & $\begin{array}{l}-.001 \\
(-0,003)\end{array}$ & - & $\begin{array}{c}-.298 \\
(-0,81)\end{array}$ & $\begin{array}{c}.031 \\
(0,24)\end{array}$ & $\begin{array}{c}-.075 \\
(-0,00)\end{array}$ & $\begin{array}{c}.740 \\
(8,85)\end{array}$ & 10,75 & 0,77019 \\
\hline$(2,1,1) \times(0,1,1) 12$ & $\begin{array}{c}.024 \\
(0,08)\end{array}$ & $\begin{array}{l}-.107 \\
(-0,95)\end{array}$ & $\begin{array}{c}-.248 \\
(-0,78)\end{array}$ & - & - & $(12,53)$ & 10,21 & 0,85531 \\
\hline$(0,1,2) \times(0,1,1)_{12}$ & - & - & $\begin{array}{c}-.291 \\
(-3,77)\end{array}$ & $(0,51)$ & - & $\begin{array}{c}.772 \\
(13,06)\end{array}$ & 11,44 & 0,83256 \\
\hline
\end{tabular}




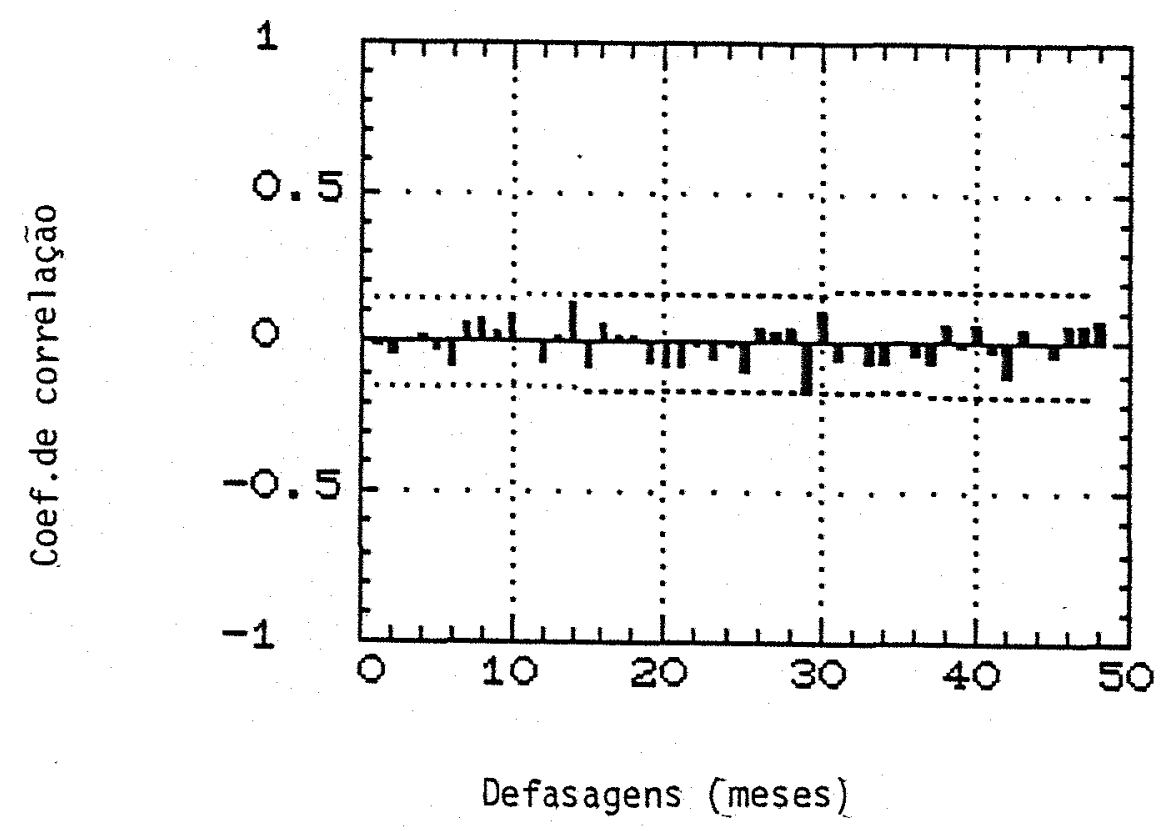

Figura 5.4. Estimativas das autocorrelações dos resíduos do modelo SARIMA $(0,1,1)(0,1,1)_{12}$

resîduo e a correlação cruzada, respectivamente, apresentassem, na de fasagem 72, valor superior a duas vezes o desvio padrão. Entretanto, tendo calculado as autocorrelações atē a defasagem 96 (embora as figuras apresentadas mostrem os resultados apenas atē a defasagem 50), não foi constatada nenhuma autocorrelação significativa na defasagem 72 ou pröxima a essa defasagem, apesar de ser nitida na série a presença dos ciclos plurianuais.

Na Figura 5.5 estão apresentadas as previsões num ion go perTodo de tempo, mostrando apenas a tendēncia e o componente sazonal. 
Para comprovar o fato tambēm foram feitas previsões com outros modelos que haviam sido descartados anteriormente, jā que, para a escolha do melhor modelo tambēm deve ser considerada a obtenção de boas previsões. Entretanto, os resultados mostraram-se bastante semelhantes aos do $\operatorname{SARIMA}(0,1,1)(0,1,1)_{12}$.

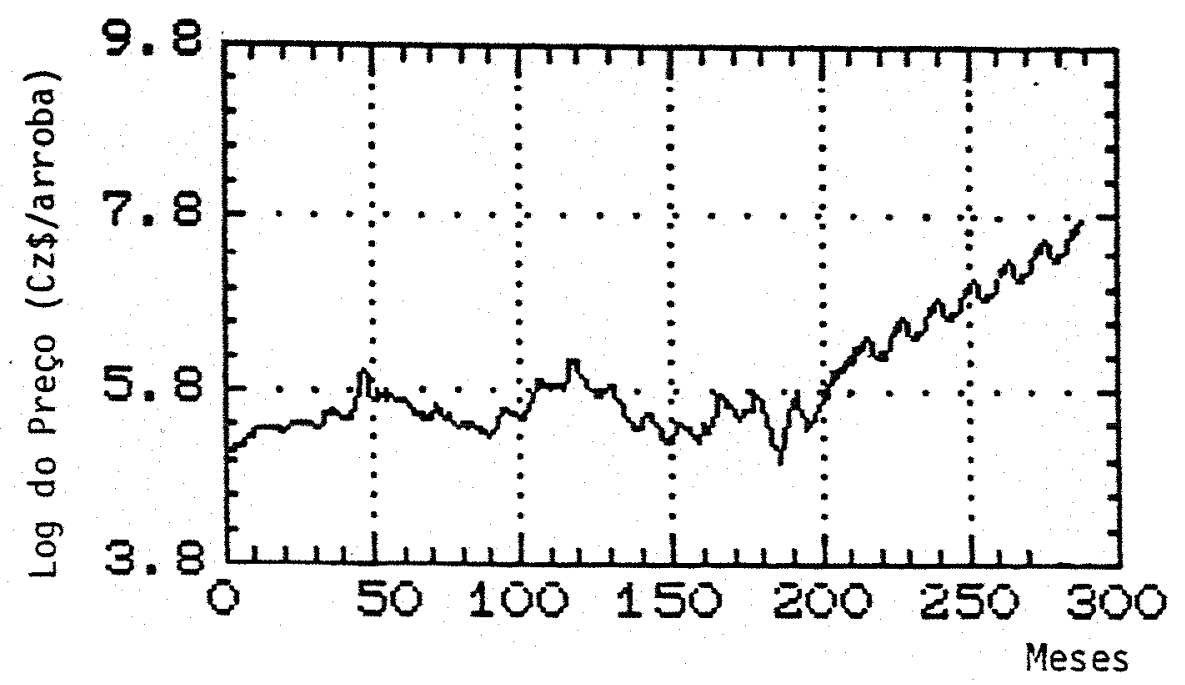

Figura 5.5. Previsões de 84 meses ( 7 anos) obtidas a partir do mès 205 (jan. de 1987) pelo modelo $\operatorname{SARIMA}(0,1,1)(0,1,1) 12$ 


\subsubsection{Mode1o Harmönico}

Tentando captar de forma apropriada as variações sazonais e os ciclos plurianuais, obtendo com isto um bom ajuste e consequentemente boas projeçōes, foi testado um modelo harmōnico para 0 mesmo período (jan.de 1970 a dez. de 1986).

Para retratar a tendēncia da sērie foi incluĩdo na regressāo um termo linear em $t$, com $t=1$ em janeiro de 1970 .

Os ciclos plurianuais foram representados por componentes harmōnicos de periodo 72 (equivalente a 6 anos) mais os seus submültiplos. Porēm, para representar as oscilações sazonais, foram utilizadas 11 variāveis binārias $S_{i t}$, as quais facilitam a interpretação das estimativas dos parāmetros, pois refletem os períodos de baixa e alta dos preços na safra e entressafra, respectivamente.

Sendo $z_{t}$ o preço real mensal da arroba do boi gordo, a equação de regressão pode ser escrita como,

$$
\log z_{t}=a_{0}+b_{0} t+\sum_{i=1}^{5}\left(c_{i} \operatorname{sen} \frac{2 \pi i t}{72}+d_{i} \cos \frac{2 \pi i t}{72}\right)+\sum_{i=1}^{11} e_{i} s_{i t}+\bar{a}_{t}
$$

Todas as variāveis foram mantidas no modelo, mesmo apre sentando efeito não-significativo.

Ajustado o modelo, obteve-se $R^{2}=0,60$, teste de Durbin-Watson $D W=0,19$ e $Q(42)=674,47$. 0 modelo apresentou um razoável ajustamento, acompanhando os ciclos estacional e plurianual. Foram feitas projeções para os 12 meses de 1987, obtendo-se valores razoavelmente próximos aos observados no mercado físico nesse período. 
Entretanto, o teste de Durbin-Watson e o valor de Q mostraram a existência de autocorrelação nos resỉduos.

\subsubsection{Modelos Mistos}

Na tentativa de se contornar os problemas de autocorrelação nos resíduos, ocorridos com a anālise harmōnica, e de incapacidade em prever os ciclos de 6 anos, ocorrido nos modelos ARIMA, foram utilizados modelos mistos.

Estes modelos foram estimados com base nos ültimos 7 anos da sērie, de janeiro de 1980 a dezembro de 1986. Esta redução do período foi testada, objetivando um melhor ajuste do modelo em ēpoca prōxima ao ano para o qual são feitas previsões.

Um dos modelos mistos foi formado pela tendēncia, com ponentes harmōnicos, variāveis binārias e por um processo auto-regressivo de ordem dois.

Foi observado que no início da série as variações estacionais eram suaves, enquanto no final eram bastante pronunciadas. Diante de tal fato, e visando um melhor ajustamento do modelo no perío do mais recente, foi introduzido um fator de ponderação, sugerido por Brown (1962, citado em Morettin e Toloi, 1985), igual a $\beta^{N-t}$, onde $N$ è o nümero de dados da sērie e $t$ e o tempo. Este mesmo autor sugeriu que o valor de $\beta$ deveria ser determinado de acordo com as características especificas da sērie en estudo. Analisando a sērie, foi estabelecido o valor 0,95 para $\beta$, o qual forneceu uma boa proporção entre os pesos da parte inicial e final do conjunto de dados. 
A regressão apresentou então a seguinte forma:

$$
\begin{aligned}
\log z_{t}=a_{0} & +b_{0} t+\sum_{i=1}^{5}\left(c_{i} \operatorname{sen} \frac{2 \pi i t}{72}+d_{i} \cos \frac{2 \pi i t}{72}\right)+\sum_{i=1}^{11} e_{i} s_{i t}+ \\
& +\phi_{1} \log z_{t-1}+\phi_{2} \log z_{t-2}+\bar{a}_{t}
\end{aligned}
$$

Os resultados encontram-se na Tabela 5.2. Foi obtido o valor de $0,923^{1}$ para o coeficiente de determinação $\left(R^{2}\right)$, mostrando 0 bom ajustamento do modelo. Entretanto, o valor do teste $Q(Q(27)=103,07)$ deixa clara a existēncia de autocorrelação nos resíduos.

Sabemos que a ocorrēncia de autocorrelação nos resíduos compromete a validade do teste $t$, e, portanto, seus valores serão utilizados, nesta pesquisa, apenas na indicação da importāncia das variāveis no modelo: o nivel de significāncia, apresentado nas tabelas, deve ser interpretado dessa maneira.

As previsōes de preços obtidas a partir do modelo foram muito boas, bem prōximas aos preços do mercado físico, como se pode observar na Tabela 5.3 e Figura 5.6. Portanto, mesmo diante da existēncia de autocorrelação nos resíduos, este modelo não foi descartado, sendo considerado um dos methores para a obtenção de previsões.

Foram testados, para o mesmo modelo descrito anteriormente, de janeiro de 1977 a dezembro de 1986, valores para o período do ciclo

1 Todos os valores do coeficiente de determinação $\left(R^{2}\right)$, nas regressöes ponderadas, foram recalculados através de comandos específicos, dian te da constatação feita pelo Prof. Rodolfo Hoffmann de que o programa de computador utilizado (RATS) fornece valores errados do $R^{2}$ em regressōes ponderadas. 
Tabela 5.2. Equação obtida do modelo misto com AR(2) para a série de preços reais mensais da arroba do boi gordo no periodo de janeiro de 1980 a dezembro de 1986

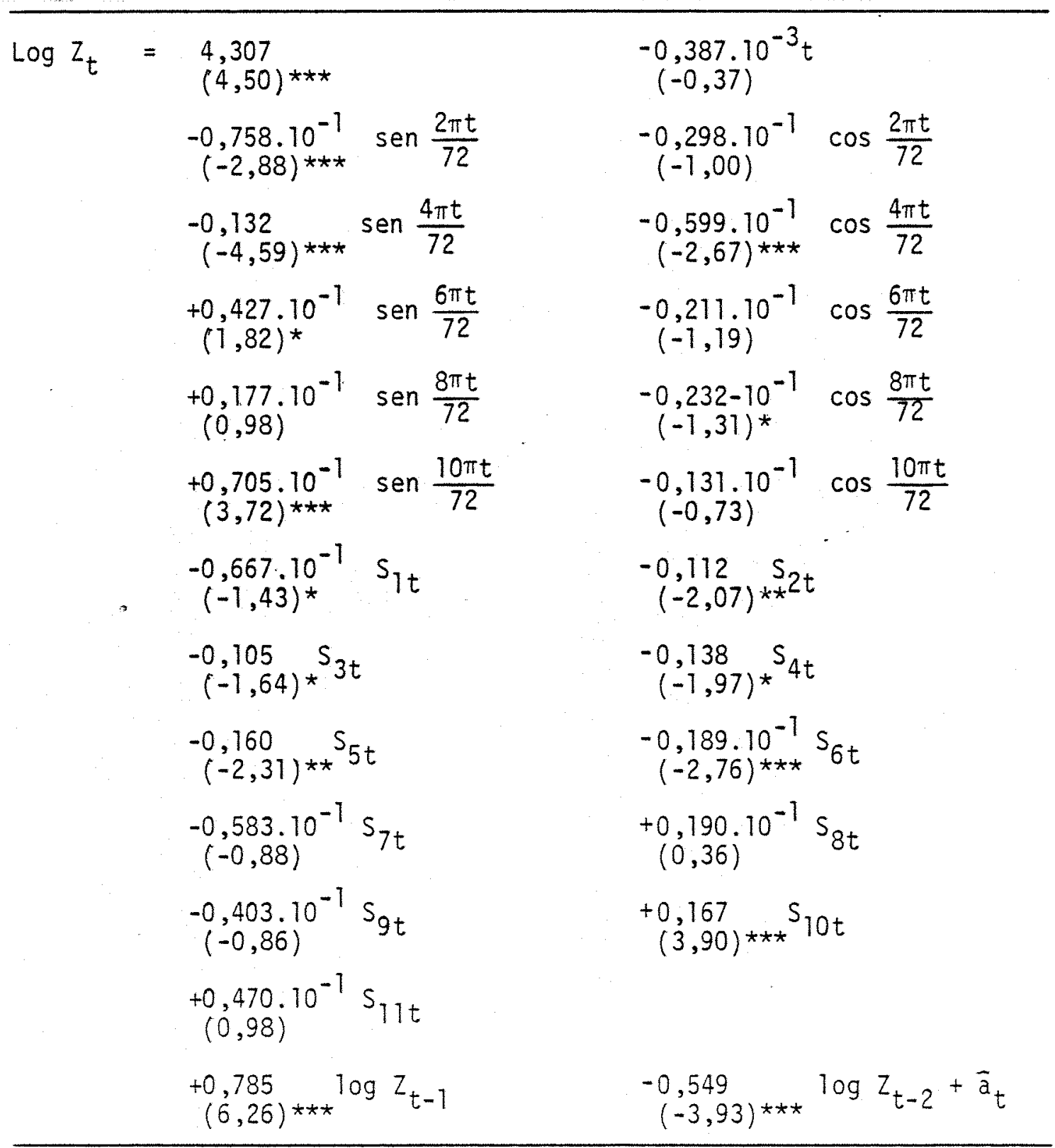

Entre parénteses encontram-se os valores do teste $t$

$* \star *=$ significativo a $1 \%$

$* *=$ significativo a $5 \%$

* = significativo a $10 \%$ 
plurianual iguais a $71,73,74,76,78,81$ e 84 meses, cada um separadamente, a fim de observar se o valor preliminarmente testado, igual a 72 meses ou 6 anos, era adequado.

De acordo com os resultados obtidos, foi possivel considerar o período de 72 meses como o melhor período plurianual, para fins de previsões.

Tabela 5.3. Previsões de preços reais da arroba do boi gordo, observações obtidas nos mercados físicos e a termo, para 1987, e valor do erro quadrätico mēdio de previsão (EQM)

\begin{tabular}{lcccccc}
\hline 1987 & $\begin{array}{c}\text { Mercado } \\
\text { fisico }\end{array}$ & $\begin{array}{c}\text { Mercado } \\
\text { a termo }\end{array}$ & $\begin{array}{c}\text { Modelo } \\
\text { SARIMA } \\
(0,1)(0,1,1)\end{array}$ & $\begin{array}{c}\text { Modelo } \\
\text { Harmonico }\end{array}$ & $\begin{array}{c}\text { Modelo } \\
\text { Misto } \\
\text { com AR(2) }\end{array}$ & $\begin{array}{c}\text { Modelo } \\
\text { Misto com } \\
\text { ARMA }(1,1)\end{array}$ \\
\hline Jan & 409,64 & - & 470,19 & 305,25 & 432,42 & 435,11 \\
Fev & 314,96 & 305,20 & 425,76 & 282,95 & 327,41 & 352,02 \\
Mar & 270,07 & - & 396,81 & 262,79 & 260,53 & 295,25 \\
Abr & 252,62 & 221,90 & 400,62 & 252,87 & 240,37 & 267,38 \\
Maio & 246,07 & - & 409,62 & 239,08 & 230,40 & 244,28 \\
Jun & 188,27 & 153,43 & 406,24 & 222,46 & 211,46 & 215,39 \\
Jul & 212,91 & - & 475,74 & 228,51 & 217,49 & 224,68 \\
Ago & 243,90 & 199,64 & 506,18 & 232,71 & 211,66 & 223,75 \\
Set & - & - & 564,72 & 244,06 & 211,85 & 235,02 \\
Out & - & - & 560,85 & 249,08 & 198,71 & 229,38 \\
Nov & - & - & 595,87 & 252,52 & 232,01 & 234,86 \\
Dez & - & - & 624,41 & 242,66 & 243,72 & 227,58 \\
\hline EQM(1) & - & $1.052,94$ & $33.254,84$ & $1.695,43$ & 344,78 & 519,59 \\
\hline
\end{tabular}

(1) o erro quadrático médio das cotaçōes do mercado a termo foi calcula do com base em 4 valores. Nos demais casos foram utilizados 8 valores (janeiro a agosto). 
A.o examinar a tabela 5.3 deve-se ter em mente que o mercado a termo faz previsōes em valores nominais, estando embutida no pre ço uma estimativa da inflação. Uma vez que o modelo utiliza valores reais, foi necessärio deflacionar, atravēs do IGP, os preços do mercado a termo e do mercado físico para que se pudesse fazer comparações.

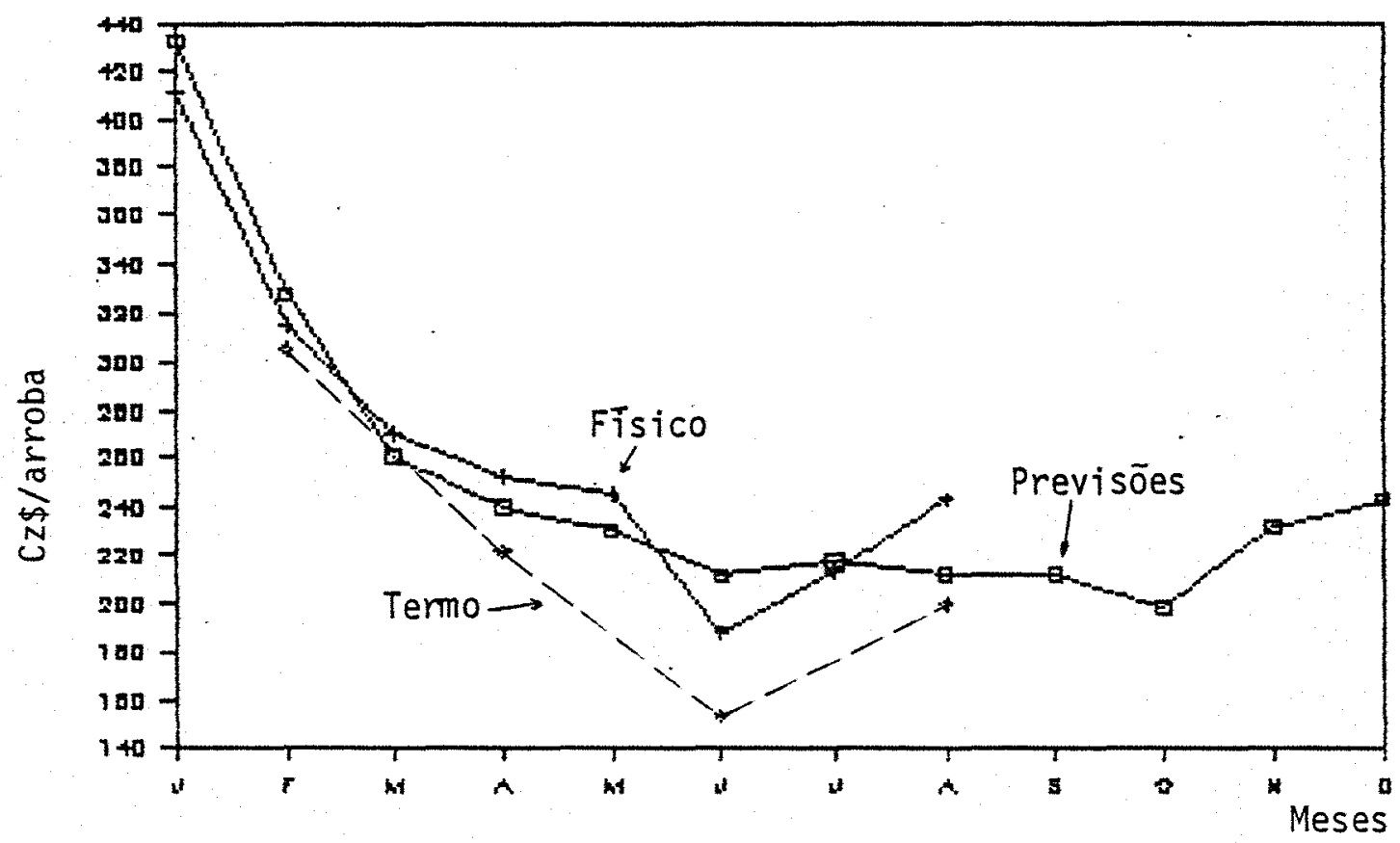

Figura 5.6. Comparação entre as previsões de preços de arroba do boi gordo obtidas do modelo misto com $A \cdot(2)$, do mercado a termo e observações do mercado físico para 1987

0 outro modelo misto testado foi composto por uma tendēn cia, componentes cíclicos, variāveis binärias e por um processo auto-re gressivo e de mēdia mōvel ARMA $(1,1)$. Devido ao processo de mēdia mōvel, não foi possivel, com os programas disponíveis, utilizar um método pon derado de estimação. 
A regressão pode ser representada por:

$$
\begin{aligned}
\log z_{t}=a_{0} & +b_{0} t+\sum_{i=1}^{5}\left(c_{i} \operatorname{sen} \frac{2 \pi i t}{72}+d_{i} \cos \frac{2 \pi i t}{72}\right)+\sum_{i=1}^{11} e_{i} S_{i t}+ \\
& +\phi_{1} \log z_{t-1}+\bar{a}_{t}-\theta_{1} \bar{a}_{t-1} \\
& \quad \text { modelo apresentou } R^{2}=0,92 \text {, e teste } Q(27)=10,94,
\end{aligned}
$$

indicando bom ajustamento e inexistência de autocorrelação nos resīduos. Os demais resultados estão apresentados na Tabela 5.4.

As previsōes obtidas encontram-se na Tabela 5.3 e Figura 5.7 , e, como no modelo anterior, foram muito boas.

Os modelos descritos anteriormente forneceram previsōes somente para o ano de 1987. Este procedimento foi inicialmente adotado visando a identificação do melhor modelo, ou seja, aquele que fosse capaz de fornecer as melhores previsões.

Observando a Tabela 5.3, atravēs de comparações entre os erros quadrätico mēdio de previsão, calculados para cada modelo descrito anteriormente, constatamos ser o modelo misto com $A R(2)$ o melhor. Foram feitas, então, a partir dele, previsões para os anos de 1981 , 1982, 1983, 1984, 1985, 1986 e 1987, que encontram-se na Tabela 5.5 e nas Figuras 5.8 a 5.14 , apresentadas na seção seguinte. O período utiTizado para esta anälise foi mais longo, iniciando em janeiro de 1970 e terminando em dezembro do ano anterior ao da previsão, sendoo modelo rea justado neste período. Uma vez que o ano de previsão era alterado conti nuamente, a utilização de um período de apenas 7 anos (janeiro de 1980 a dezembro de 1986), como foi feito no caso anterior, traria problemas de ajuste, tornando-se dificil captar a tendéncia e os ciclos plurianuais. 
Tabela 5.4. Equação obtida do modelo misto $\operatorname{com} \operatorname{ARMA}(1,1)$ para a série de preços reais mensais da arroba do boi gordo no periodo de janeiro de 1980 a dezembro de 1986

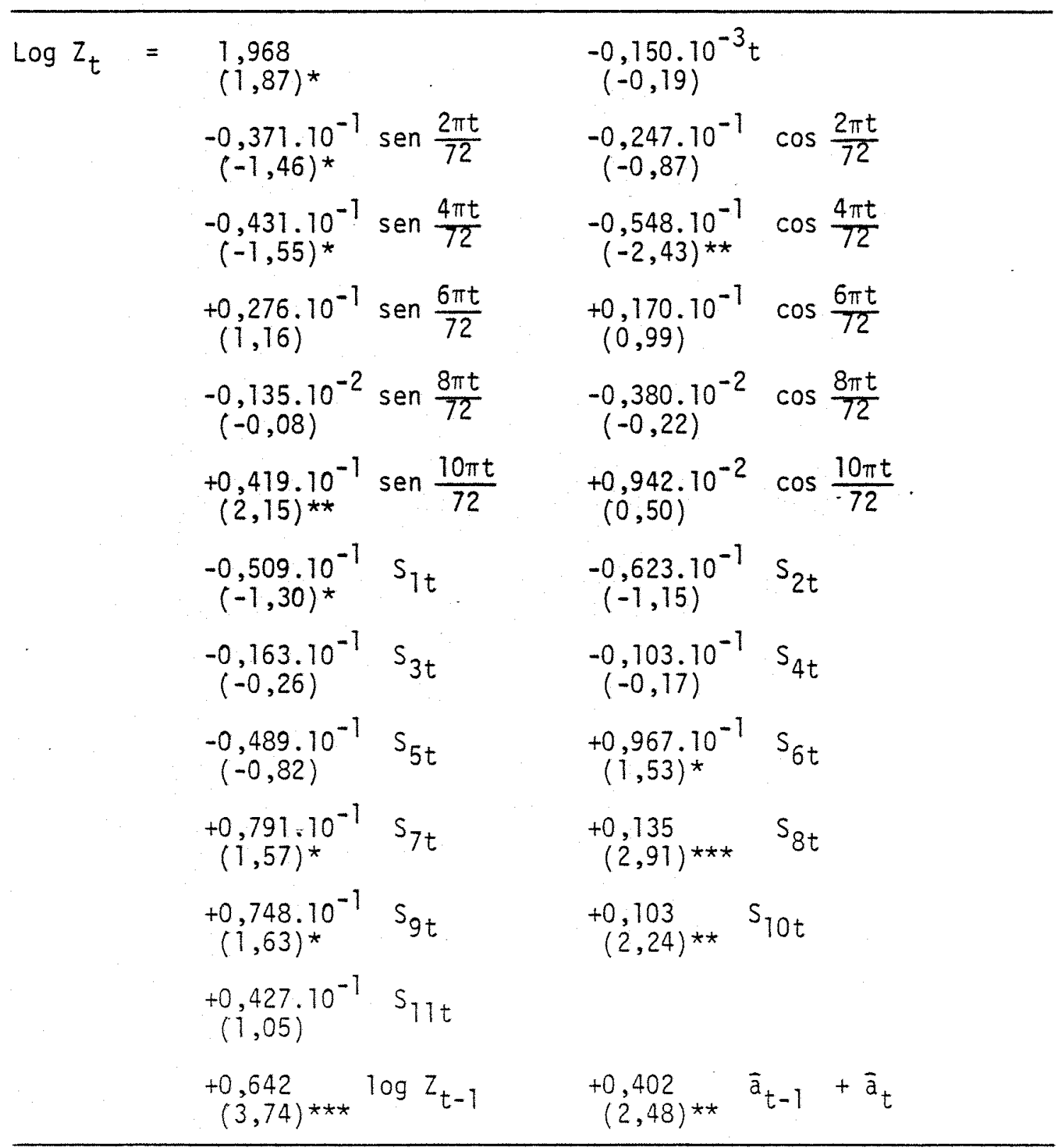

Entre parênteses encontram-se os valores do teste t.

$* \star *$ significativo a $1 \%$

** significativo a $5 \%$

* significativo a $10 \%$ 


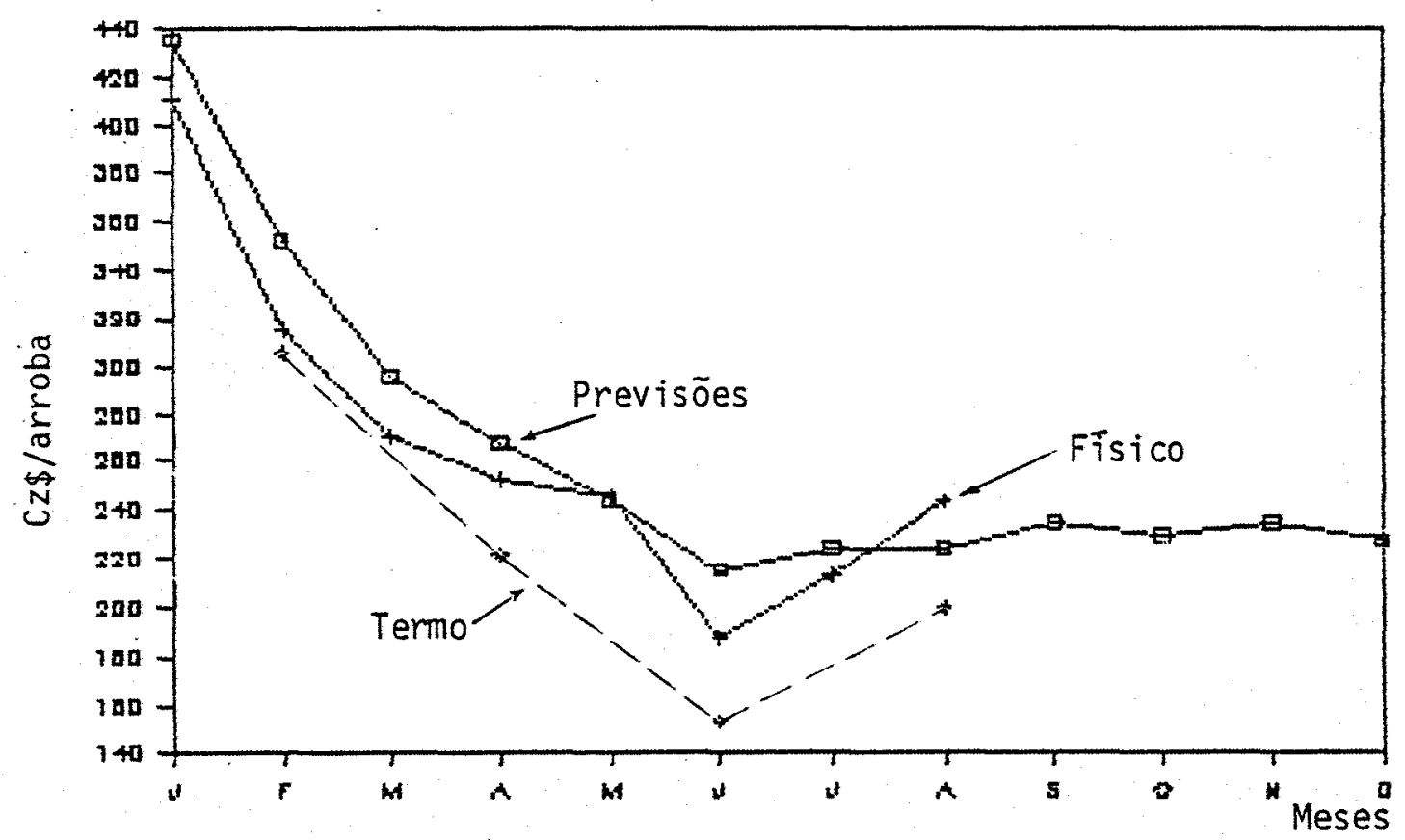

Figura 5.7. Comparação entre as previsões de preços da arróba do boi gor do obtidas do modelo misto com ARMA. $(1,1)$, do mercado a termo e observações do mercado físico para 1987

Na tesma Tabela 5.5 estão os valores do erro quadrätico médio de previsão, que tornam possivel a comparação das previsões obtidas do modelo misto com $\operatorname{AR}(2)$ e as fornecidas pela Bolsa de Mercadorias de São Paulo com relação aos preços do mercado físico para os anos de 1981 a 1987. Observamos que o modelo conseguiu prever melhor somente nos anos de 1982 e 1983; nos demais, as previsões da Bolsa foram melhores, ou seja, conseguiram se aproximar mais do mercado físico.

As principais causas das mäs previsões realizadas pelo mercado a termo para o ano de 1983 foram: uma expectativa de 100\% de in flação feita pelos agentes do mercado em dezembro de 1982 para 1983, atin gindo esta 200\%; e a maxidesvalorização do cruzeiro de 30\% ocorrida em fevereiro de 1983 possibilitando maiores exportações e aumento no preço interno. 
Tabela 5.5. Previsões de preços reais da arroba do boi gordo obtidas do modelo misto com $A R(2)$, observaçöes fornecidas nos mercados físico e a termo para o perî́odo de 1981 a 1987 e valores do erro quadrātico médio de previsão (EQM)

\begin{tabular}{|c|c|c|c|c|c|c|c|c|c|c|c|c|c|c|c|c|c|c|c|c|c|}
\hline \multirow{2}{*}{$\begin{array}{l}\text { Me- } \\
\text { sex }\end{array}$} & \multicolumn{3}{|c|}{1981} & \multicolumn{3}{|c|}{1982} & \multicolumn{3}{|c|}{1983} & \multicolumn{3}{|c|}{1984} & \multicolumn{3}{|c|}{1985} & \multicolumn{3}{|c|}{1986} & \multicolumn{3}{|c|}{1987} \\
\hline & Prev. & Fis. & Bolso & Prev. & Fis. & Bolsa & Prev. & Fis. & Bolsa & Prev. & Fis. & Bołsa & Prev. & Fis. & Boisa & Prev. & fis. & Bolsa & Prev. & Fis. & Bolsa \\
\hline Jan & 300.23 & 294.51 & * & 244,08 & 225.63 & - & 190.83 & 187.68 & - & 267,39 & 275.79 & - & 260,56 & 235,76 & - & 293,56 & 257,09 & $\because$ & 457,30 & 409.65 & - \\
\hline Fer & 282,01 & 268.93 & 277.51 & 237,36 & 203,04 & 189.99 & 176,45 & 183,68 & 160,13 & 248.57 & 265,69 & 258,63 & 261,34 & 204,64 & 216,83 & 277,15 & 225.98 & 222,39 & 32,41 & 314,96 & 305,20 \\
\hline phr & 265,54 & 250,67 & - & 231,97 & 188.15 & • & 166.35 & 184,71 & - & 236,62 & 248,15 & - & 259,06 & 179.37 & - & 254,32 & 213,05 & - & 302,15 & 270,07 & $\cdot$ \\
\hline Aur & $25 y .53$ & 238.24 & 259,24 & 230,87 & 183.54 & 169,19 & 164,63 & 222.32 & 141,69 & 251,84 & 233.67 & 257,35 & 272.92 & 169,50 & 213.17 & 241,76 & 223,20 & 230,01 & 266,02 & 252,62 & 221,90 \\
\hline Mat & 253,00 & 226,65 & - & 226,43 & 185,44 & $\therefore$ & 167,66 & 218,27 & - & 248,75 & 270,87 & - & 304.76 & 157,85 & - & 229,69 & 235,86 & - & 237,65 & 246,07 & $*$ \\
\hline Juni & 247,50 & 209,09 & 257,15 & 215,63 & $i 80.72$ & 154,74 & 168.58 & 202,49 & 128,09 & 238,87 & 261,30 & 252,07 & 308.36 & 146.56 & 226,05 & $203, n$ & 257,44 & 270,54 & 207,55 & 188,27 & 153,43 \\
\hline inl & 260,31 & 208,35 & $=$ & 219.11 & 225.19 & - & 199,55 & 240,87 & - & 282,61 & 266,51 & - & 356.52 & 206.34 & - & 235.01 & 284.18 & - & 209,22 & 213,91 & - \\
\hline Ryo & 275,68 & 212,73 & 273.91 & 222,90 & 226.31 & 160,06 & 216,06 & 255.14 & 124,87 & 304,14 & 274,46 & 277,96 & 388.91 & 254.43 & 234,25 & 249,72 & 311,59 & 383,60 & 202.04 & 243,90 & 199,64 \\
\hline Set & 293,83 & 239,72 & = & 236,34 & 228,49 & - & 240,30 & 315,60 & - & 358,89 & 342,65 & & 479,31 & 272,28 & - & 270.57 & 335,40 & . & 199,19 & - & - \\
\hline Giut & 321,76 & 251,98 & 303.48 & 245.67 & 217,83 & 186.71 & 256,52 & 310,62 & 123.42 & $374,6 !$ & 318,38 & 297,76 & 473.58 & 287,25 & 250,05 & 264.45 & 322,39 & 489,65 & 182,06 & • & - \\
\hline Nov & 320.16 & $25 E, 01$ & - & 239.43 & 208,28 & - & 262,40 & 295.88 & - & 377.29 & 288.92 & - & 445,10 & 331,23 & - & 268.16 & 434,52 & - & 206,34 & $\cdot$ & - \\
\hline$U_{1}=2$ & 298.96 & 242,53 & 278.83 & 220.01 & 198.08 & 163,66 & 256.08 & 283,70 & 100.56 & 371,55 & 260,09 & 253,57 & 404.18 & 299,58 & 204,34 & 243.36 & 499.10 & 474,38 & 213,05 & $\cdot$ & - \\
\hline EQM & 14,18 & - & .40 & 909.50 & - & $1.265,57$ & 1. 762,83 & - & 357.59 & 18.12 & - & 195,95 & 17.563 .72 & - & 3.206 .72 & $9.652,47$ & - & $5.667,22$ & $1.123,52$ & - & .052 .94 \\
\hline
\end{tabular}


Observando as figuras 5.8 a 5.14 , referentes às previsões obtidas, notamos que o modelo estatístico conseguiu captar de forma adequada as tendências de alta e baixa dos preços, embora em algumas vezes o preço tenha se distanciado do realmente ocorrido.

Para fins de negociações em Bolsa, conhecer a tendēncia do preço, isto $\bar{e}$, um aumento ou queda, $\bar{e}$ de grande importāncia, uma vez que os participantes do mercado, de posse dessas informações, podem liquidar suas posições e evitar grandes prejuízos.

Ainda tentando melhorar as previsões apresentadas na Tabela 5.5, foi ajustado um modelo ARMA $(1,1)$ aos residuos obtidos do modelo misto com $A R(2)$ e feitas as previsöes do resíduo, somando-as às previsões jā obtidas no mesmo perīodo. Este procedimento eliminou a autocorrelação dos resĩduos, entretanto, apesar das estimativas dos parāmetros do modelo ARMA $(1,1)$ apresentarem-se significativas, o valor da previsão do resíduo foi muito pequeno, quase näo alterando as previsões do modelo misto com $\operatorname{AR}(2)$. Sendo um procedimento mais complexo e demorado e não contribuindo para melhorar sensivelmente os resultados, foi descartado.

\subsubsection{Fatores modificadores de preços}

Nesta seção são apresentados e discutidos, para os anos de 1981 a 1987, alguns fatores, de ordem econômica, política e social, que provocaram variaçōes nos preços, de forma a, em diversos casos, alterar as oscilações nomais do ciclo pecuārio, contrariar as expectativas dos especialistas do mercado e prejudicar as previsōes. 


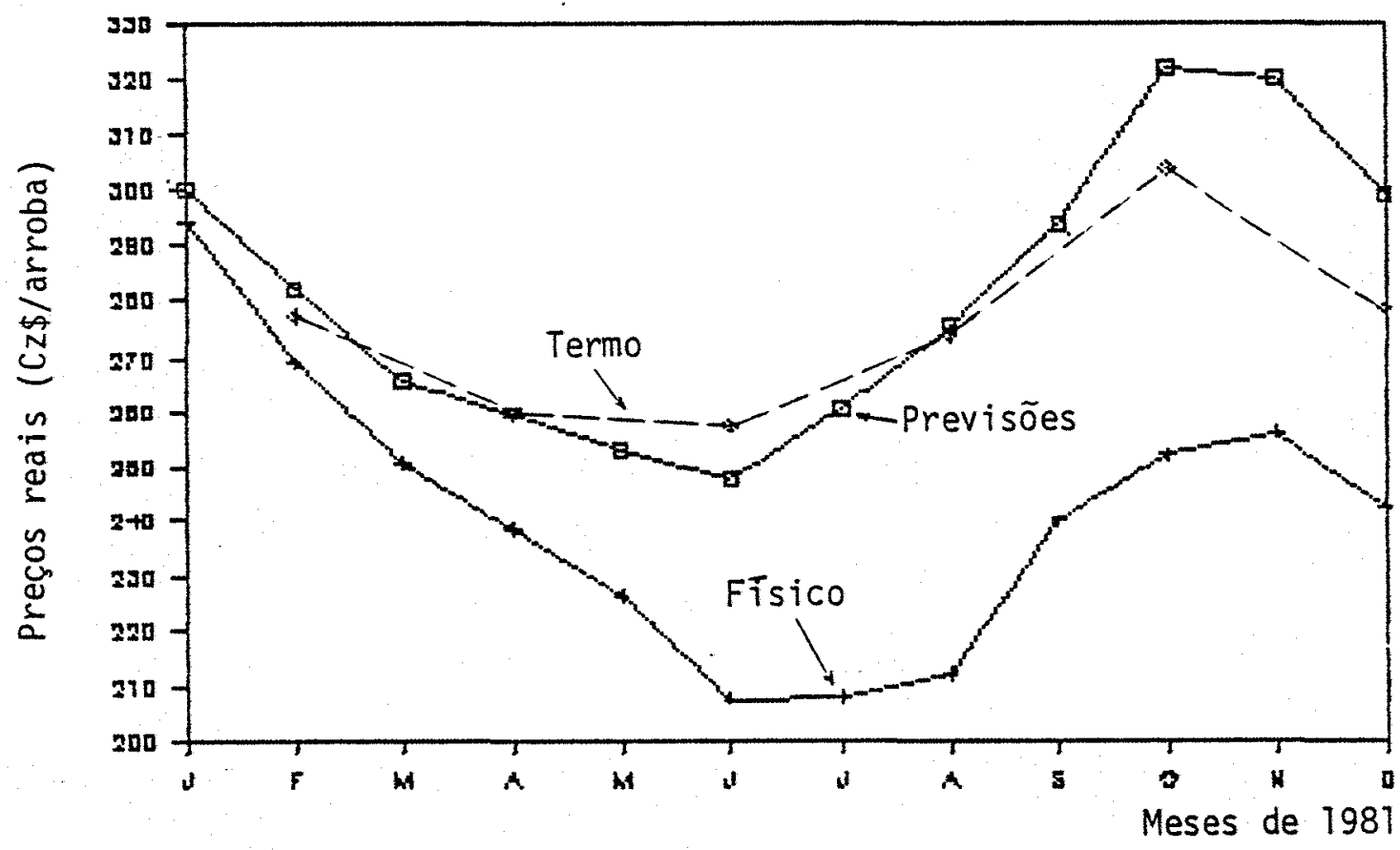

Figura 5.8. Comparaçōes entre as previsōes de preços da arroba do boi gordo obtidas pelo modelo misto com $A R(2)$, pelo mercado a termo e observações do mercado físico para 1981

0 ano de 1981 foi marcado pelo aumento da oferta de carne bovina devido ao aumento do abate de matrizes em relaçäo a 1980 , em consequência da queda dos preços reais da carne, jă caracterizando um periodo descendente do ciclo pecuārio. A situação foi ainda agravada pela mudança na cobrança do Imposto sobre Circulação de Mercadorias - ICM a partir de janeiro, passando de $4,75 \%$ para $15,5 \%$.

o consumo "per capita" de carne caiu de $16,6 \mathrm{~kg} / \mathrm{hab} / \mathrm{ano}$ em 1980 para $15,2 \mathrm{~kg} / \mathrm{hab} / a n o$ em 1981 , segundo dados da USDA. Este fato 
pode ser explicado pelo perīodo recessivo peloqual passava o pais (ver Tabela 5.6).

Tentando aliviar a crise do setor pecuārio, o governo adquiriu como estoque regulador para a entressafra 263,5 mil toneladas de carne, considerado na época um volume recorde, alēm de intensi ficar a exportação.

Tabela 5.6. Variação do Produto Interno Bruto brasileiro no período $1980-86$

\begin{tabular}{lcc}
\hline Anos & $\begin{array}{c}\text { Indice do PIB } \\
\text { "per capita" }\end{array}$ & $\begin{array}{c}\text { Variação } \\
\%\end{array}$ \\
\hline 1980 & 100,0 & 6,5 \\
1981 & 94,3 & $-5,7$ \\
1982 & 92,9 & $-1,5$ \\
1983 & 88,3 & $-4,9$ \\
1984 & 91,1 & 3,1 \\
1985 & 96,2 & 5,6 \\
1986 & 101,6 & 5,6 \\
\hline
\end{tabular}

FONTE: Conjuntura Econōmica 41(5):15, maio 1987.

As exportações em 1982 continuaram aumentando. Entretanto, a reversão do ciclo pecuārio, esperada por muitos especialistas de mercado, não ocorreu, permanecendo os preços reais ainda mais baixos en relação a 1981 . 


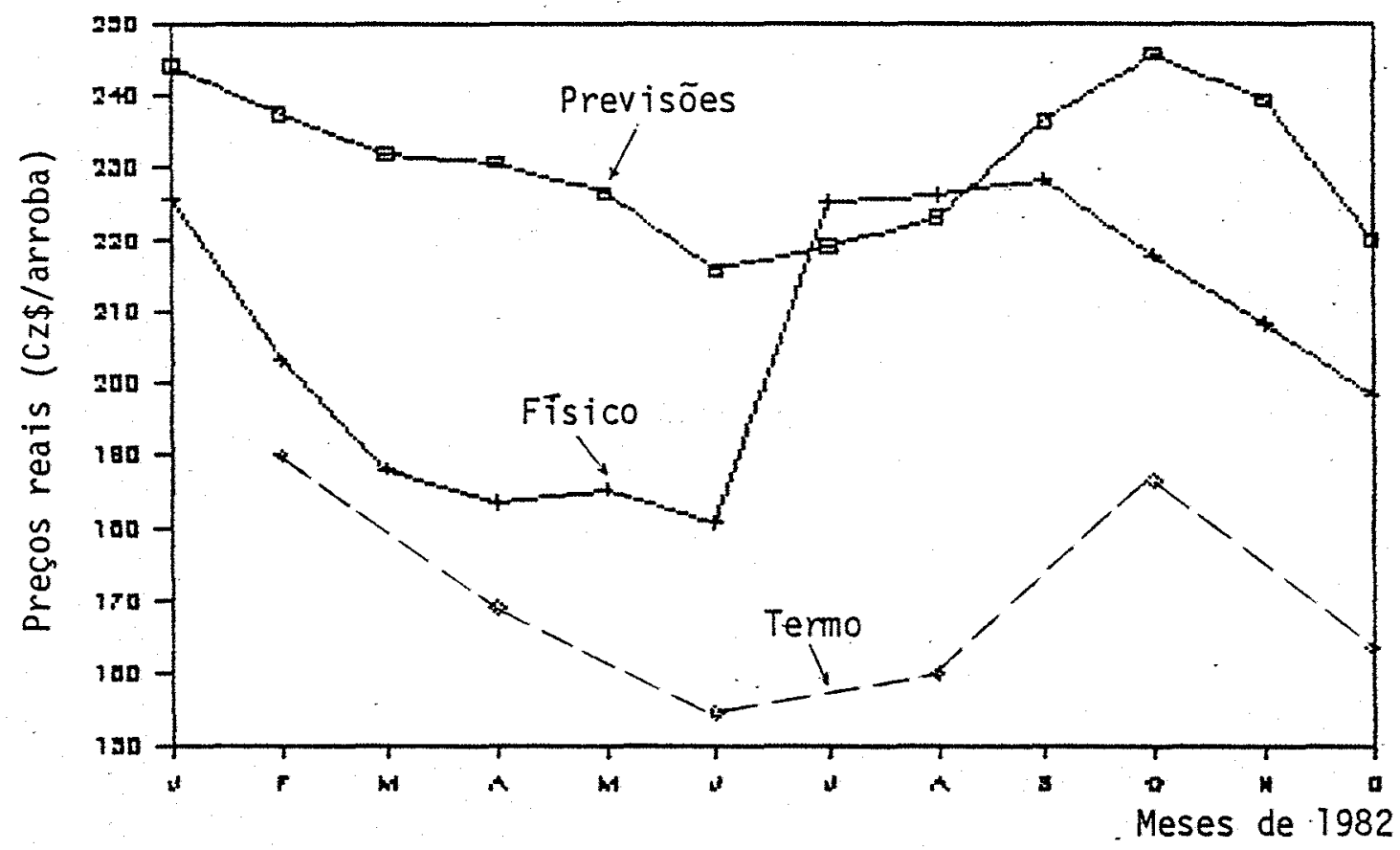

Figura 5.9. Comparações entre as previsöes de preços da arroba do boi gordo obtidas pelo modelo misto $\operatorname{com} \operatorname{AR}(2)$, pelo mercado a termo e observações do mercado físico para 1982

A queda dos preços jā havia sido prevista pelo governo, devido à abundante oferta de carne bovina e a continuidade da recessão econômica, o que o levou a retirar a Cobal da administração dos estoques de carne congelada na entressafra, deixando o setor pecuário mais livre para que se regulasse atravës das leis de mercado. Por outro lado, implementou politicas anticíclicas de financiamento da reten ção de matrizes e do boi em pé. 


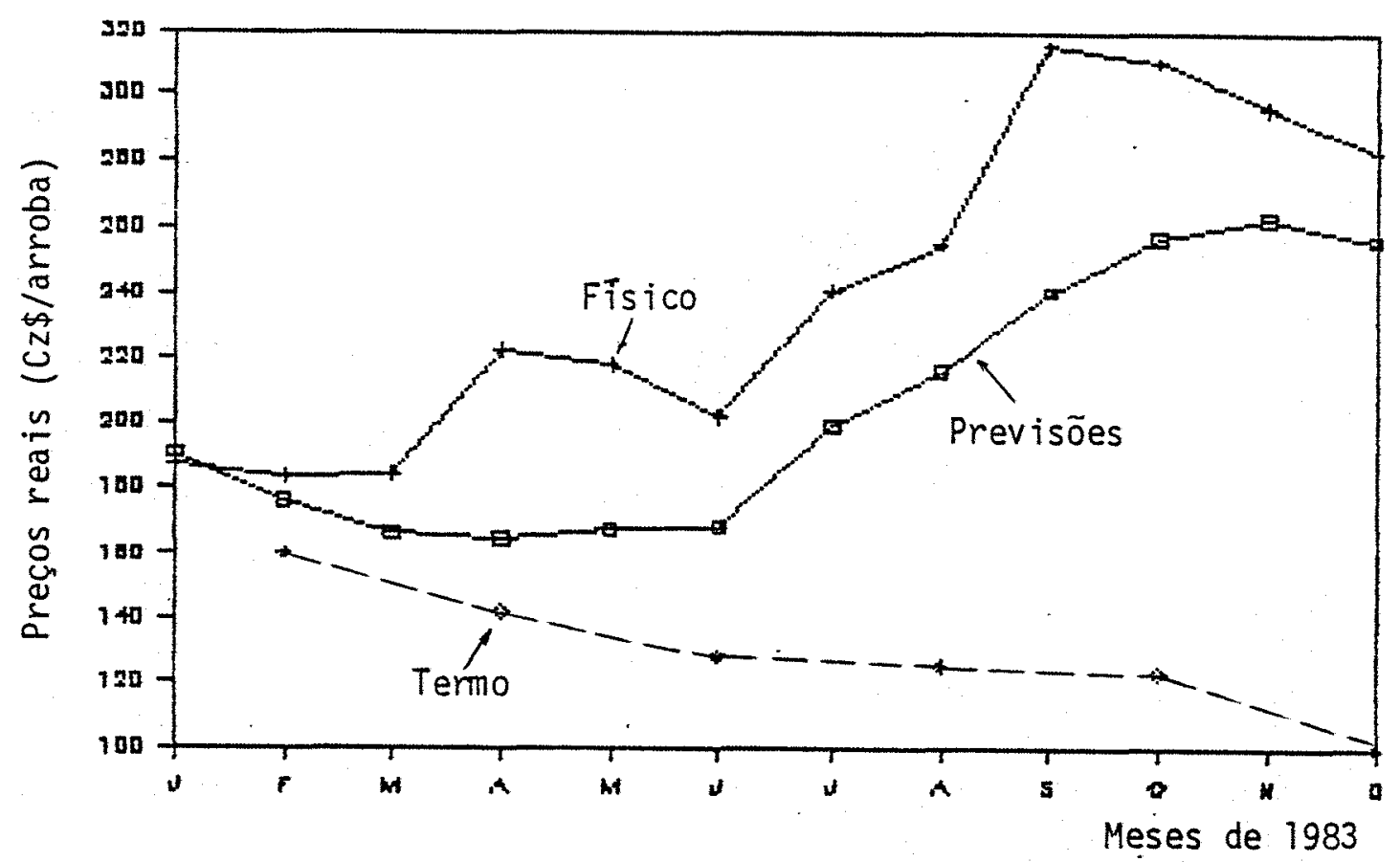

Figura 5.10. Comparações entre as previsōes de preços da arroba do boi gordo obtidas pelo modelo misto com $\operatorname{AR}(2)$, pelo mercado a termo, e observações do mercado físico para 1983

Sendo caracterizado por um período ascendente do ciclo pecuārio, o ano de 1983 foi marcado por grandes aumentos na exportação de carne bovina, ajudada pela diminuição da oferta por parte dos dois principais paîses exportadores da ēpoca, Austrātia e Argentina, como consequência, respectivamente, da seca e da Guerra das Malvinas. Diante deste quadro, o Brasil passou a ser o 30 maior exportador mundial, de acordo com dados da USDA, apōs a Austrātia e Argentina. Porêm, jā nesta época é posto em dưvida a manutenção deste volume de 
exportação nos anos subsequentes, uma vez que a pecuāria brasileira, alēm de apresentar baixíssimos îndices zootēcnicos, sofreria dentro de alguns anos a escassez de animais para abate, resultado. da matança indiscriminada de fēmeas. Diante de tais problemas, seria difícil o país conseguir manter suas exportaçōes elevadas, mesmo se a demanda in terna fosse reprimida, como resultado de políticas de arrocho salarial e consequente queda do poder aquisitivo da população.

Ainda no ano de 1983 , os negócios realizados no mercado a termo da Bolsa de Mercadorias de São Paulo movimentaram quantias mais elevadas do que aquelas envolvidas em transações com ouro, café ou soja; entretanto, no final do ano, o governo central interveio no mercado a termo do boi gordo, acusando-o de especulativo e cancelando a isenção de imposto de renda, decretadà em março de 1982, para as operações relativas a boi em pē. Este fato resultou numa drästica redução dos contratos em aberto. Vale porēm ressaltar que os preços pré vistos nesta ëpoca, para o ano de 1984, mostraram exatamente a realidade do mercado.

O Brasil em 1984 ocupou o 20 lugar em exportações mundiais, logo apōs a Austrātia, com $480 \mathrm{mil}$ toneladas, segundo a USDA. No entanto, o consumo "per capita" caiu para $13,2 \mathrm{~kg} / \mathrm{hab} / \mathrm{ano}$ neste ano, sendo um dos mais baixos das ültimas dëcadas. 


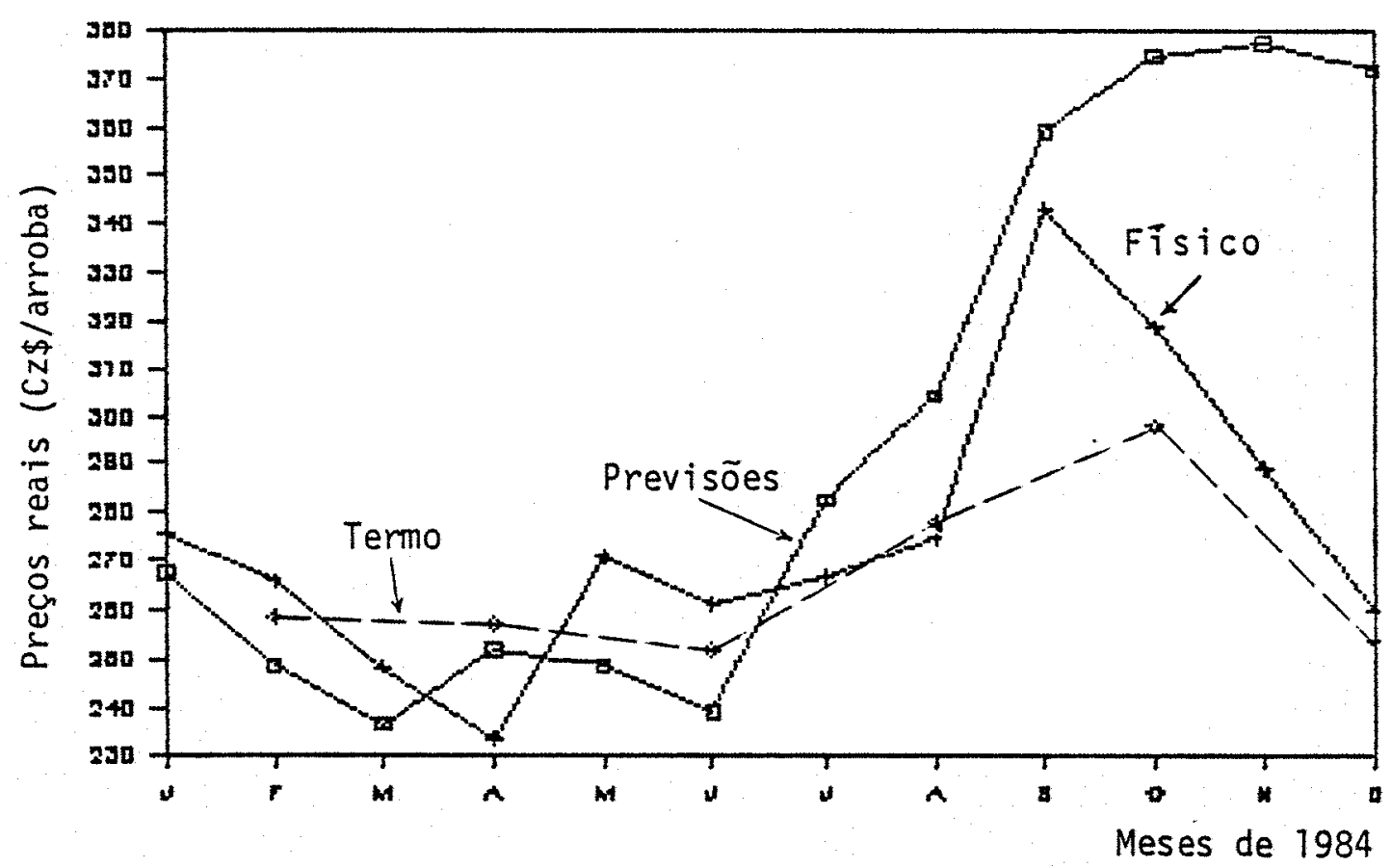

Figura 5.11. Comparaçōes entre as previsōes de preços da arroba do boi gordo obtidas pelo modelo misto com $A R(2)$, pelo merca do a termo, e observações do mercado físico para 1984

Segundo dados do FIBGE, o mès de janeiro foi caracterizado pela maior matança de fémeas desde 1975, que continuou elevada durante todo ano. Diante destas estatisticas, constatou-se a entrada do Brasit no 30 ano consecutivo em que a participação de matrizes no abate global foi superior a um terço da quantidade total de animais sacrificados. Esses dados deixaram claro que num futuro prōximo haveria redução da oferta de carne bovina. 


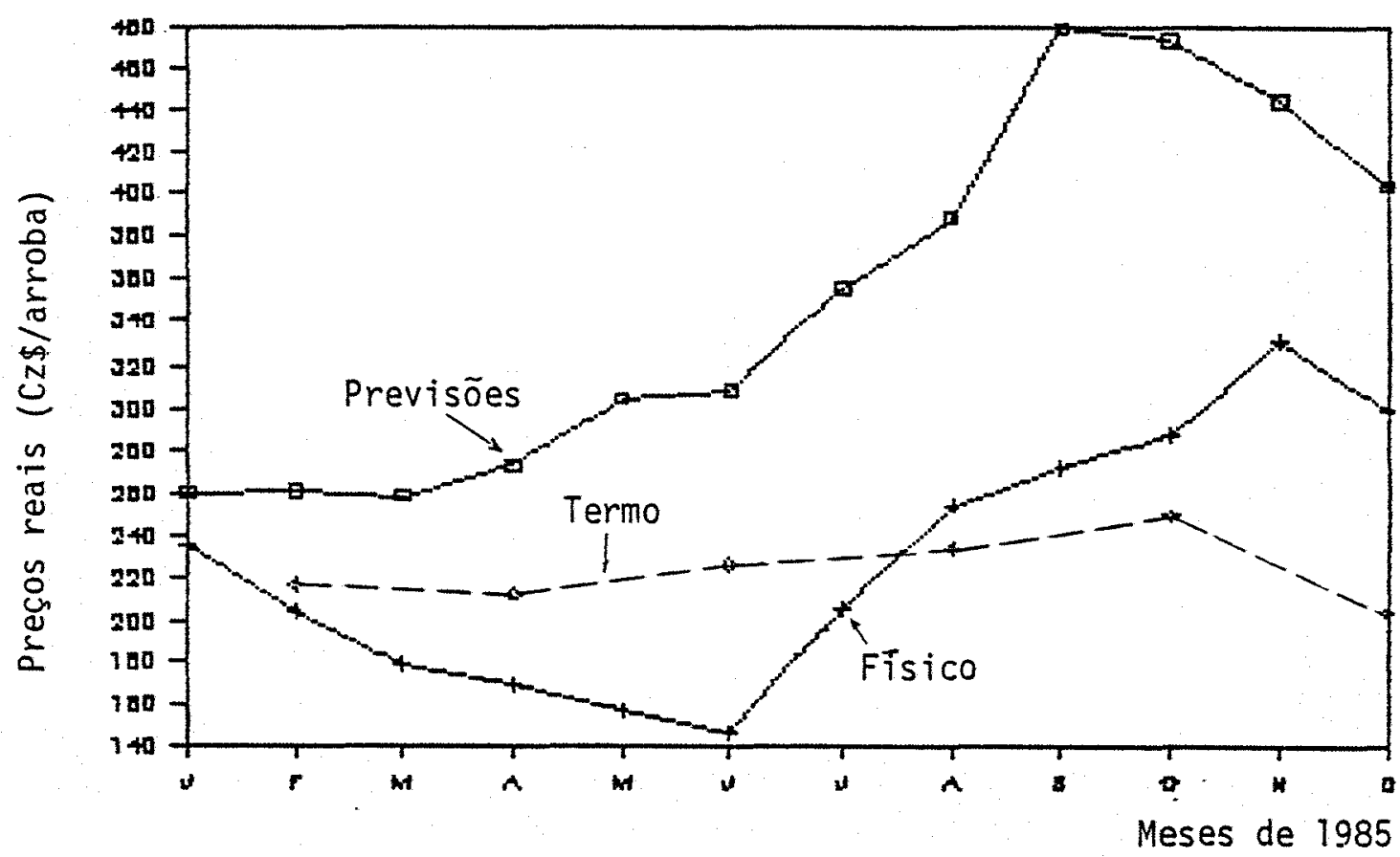

Figura 5.12. Comparações entre as previsões de preços da arroba do boi gordo obtidas pelo modelo mis to com $A R(2)$, pelo mercado a termo e observações do mercado físico para 1985

Marcado inicialmente por baixos preços e crescentes per das reais por parte dos pecuaristas, no ano de 1985 deu-se continuidade a grandes exportações, auxiliadas por uma politica de minidesvalorizações diärias implementada pelo Banco Central, que aumentou a competiti vidade das exportações brasileiras no mercado internacional e facilitou o escoamento de volumes não consumidos internamente.

De junho a novembro o preço real da arroba do boi gordo sofreu um aumento excepcional de $126 \%$, em função do período de 
entressafra, do bom ritmo das exportaçōes no primeiro semestre e principalmente por ser o ano de 1985 esperadamente de fase ascendente do ciclo, jā refletindo a matança de fềmeas em anos anteriores. No entan to, as quedas nos preços verificadas no primeiro semestre são totalmente atipicas.

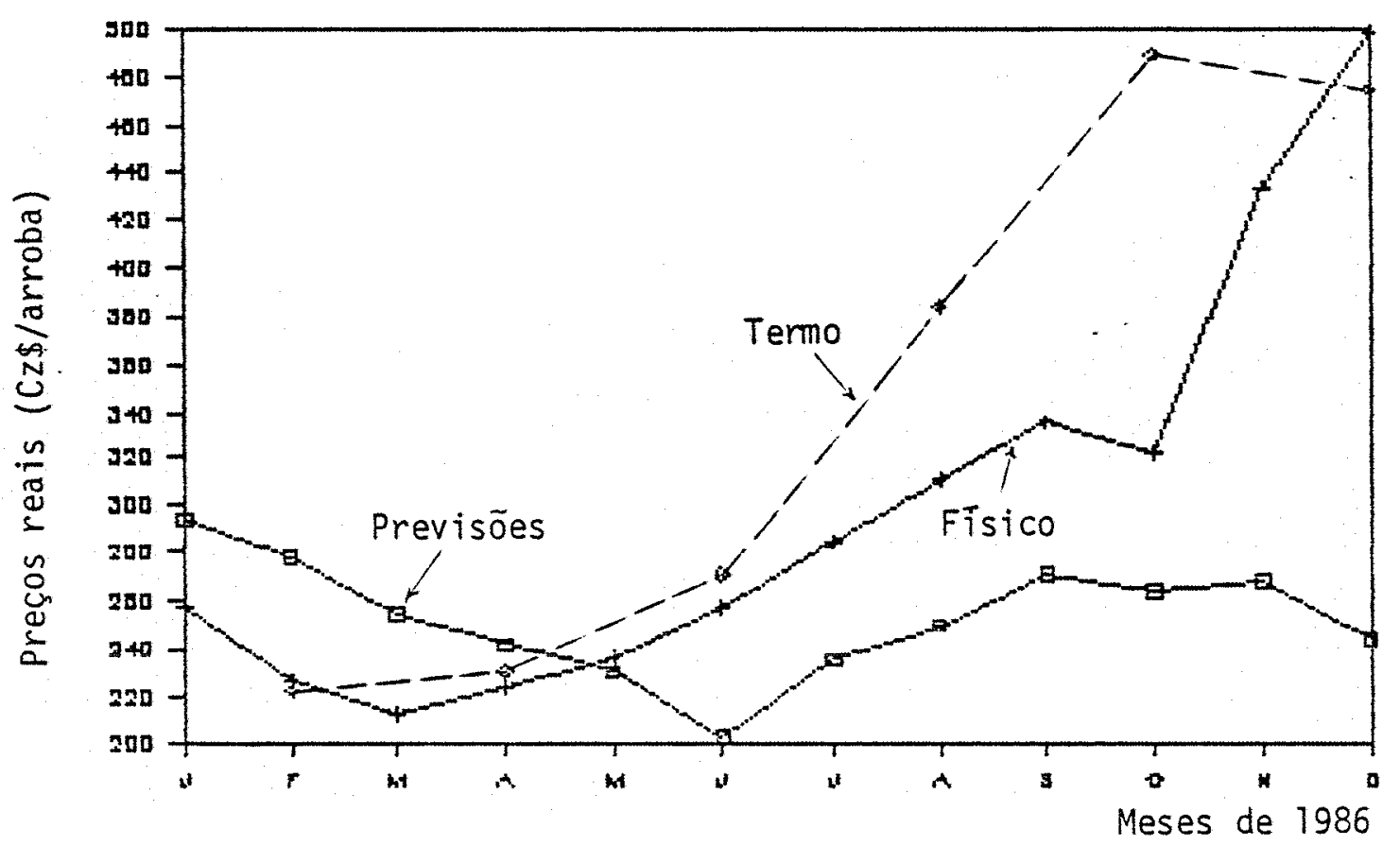

Figura 5.13. Comparaçōes entre as previsões de preços da arroba do boi gordo obtidas pelo modelo misto com $\operatorname{AR}(2)$, pelo mer cado a termo e observações do mercado físico para 1986 
Em 28 de fevereiro de 1986 foi decretado o P1ano de Estabilização Econōmica, cujas políticas de congelamento de preços e extinção da correção monetāria provocaram um aumento da demanda de carne por parte dos consumidores, principalmente pelo aumento do poder aquisitivo da população e a diminuição da poupança interna.

A carne bovina com preço tabelado no mercado varejista se tornou escassa pela falta de boi gordo pronto para abate, resultante das matanças de matrizes em anos anteriores e pela retenção de animais nos pastos. Segundo dados do FIBGE, os abates de julho a dezembro foram 38\% inferiores aos do mesmo periodo de 1985, apresentando 0 mês de setembro de 1986 o mais baixo volume de animais abatidos desde 1975.

Por pressōes de demanda, alēm do elevado preço dos ani mais de reposịção (boi magro e bezerro), que não foram tabelados, iniciou-se a cobrança de āgio sobre o preço da carne, atingindo em dezembro de 1986 o maior pico de alta de toda a série histōrica.

Medidas foram tomadas pelo governo tentando solucionar os problemas da alta dos preços e escassez da carne; entre elas podemos citar o confisco do boi no pasto, o aumento das importações, que se gundo a Companhia de Financiamento da Produção (CFP) totalizaram 458 mil toneladas em 1986, contra 50 mil toneladas em 1985, a redução das exportações da ordem de $28 \%$ em relação ao ano anterior, que fizeram 0 Brasil perder sua jă garantida fatia do mercado externo e a intervenção do Banco Central na Bolsa de Mercadorias de São Paulo, suspendendo as negociaçōes de contratos com boi gordo e impondo restriçōes que inviabilizaram seu funcionamento até maio de 1987. 


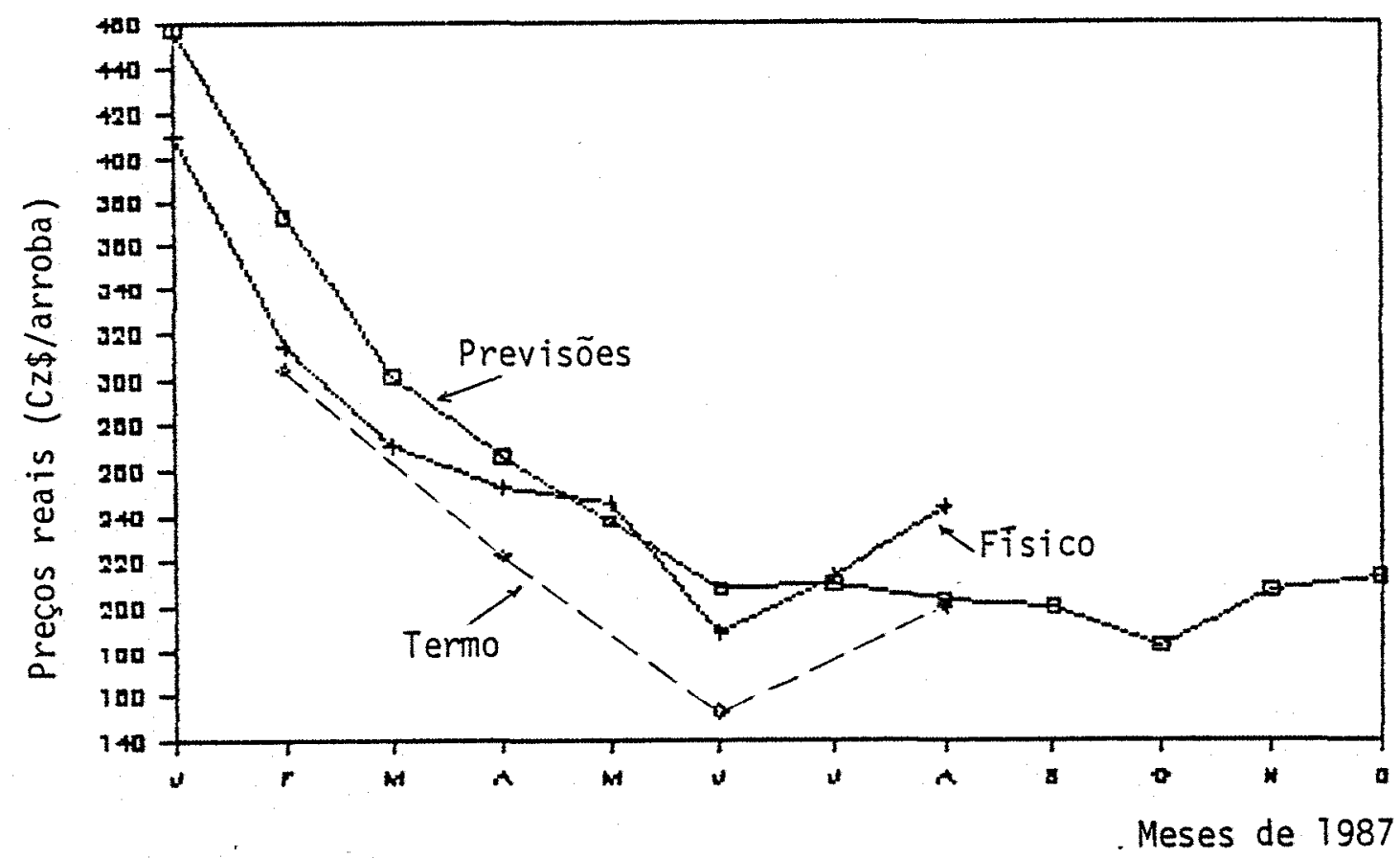

Figura 5.14. Comparações entre as previsões de preços da arroba do boi gordo obtidas pelo modelo misto com $\operatorname{AR}(2)$, pelo mercado a termo e observações do mercado físico para 1987

0 ano de 1987, caracterizado por um periodo descendente do ciclo pecuārio, teve a queda dos preços agravada devido a uma retração da demanda, causada pela perda do poder de compra dos salārios da ordem de $27,4 \%$, no periodo de janeiro a julho, para a Grande São Paulo, segundo pesquisa realizada pela Fundação Sistema Estadual de Anālise de Dados (SEADE) e pelo Departamento Intersindical de Estatîstica e Estudos Sócio-Econômicos (DIEESE). Esta mesma pesquisa também revelou uma diminuição no total de salärios pagos de $27,9 \%$ de janeiro a jutho, causada pelo aumento do nümero de desempregados, pela 
corrosão inflacionāria e pela prätica de rotatividade de mão-de-obra.

Outro fator agravante da queda dos preços da arroba do boi gordo foi o aumento da oferta de animais, resultante de um estoque de aproximadamente 100 mil toneladas do produto importado no ano anterior, alēm das exportaçōes limitadas a $40 \%$ da mēdia exportada em 1984 e 1985 .

Diante da liberaçāo das exportaçōes a partir de novembro e do período de entressafra, é esperado um pequeno aumento nos pre ços da carne, atravēs da eliminação de parte do excedente do mercado interno e diminuição da oferta de animais para abate, respectivamente.

\subsection{Boi Magro}

Diante das semelhanças entre as sēries de preços do boi magro e da arroba do boi gordo, que podem ser observadas nas figuras 5.15 e 5.1 , respectivamente, e tendo sido concluido para o boi gordo que o melhor modelo de previsão foi o misto com $\operatorname{AR}(2)$, adotou-se o mes mo modelo para o ajuste e previsão de preços na sērie do boi magro.

Desta forma, apōs a transformação logarítmica dos dados, o modelo foi ajustado à série nos períodos de janeiro de 1974 a dezembro de 1980, prevendo o ano de 1981 , e de janeiro de 1980 a dezembro de 1986, prevendo 1987. Note-se que o ajustamento è sempre fej to com base em um período de sete anos.

Os resultados estäo apresentados nas Tabelas 5.7 e 5.8 , e como descrito anteriormente para o boi gordo, trata-se de uma regressão ponderada com componentes harmönicos, variäveis binärias e um 
autoregressivo de ordem dois, onde nenhuma variāvel foi eliminada da regressão, mesmo não apresentando influēncia significativa.

As previsões obtidas a partir deste modelo estão mostra das na Tabela 5.9 e nas Figuras 5.16 e 5.17.

Neste caso foram feitas apenas comparações das previsões com o mercado físico, uma vez que não hā negociações com a categoria boi magro no mercado a termo da Bolsa de Mercadorias de São Pau10 . 


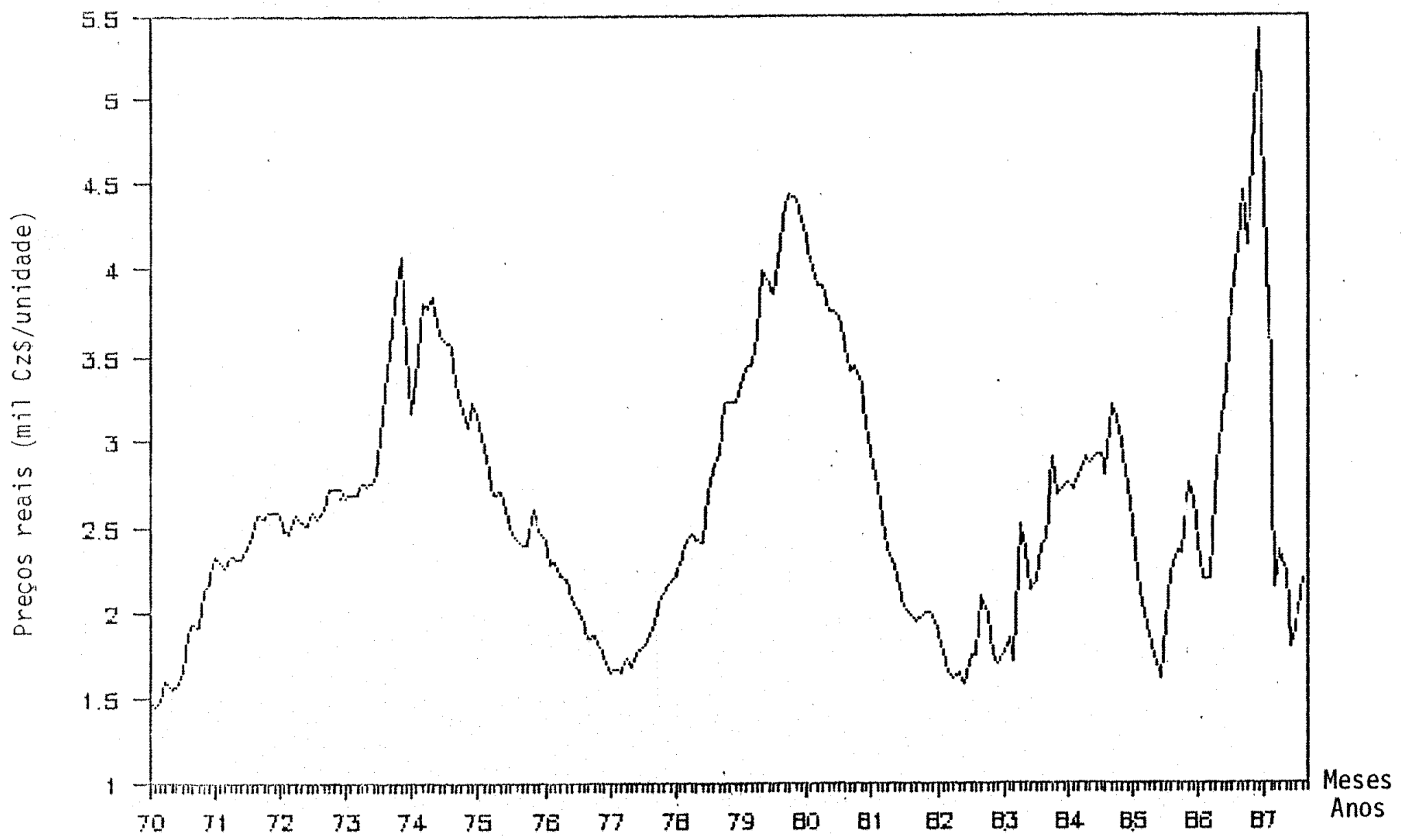

Figura 5.15. Grä́fico dos preços reais mensais do boi magro no período de janeiro de 1970 a agosto de 1987. 
Tabela 5.7. Equação obtida do modelo misto com $A R(2)$ para a série de preços reais mensais do boi magro no período de janeiro de 1974 a dezembro de 1980

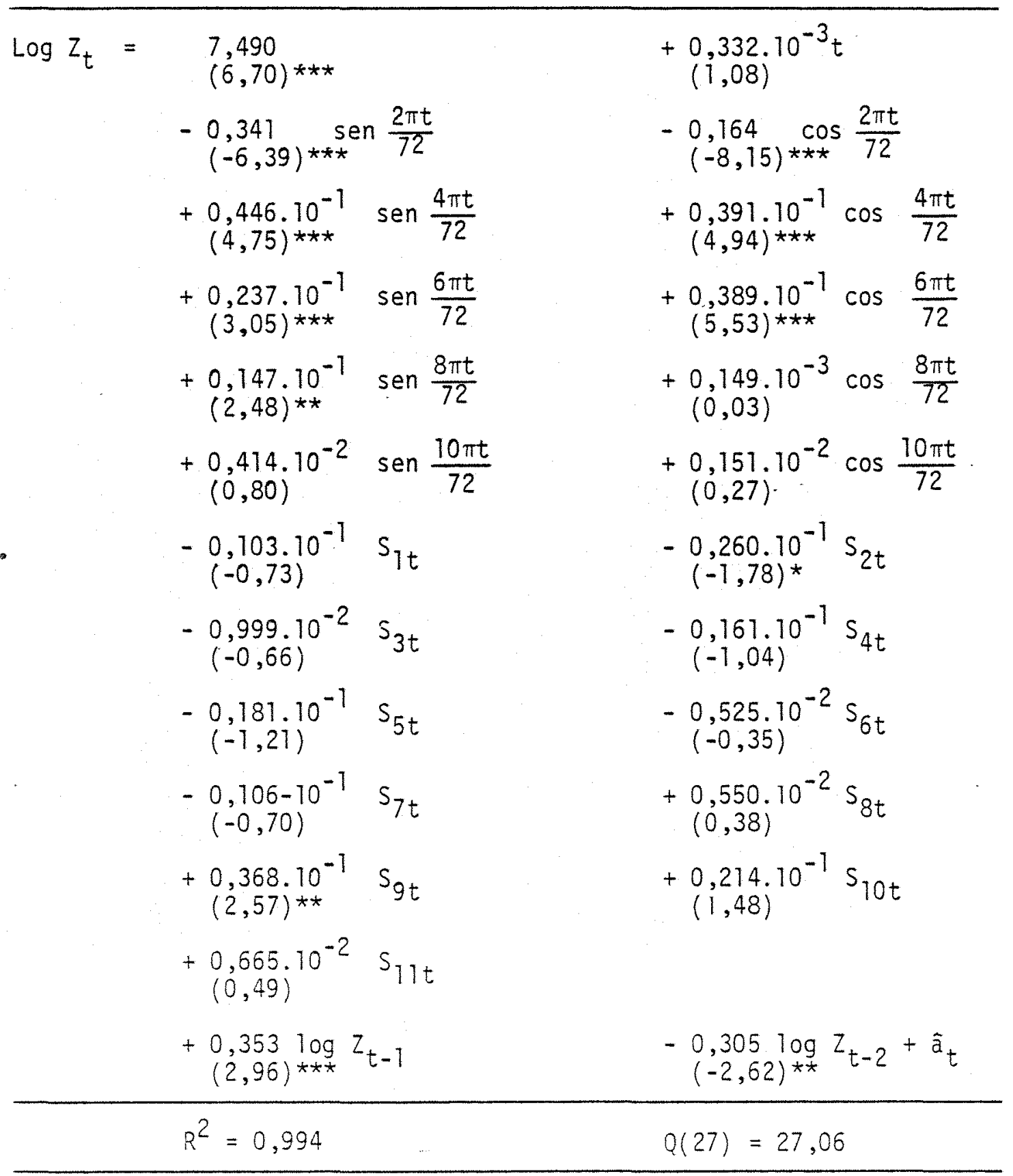

Entre parēnteses encontram-se os valores do teste $t$

$* * *$ significativo a $1 \%$

** significativo a $5 \%$

* significativo a $10 \%$ 
Tabela 5.8. Equação obtida do modelo misto com AR(2) para a sērie de preços reais mensais do boi magro no período de janeiro de 1980 a dezembro de 1986

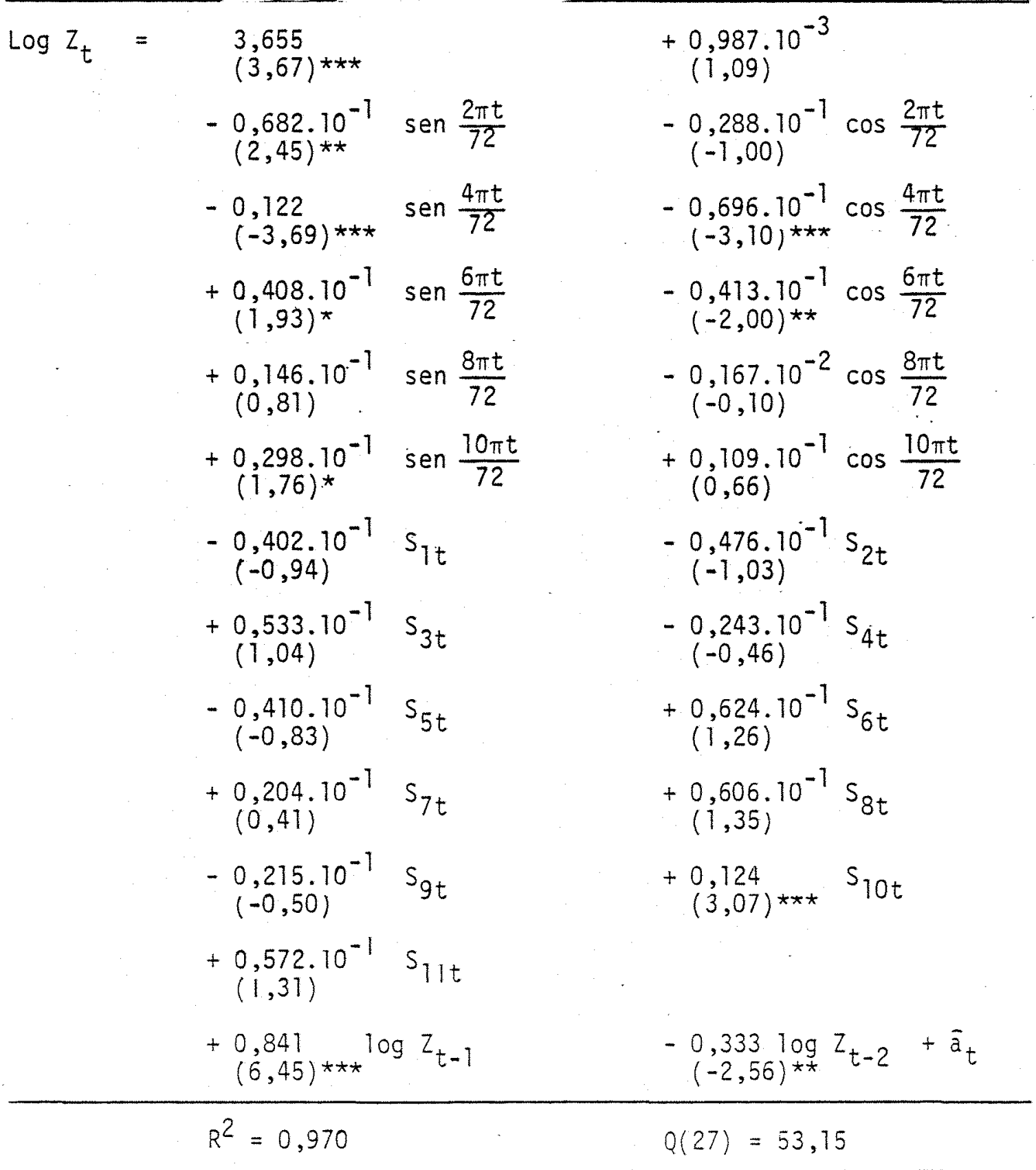

Entre parēnteses encontram-se os valores do teste $t$

*** significativo a $1 \%$

** significativo a $5 \%$

* significativo a $10 \%$ 
Tabela 5.9. Previsões de preços do boi magro obtidas pelo modelo misto com AR(2) e preços do mercado físico para 1981 e 1987

\begin{tabular}{lccccc}
\hline \multirow{2}{*}{ Previsão } & \multicolumn{2}{c}{1981} & & \multicolumn{2}{c}{1987} \\
\cline { 2 - 3 } \cline { 6 - 6 } & Previsão & Mercado Físico & & Previsão & Mercado Físico \\
\hline Janeiro & $2.960,54$ & $2.932,53$ & & $4.933,79$ & $4.387,77$ \\
Fevereiro & $2.855,62$ & $2.709,02$ & & $4.094,32$ & $3.421,25$ \\
Março & $2.732,27$ & $2.543,16$ & & $3.421,60$ & $2.149,96$ \\
Abri1 & $2.691,77$ & $2.387,15$ & & $3.285,92$ & $2.357,25$ \\
Maio & $2.637,06$ & $2.260,88$ & $2.954,00$ & $2.229,89$ \\
Junho & $2.576,60$ & $2.155,21$ & $2.555,78$ & $1.802,68$ \\
Julho & $2.567,98$ & $2.039,54$ & $2.484,41$ & $1.903,65$ \\
Agosto & $2.542,39$ & $1.992,06$ & $2.354,66$ & $2.203,90$ \\
Setembro & $2.557,18$ & $1.950,19$ & $2.306,13$ & - \\
Outubro & $2.635,99$ & $1.980,77$ & $2.093,85$ & - \\
Novembro & $2.603,53$ & $1.997,00$ & $2.235,91$ & - \\
Dezembro & $2.512,08$ & $1.982,34$ & $2.282,70$ & - \\
\hline
\end{tabular}




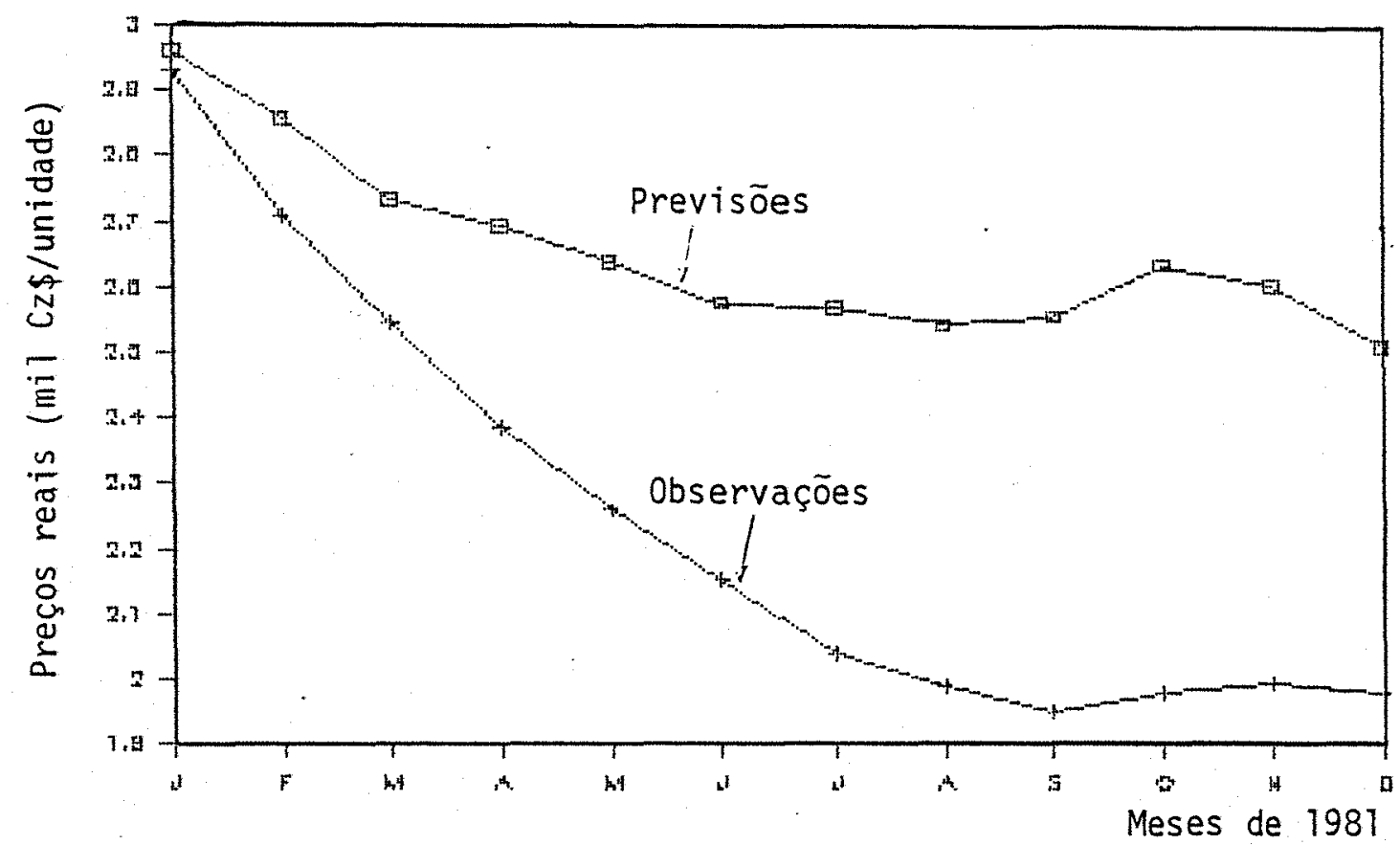

Figura 5.16. Comparações entre as previsões de preços do boi magro obtidas pelo modelo misto com $A R(2)$ e observações do mercado físico para 1981

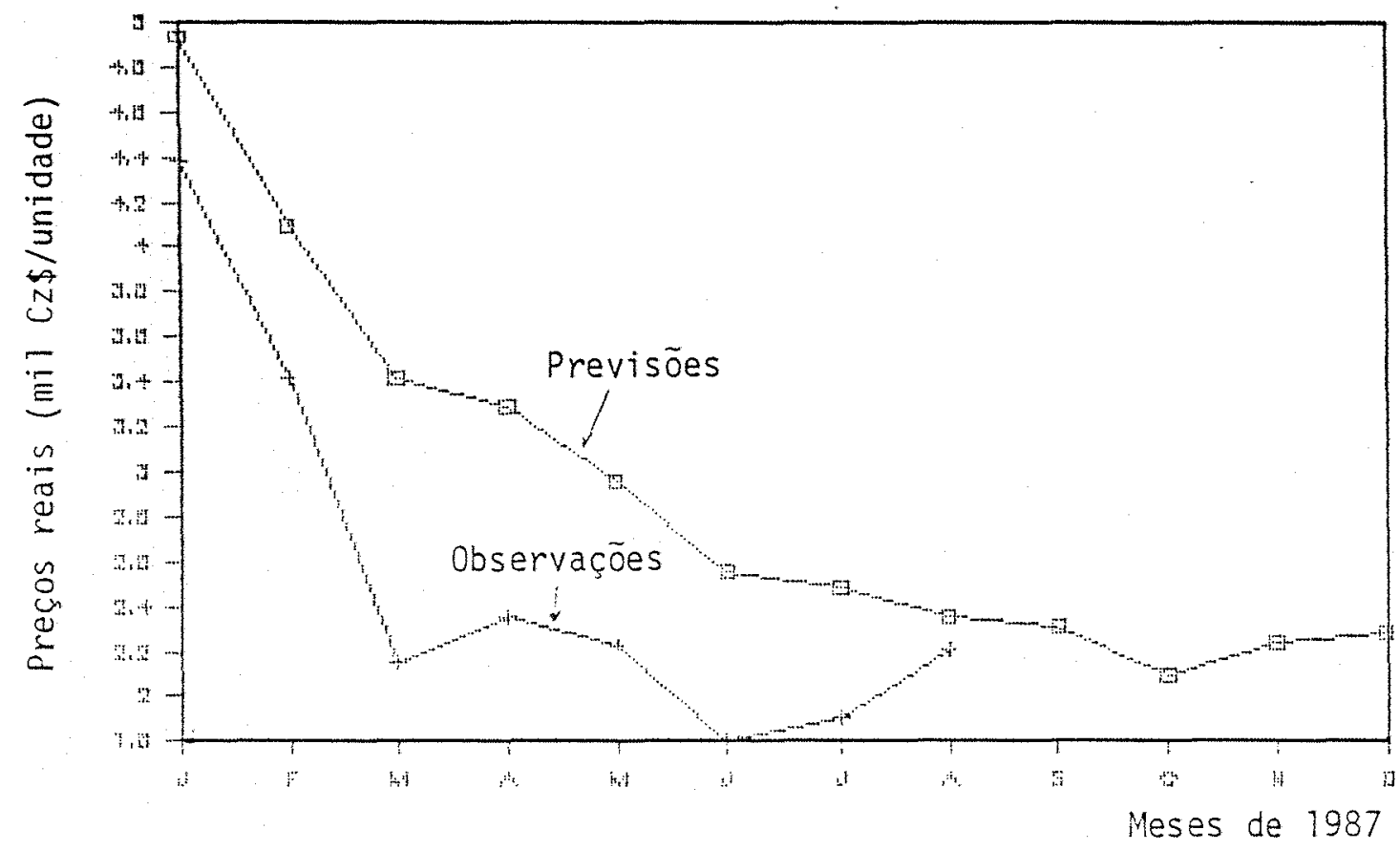

Figura 5.17. Comparaçōes entre as previsöes de preços do boi magro obtidas pelo modelo misto com $A R(2)$ e observaçöes do mercado fisico para 1987 


\subsection{Bezerro}

Analisando as Figuras 5.15 e 5.18 vemos que as variações dos preços do bezerro acompanham as variaçōes dos preços do boi magro, ha vendo grande semelhança entre as duas séries. Diante da observação deste fenômeno surgiu a idéia de obter previsões de preços do bezerro com base nos preços do boi magro, atravēs de uma regressão.

0 melhor modelo obtido, isto $\bar{e}$, aquele que apresentou o maior coeficiente de determinação, foi a regressão do logarítmo do pre ço do bezerro em função de uma constante, do logarítmo do preço do bezer ro defasado de um mês, do logaritmo do preço do boi magro e de um componente de mëdia mövel de ordem um.

Os resultados obtidos foram:

$\log 21_{t}=\underset{(-2,90)(11,15)}{-1,038+0,769} \operatorname{ll}_{t-1}+\underset{(3,30)}{0,339} \log 22_{t}+\underset{(4,03)}{0,420} \bar{a}_{t-1}+\bar{a}_{t}$

onde

$21_{t}$ são os preços do bezerro nos meses $t$

$21_{t-1}$ são os preços do bezerro nos meses $t-1$

$\mathrm{Z2}_{\mathrm{t}}$ são os preços do boi magro nos meses $t$

0 coeficiente de determinação $\left(R^{2}\right)$ foi de 0,989 ; 0 teste $Q(27)$ igual a 83,57 mostrou a existência de autocorrelação nos residuos e os valores do teste $t$ apresentados entre parenteses mostraram-se todos significativos ao nivel de $1 \%$ de probabilidade.

Esta regressão visou inicialmente a obtenção da previsão dos preços do bezerro no ano de 1981. Para tanto, foi utitizado um 


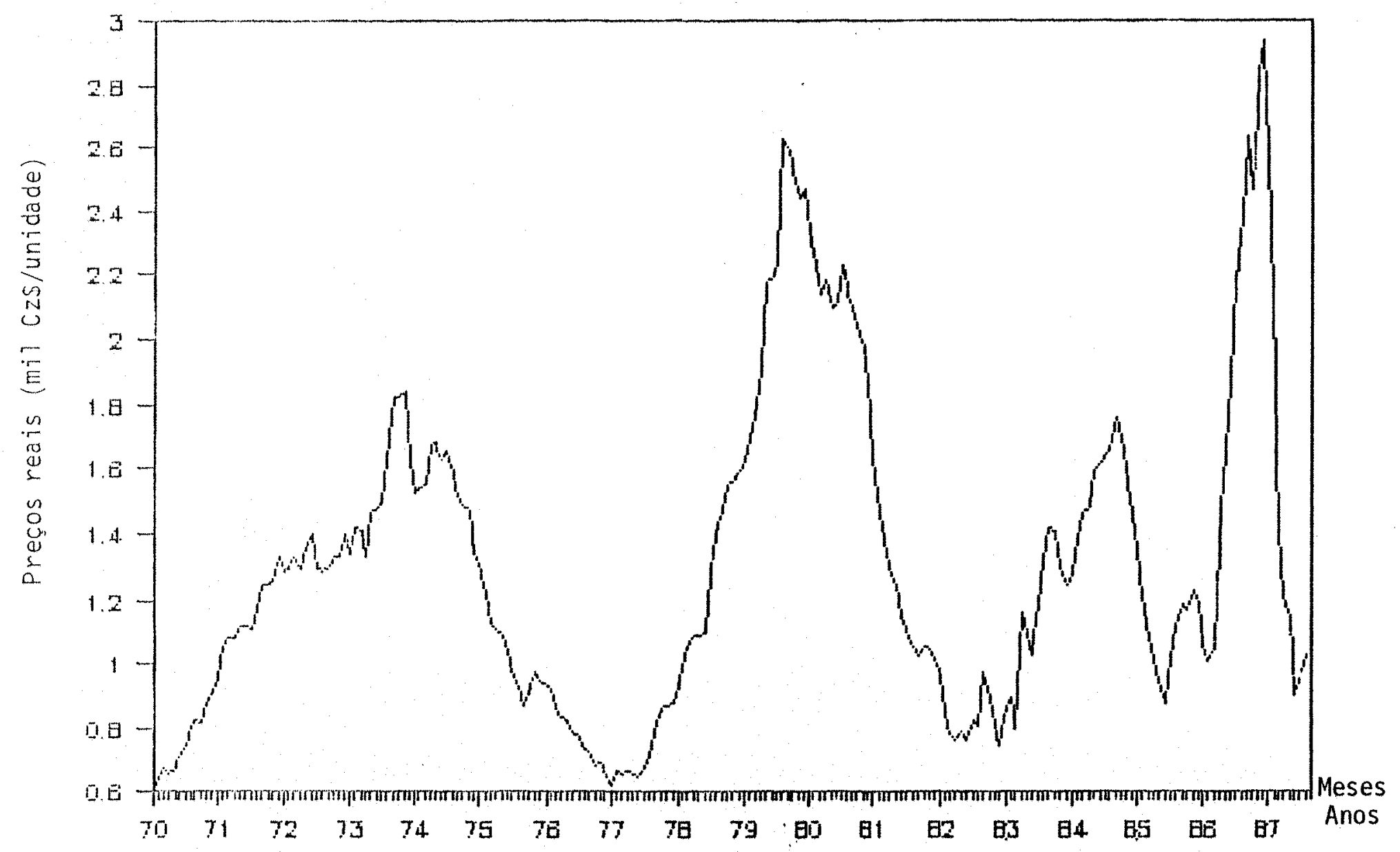

Figura 5.18. Gráfico dos preços rea is mensais do bezerro no perĩodo de janeiro de 1970 a agosto de 1987 
período de 7 anos (janeiro de 1974 a dezembro de 1980). Os preços do boi magro no ano de 1981, obtidos no mercado físico foram substituidos pel.as previsões encontradas anteriomente, atravēs do modelo misto com $\operatorname{AR}(2)$ e mostradas na Tabela 5.9. Com as previsões do boi magro em 1981 foi possí vel, atravēs da regressão, prever os preços do bezerro neste mesmo ano.

0 mesmo procedimento foi utilizado para prever os preços do bezerro em 1987, ajustando a regressão no perīodo de janeiro de 1980 a dezembro de 1986 e substituindo os preços do boi magro no mercado fisico no ano de 1987 pelas previsões jā obtidas.

A regressão resultou em:

$\log 21_{t}=\underset{(-7,80)}{-1,597}+\underset{(5,57)}{0,270} \log 21_{t-1}+\underset{(15,31)}{0,873} \log 22_{t}+\underset{(4,93)}{0,500} \bar{a}_{t-1}+\bar{a}_{t}$

Neste caso, o coeficiente de determinação $\left(\dot{R}^{2}\right)$ foi de 0,983 , O teste $Q(27)=43,19$ e os valores do teste $t$ entre parenteses tam bëm apresentaram-se todos significativos ao nível de $1 \%$ de probabilidade.

Vale ressaltar que este mesmo modelo poderia ter sido utilizado para obter previsões do boi magro em função dos preços do bezerro, utilizando para isso preços do boi magro como variāvel dependente e preços do bezerro no mês $t$ e do boi magro defasados $(t-1)$ como variāveis independentes.

A fim de comparar o desempenho das previsões de preços obtidas pelas regressões apresentadas anteriormente e as obtidas atravēs do modelo misto com $A R(2)$, ajustou-se tambēm à série de preços do bezerro um mode1o misto com $A R(2)$ nos mesmos periodos (1974 a 1980 e 1980 a 1986), cujos resultados são mostrados nas Tabelas 5.10 e 5.11 . As previsões encontram-se na Tabela 5.12 e Figuras $5.19,5.20,5.21$ e 5.22. Com 
base no erro quadrätico médio de previsão concluímos que para 0 ano de 1981 a regressão com base nos preços do boi magro previu melhor, enquanto para 1987 o modelo misto com $A R(2)$ apresentou resultados melhores. Nes te caso, os métodos apresentados podem ser utilizados de forma alternativa. 
Tabela 5.10. Equação obtida do modelo misto com $A R(2)$ para a série de preços reais mensais do bezerro no perīodo de janeiro de 1974 a dezembro de 1980

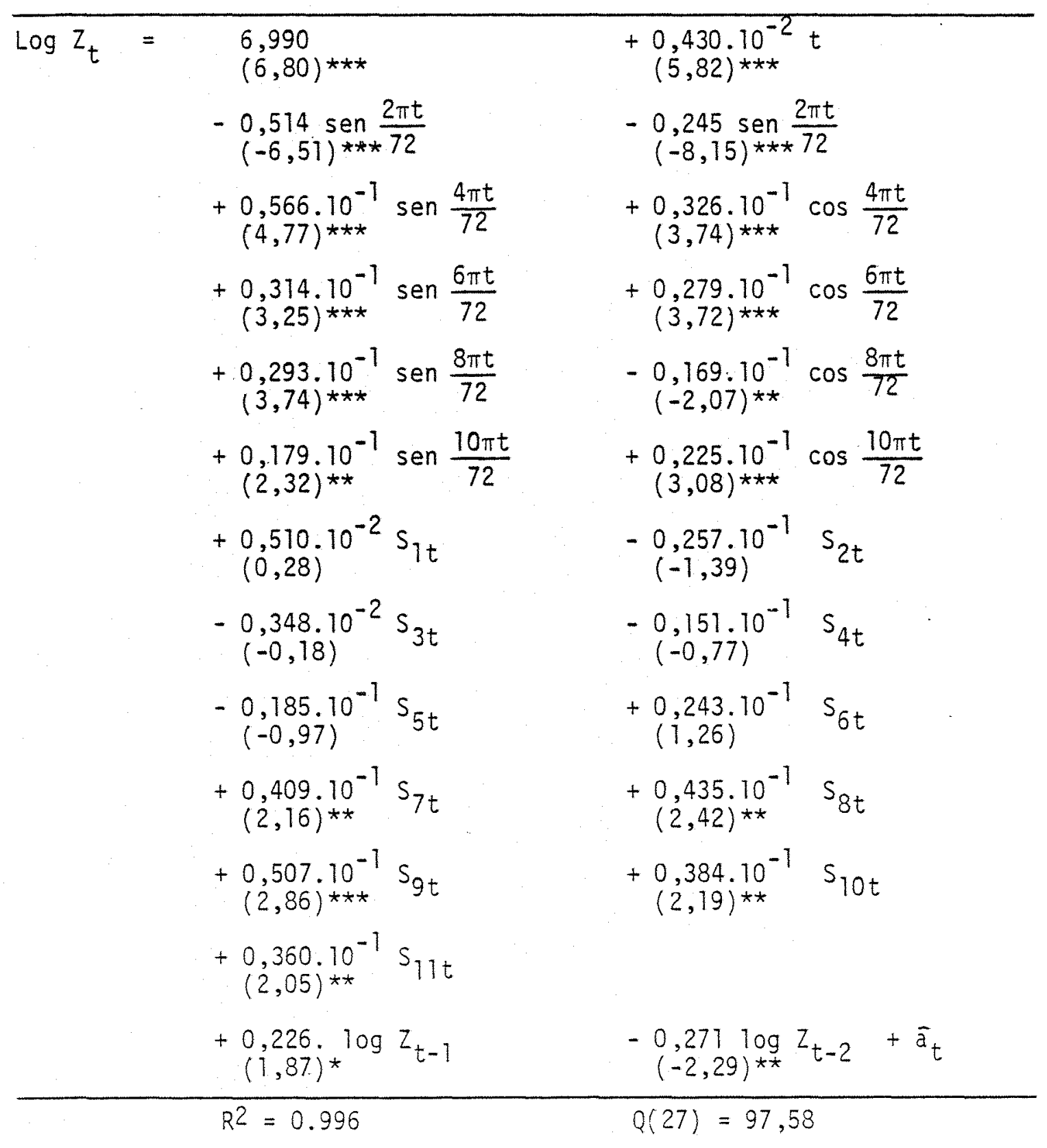

Entre parênteses encontram-se os valores do teste $t$

$* * *$ significativo a $1 \%$

* significativo a $5 \%$

* significativo a $10 \%$ 
Tabela 5.11. Equação obtida do modelo misto com $A R(2)$ para a sērie de preços reais mensais do bezerro no período de janeiro de 1980 a dezembro de 1986

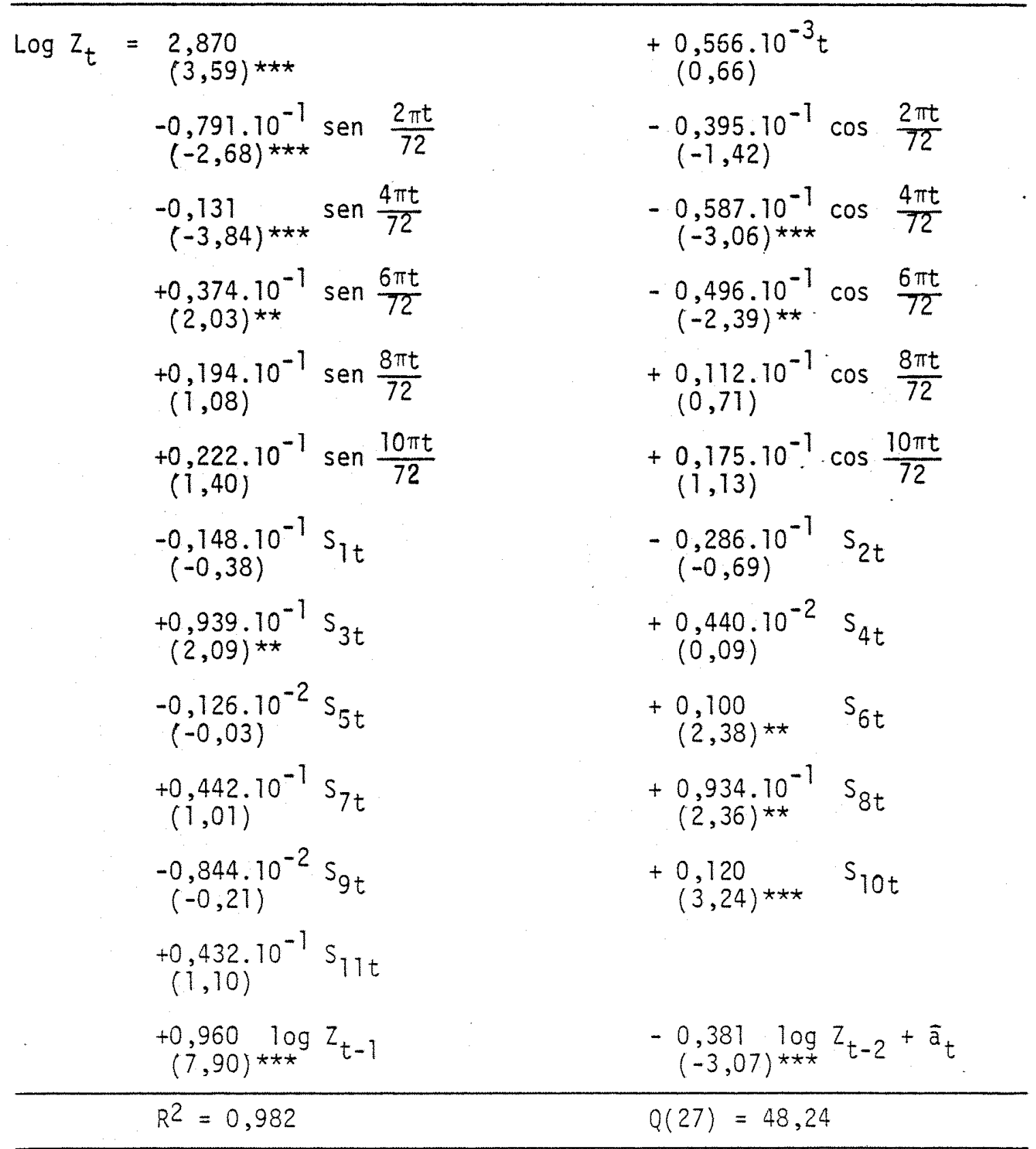

Entre parēnteses encontram-se os valores do teste $t$

*** significativo a $1 \%$

** significativo a $5 \%$

* significativo a $10 \%$ 
Tabela 5.12. Previsões de preços reais do bezerro e observaçōes do mer cado físico para 1981 e 1987

\begin{tabular}{|c|c|c|c|c|c|c|}
\hline \multirow[b]{2}{*}{ Meses } & \multicolumn{3}{|c|}{1981} & \multicolumn{3}{|c|}{1987} \\
\hline & $\begin{array}{l}\text { Modelo } \\
\text { misto } \\
\text { com } \\
\operatorname{AR}(2)\end{array}$ & Regressão & $\begin{array}{c}\text { Mercado } \\
\text { Físico }\end{array}$ & $\begin{array}{l}\text { Modelo } \\
\text { mis to } \\
\text { com } \\
\operatorname{AR}(2)\end{array}$ & Regressão & $\begin{array}{l}\text { Mercado } \\
\text { Fisico }\end{array}$ \\
\hline Jan & $1.711,43$ & $1.753,66$ & $1.640,77$ & $2.632,06$ & $2.820,27$ & $2.583,71$ \\
\hline Fev & $1.612,51$ & $1.640,25$ & $1.460,08$ & $2.206,10$ & $2.466,09$ & $1.888,70$ \\
\hline Mar & $1.487,98$ & $1.534,91$ & $1.379,64$ & $1.823,89$ & $2.033,37$ & $1.404,36$ \\
\hline $\mathrm{Abr}$ & $1.431,77$ & $1.457,17$ & $1.303,39$ & $1.741,35$ & $1.863,03$ & $1.217,64$ \\
\hline Mai & $1.359,31$ & $1.380,25$ & $1.248,53$ & $1.553,26$ & $1,657,99$ & $1.139,19$ \\
\hline Jun & $1.293,27$ & $1.317,69$ & $1.749,05$ & $1.342,06$ & $1.415,81$ & $.900,71$ \\
\hline Jul & $1.307,43$ & $1.270,07$ & $1.107,34$ & $1.294,69$ & $1.323,50$ & 944,16 \\
\hline Ago & $1.317,84$ & 1.230 .45 & $1.054,79$ & $1.211,45$ & $1.240,15$ & $1.026,09$ \\
\hline Set & $1.300,59$ & $1.203,18$ & $1.023,97$ & $1.184,11$ & $1.196,57$ & \\
\hline Out & $1.293,37$ & $1.194,85$ & $1.051,55$ & $1.058,63$ & $1.089,28$ & \\
\hline Nov & $1.275,83$ & $1.183,51$ & $1.043,01$ & $1.082,61$ & $1.124,56$ & \\
\hline Dez & $1.266,55$ & $1.160,71$ & $1.018,33$ & $1.064,95$ & $1.154,99$ & \\
\hline & $32.329,19$ & $23.911,97$ & & $134.604,93$ & $240.715,45$ & \\
\hline
\end{tabular}




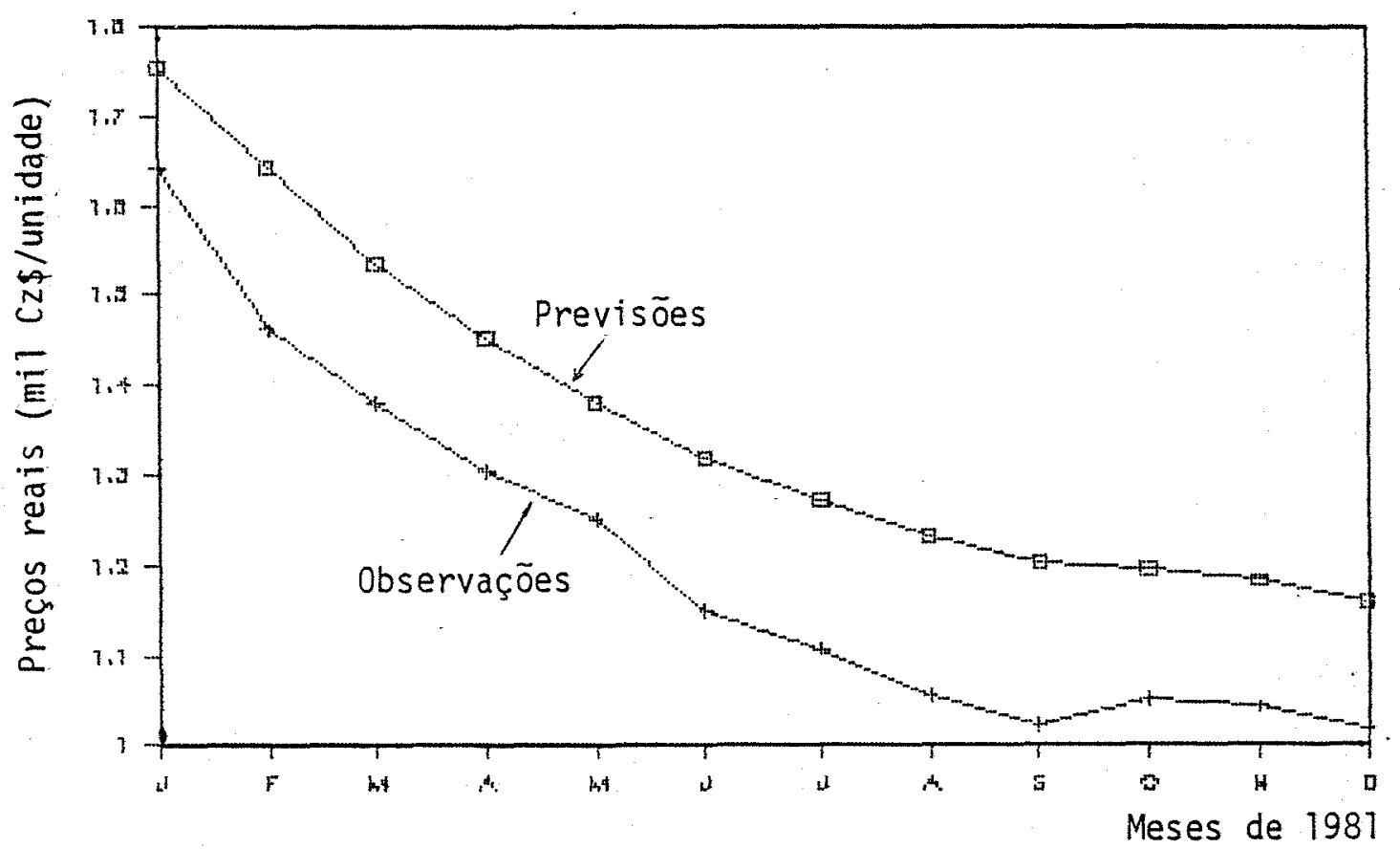

Figura 5.19. Comparações entre as previsöes de preços do bezerro obtidas da regressão com boi magro e observações do mercado fi fiso para 1981

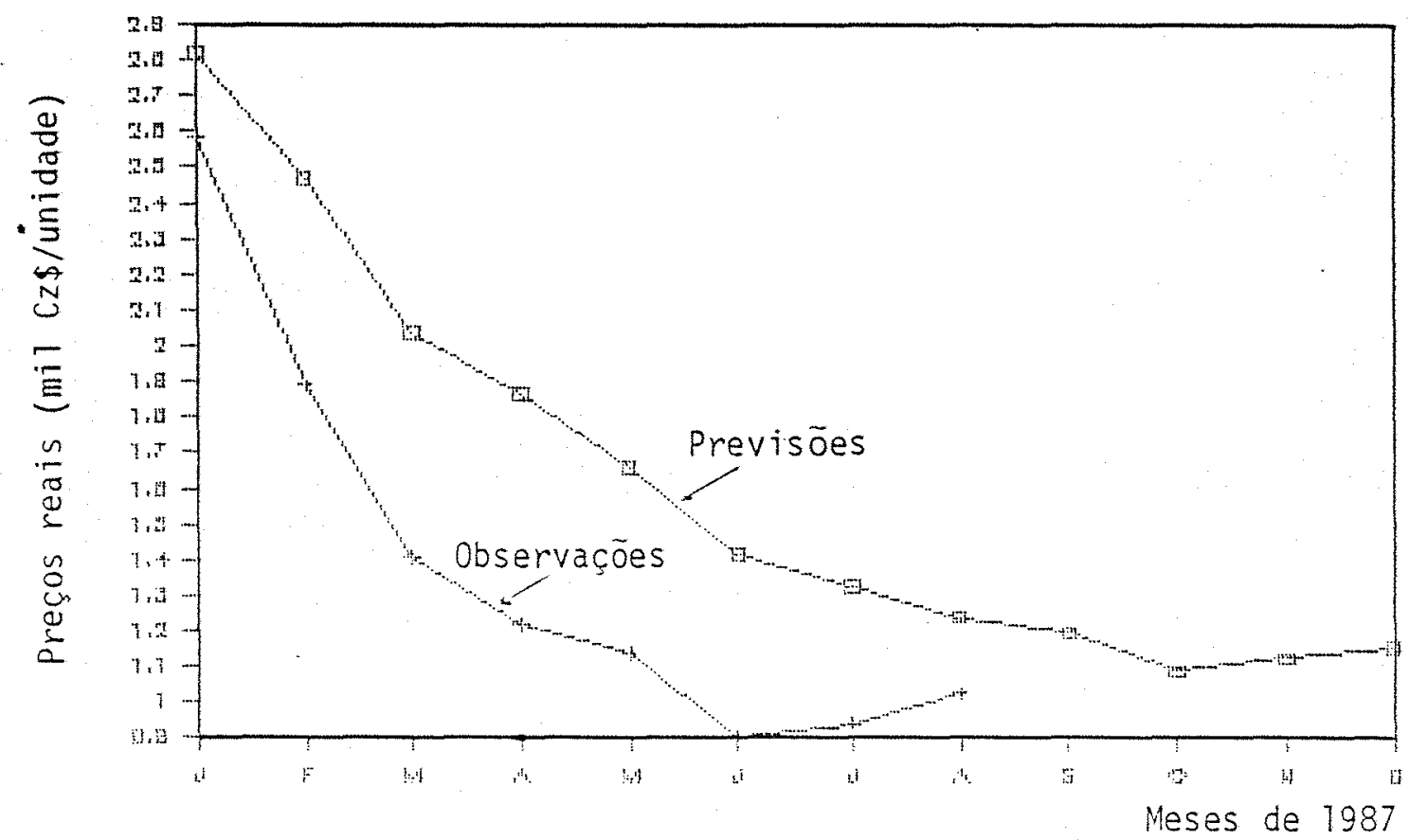

Figura 5.20. Comparaçōes entre as previsões de preços do bezerro obtidas da regressão com boi magro e observaçoes do mercado fistco para 1987 


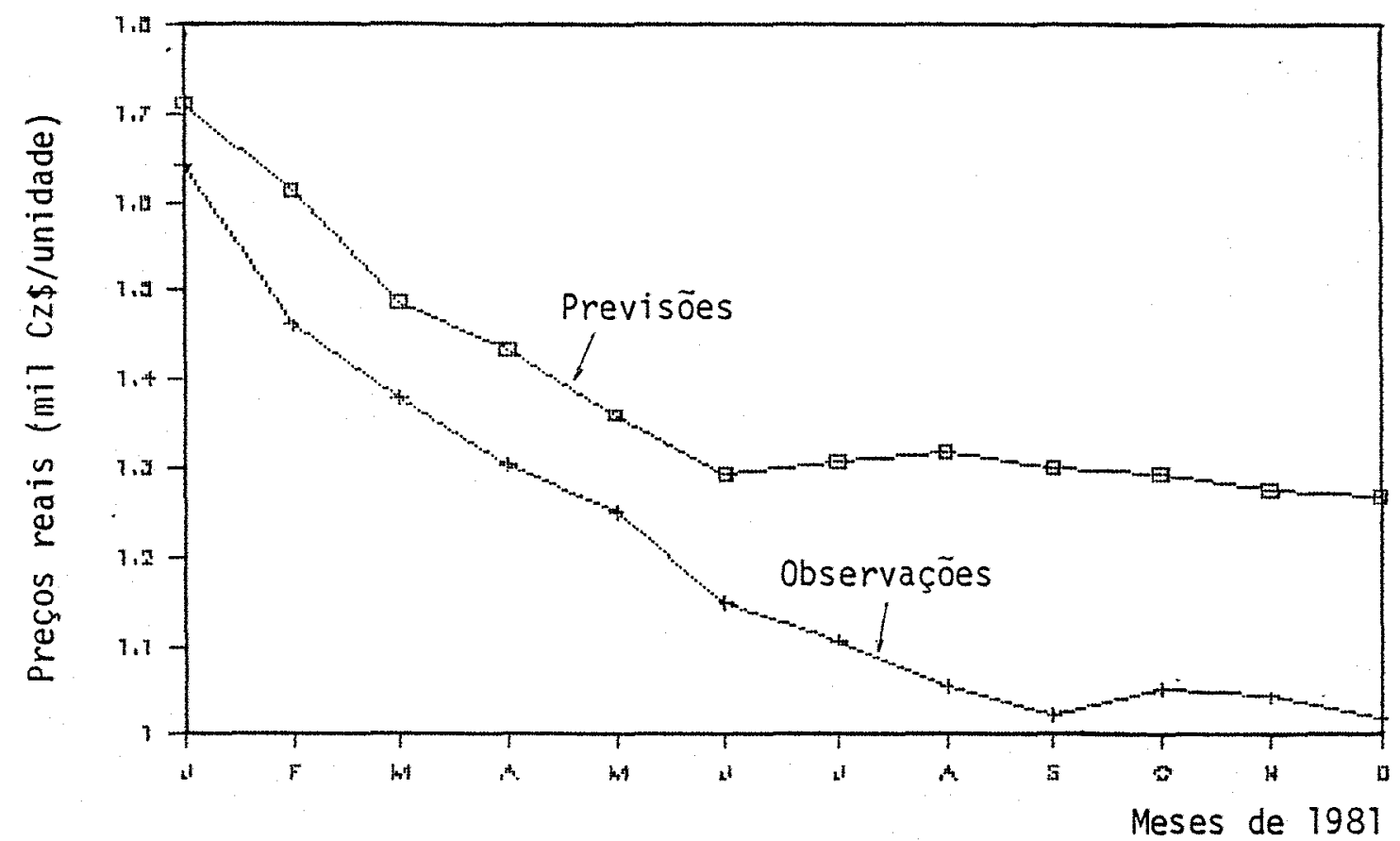

Figura 5.21. Comparaçōes entre as previsōes de preços do bezerro obtidas do modelo misto com $A R(2)$ e observaçöes do mercado físico para 1981

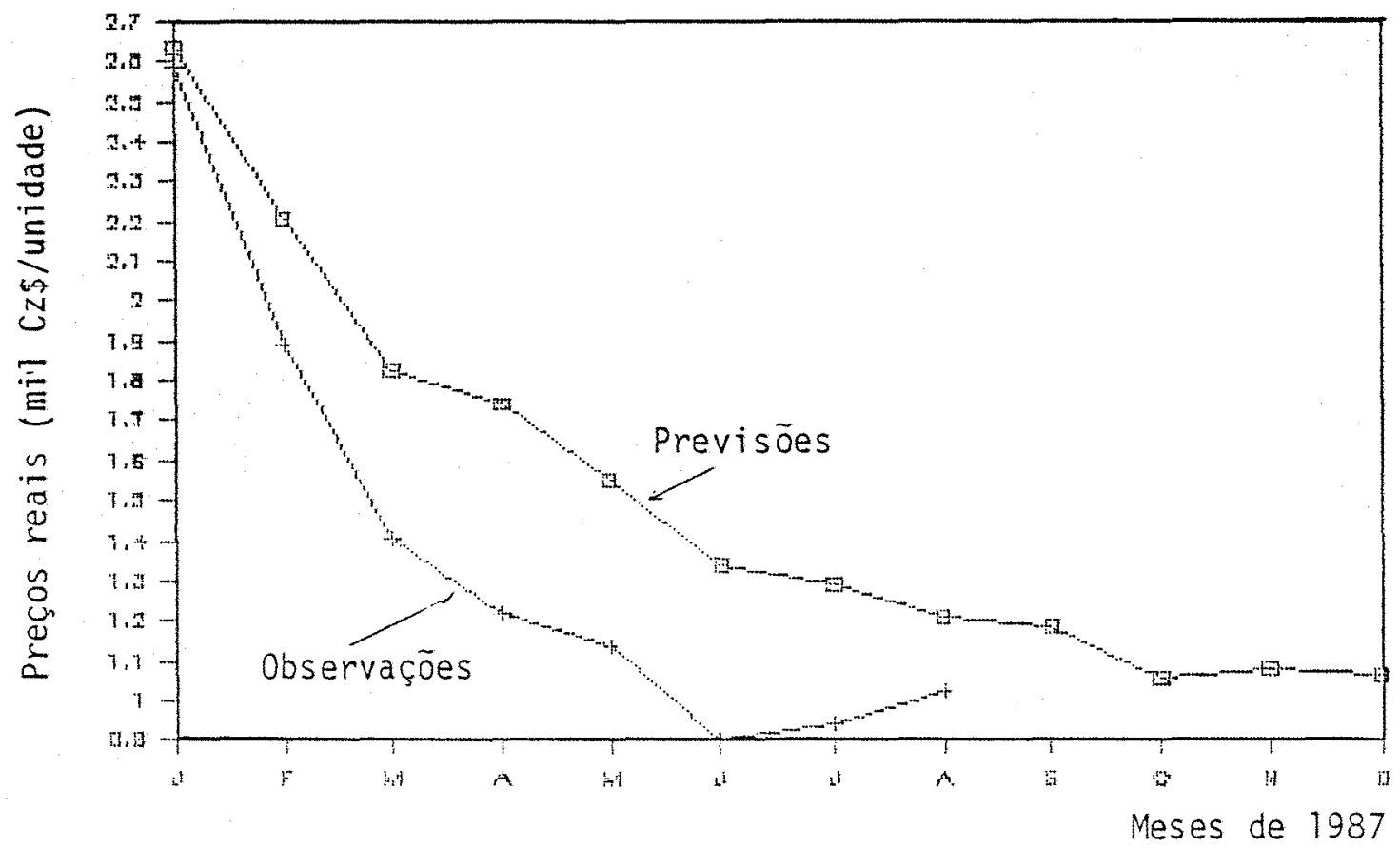

Figura 5.22. Comparações entre as previsões de preços do bezerro obtidas do modelo misto com $A R(2)$ e observações do mercado físico para 1987 


\section{CONCLUSOES}

Não foi possivel ajustar um modelo ARIMA apropriado $\bar{a}$ sērie de preços da arroba do boi gordo, que contēm variações cíclicas estacionais e plurianuais. 0 modelo ajustado não conseguiù prever os ciclos plurianuais.

0 modelo harmōnico e o modelo misto ponderado com $\operatorname{AR}(2)$, quando aplicados à sērie temporal, resultaram em bom ajuste e boas previsōes; porēm, foi constatada autocorrelação nos residuos. Para solucionar este problema, foi necessārio introduzir um processo de média mō vel, o que só foi possîvel com a eliminação da ponderação.

Para comparar a capacidade preditiva dos modelos ajustados foi calculado o erro quadrätico mēdio de previsão para cada mode10, comparando-se as previsões com as observações do mercado físico. Ajustando os modelos mistos, no período de janeiro de 1980 a dezembro de 1986, e prevendo os preços de 1987, os resultados mostraram ser o modelo misto com $A R(2)$ o que forneceu melhores previsões, vindo em se guida o modelo misto com $\operatorname{ARMA}(1,1)$, o mercado a termo, o modelo 
harmōnio e por ūitimo o $\operatorname{SARIMA}(0,1,1) \times(0,1,1)_{12}$, estes dois ūltimos ajustados no período de janeiro de 1970 a dezembro de 1986.

Com base no methor modelo, ou seja, o misto com $\operatorname{AR}(2)$, foram obtidas previsões de preços para os anos de 1981 a 1987, utilizando para a anāilise um período de tempo major em relação ao utilizado anteriormente, com dados a partir de 1970. Os resultados mostraram que as previsões obtidas atravēs deste modelo foram superiores às obtidas na Bolsa de Mercadorias de São Paulo somente em 1982 e 1983.

\section{E interessante observar, que, a utilização de técnicas} estatisticas e computacionais complexas e trabalhosas para a obtenção de previsões de preços, muitas vezes, não consegue superar as previsões obtidas no mercado futuro. E importante salientar tambēm, que, às previsões de preços, obtidas na Bolsa de Mercadorias são dadas em valores nominais, estando, portanto, associadas a uma previsão da inflação.

No mercado a termo existem, basicamente, duas anālises que visam a obtenção de previsões, a tēcnica e a fundamenta 1 . A anāiise tēcnica utiliza gräficos contendo preços, volume de contratos e contratos em aberto, e reflete o comportamento dos negociantes do mercado. Jà a anālise fundamental leva em consideração fatores determinantes da oferta e demanda, ou seja, aspectos de produção, consumo, comercialização e existência de produtos complementares e substitutos no mercado in teno e externo, que podem afetar os preços das mercadorias. Além destas anālises, a pröpria vivencia e opinião dos especialistas deste mercado, ou seja, o "feeling", contribui para a obtenção de boas previsões. 
Talvez, o ideal para a obtenção de melhores previsões seja associar as tēcnicas econométricas aos conhecimentos de fatores de ordem politica e social, juntamente com o "feeling" dos especialistas.

As previsões de preços do boi magro e bezerro não puderam ser comparadas às do mercado a termo, pois estas categorias não são negociadas na Bolsa de Mercadorias de São Paulo.

Devido à semelhança entre as sēries de preços do boi magro e bezerro, constatou-se que os preços do bezerro poderiam ser previstos a partir das previsōes de preços para o boi magro, atravēs de uma regressão.

As previsões dos preços do bezerro obtidas para 1981 atravēs do modelo misto com AR(2) foram methores, quando comparadas às obtidas pela regressão com base nos preços do boi magro, entretanto, este ūltimo modelo foi superior na obtenção de previsões para 1987. Dian te destes resultados, não $\bar{e}$ possivel recamendar um desses mētodos como methor em relação ao outro. 


\section{REFERENCIAS BIBLIOGRAFFICAS}

AGRICULTURA SITUAÇÃo E PERSPECTIVAS 87/88, São Paulo, 3:99-100, 1987.

AMARAL, E. Anālise Harmōnica e Previsão a Longo prazo. Anais da Reunião Internacional de Biometria. Piracicaba. 1975. p.232-271.

ANDRADE, R. O Mercado a Termo como Instrumento de Orientação de Politica Agrícola. Viçosa. 1985. 124p. (Mestrado - Universidade Federal de Viçosa).

BOTELHO, F.A. Curso de Formą̧ão em Negöcios a Termo: A Anālise Técni ca no Mercado de "Commodities". São Paulo, Bolsa de Mercadorias de Säo Paulo. 50 .

BOX, G.E. e G.M.JENKINS. Time Series Analysis: Forecasting and Controz. San Francisco. Holden-Day. 1976. 575p.

BRANDT, S.A. Comercializagão Agricota. Piracicaba, Livroceres. 1980. 1950. 
BRANDT, J.A. e D.A.BESSLER. Composite Forecasting: An Application with U.S. Hog Prices. Amer.J.Agr.Econ. 63(1): 1981. 136-140p.

CASTRO, P.R. e R.FERNANDEZ. Conjectures and Evidences on the Behavior of the Brazilian Beef Cattle Market. 1956-1974. Mimeogr.

CHATFIELD, C. The Analysis of Time Series, 3 a ed. New York, Chapman and Ha11 Ltd. 1984, 286p.

COELHO, H. Emprego da Anālise Harmōnica a Dados de Produção de Citros, Piracicaba, 1980. 124p. (Mestrado - Escola Superior de Agricultura "Luiz de Queiroz"/USP).

DIEESE registra aumento do desemprego em São Paulo. Folha de São Pau10, São Pau10, 22 set. 1987. p.A28.

DIAS, G.D. Avaliação da Polfitica Econômica para a Pecuäria de Corte no Brasil. Rio de Janeiro. 1972. 100p. (Doutorado - Fundação Getūitio Vargas).

DORAN, H.E. e J.J.QUILKEY. Harmonic Analysis of Seasonal Data: Some Important Properties. Am.J.Agric.Econ., Manasha, 1972. 54(4):646-651p.

DUARTE, G.S. Curva Epideniolögica da Ferrugem Alaranjada do Cafeeiro na Zona da Mata-MG, Piracicaba. 1974. 65p. (Mestrado-Escola Superior de Agricultura "Luiz de Queiroz"/USP). 
DUARTE, G.S. e D.BARBIN. Curva Epidemiolōgica da Ferrugem Alaranjada do Cafeeiro na Zona da Mata-MG. Anais da Reunião Intermacional de Biometria. Piracicaba, 1975. 167-184p.

ESTADOS UNIDOS. Department of Agriculture. Agricultural Research Service. Dairy, Livestock and Pouttry. Washington, 1986. 68p.

GARCIA, E.A.C. Os preços da Pecuāria Bovina do Pantanal Matogrossense. Pesquisa Agropecuäria Brasileira. Brasitia, 19(2): 1984, p.123-148.

GONÇALVES, E.G. Comparação de Modelos para Previsão de Séries Temporais - Sërie de Precipitações Pluviais Mensais no Munictipio de Pindorama-SP. Piracicaba, 1983. 162p. (Mestrado-Escola Superior de Agricultura "Luiz de Queiroz"/USP).

GREENBERG, E. e C.E.WEBSTER Jr., Advanced Econametrics. A Bridge to the Literature, USA. John Wiley \& Sons. 1983.

HOFFMANN, R. e S.VIEIRA. Anälise de Regressão. Lma Introducão à Econometria. $2^{\mathrm{a}}$ ed., São PauTo, Hucitec, 1983. 379p.

IBGE. Pesquisa mensal de abate de animais, Rio de Janeiro. 
JUST, R.E. e G.C.RAUSSER. Commodity Price Forecasting with LargeScale Econometric Models and the Futures Market. Amer.J.Agr.Econ. $63(2)$ : 1981. 197-208p.

MASCOLO, J.L. Um Estudo Economētrico da Pecuäria de Corte no Brasil. Rio de Janeiro, 1980. 100p. (Doutorado - Fundação Getūi io Vargas).

MASCOLO, J.L. E A.L.S.P.SOUZA. A Politica Comercial Brasileira Recente e o seu Impacto na Agricultura de Exportação. Rio de Janeiro. Eundação Centro de Estudos do Comércio Exterior. (Relatōrio de Pesquisa) 1983. 100p.

MONTELLO, J. Estatistica para Economistas, Rio de Janeiro, APEC Editora S.A. 1970. 333p.

MoretTin, P.A. Anālise Harmōnica de Processos Estocāsticos. 120 Cozóquio Brasizeiro de Matemätica, Poços de Caldas, MG. 1979. 43-73p.

MORETTIN, P.A. e C.M.C.TOLOI. Previsão de Sëries Temporais. São Pauto. Atual Editora Ltda. 1985. 436p.

OKAWA, H. Anālise Harmōnica das Variações dos Preços e das Quantidades de Sardinha Fresca no Mercado Atacadista de São Paulo - 1981/82. Piracicaba. 1985. 96p. (Mestrado - Escola Superior de Agricultura "Luiz de Queiroz"/USP). 
PECUARIA DE CORTE. Agroanalysis, Rio de Janeiro, diversos.

PECUARIA DE CORTE. Suma Agrícola e Pecuāria, São Paulo, diversos.

PINo, F.A. Anālise de Intervenção em Sēries Temporais - Aplicaçōes em Economia Agrícola. São Paulo, 1980. 253p. (Mestrado - Instituto de Matemātica e Estatística/USP).

REGRESSION ANALYSIS for Time Series. T.A.DOAN e R.B.LITTERMAN. Minneapolis, 1984.

SANVICENTE, A.Z. Curso de Eormação em Negöcios a Termo: Anāilse Fundamenta1. São Paulo, Bolsa de Mercadorias de São Paulo. 17p.

SCHMITZ, A e WATTS, D.G. Forecasting Wheat Yields: an application of parametric time series modelling. American Journal of Agricultural Economics, 52(2): 1970. 247-254p.

SILVEIRA Jr., P. Modelo de Crescimento para Bovinos da Raça Ibagē, ten do em conta a Oscilação Estacional. Pelotas, RS. 1979. 121p. (Titular - Universidade Federal do Paranā).

STATISTICAL GRAPHICS SYSTEM. United States of America. Statistical Graphics Corporation. Copyright, 1985. 
TSUNECHIRO, A. O Desempenho dos Mercados a Termo: Os Casos do Café, Soja e Boi Gordo na Bolsa de Mercadorias de São Paulo. São Paulo, 1983. 124p. (Mestrado - Faculdade de Economia e Administração/USP).

YO, G.T. Operações a termo de mercadorias: Commodities. São Paulo, Gedimex, 1981. 206p. 


$$
A P E N D I C E
$$




\begin{tabular}{|c|c|c|c|c|c|c|c|c|c|c|c|c|}
\hline Anos & $\mathrm{J}$ & $\mathrm{F}$ & M & A & M & $\mathrm{J}$ & $\mathrm{J}$ & A & $S$ & 0 & $N$ & D \\
\hline 1970 & 158,4 & 161,0 & 163,0 & 175,2 & 171,2 & 171,2 & 179,5 & 194,1 & 195,9 & 205,3 & 210,9 & 217,6 \\
\hline 1971 & 212,6 & 213,7 & 211,4 & 209,2 & 208,8 & 208,0 & 206,2 & 207,8 & 208,2 & 216,5 & 220,5 & 223,7 \\
\hline 1972 & 223,8 & 223,1 & 221,4 & 222,9 & 220,1 & 215,9 & 214,3 & 213,0 & 233,1 & 254,7 & 256,2 & 257,7 \\
\hline 1973 & 261,1 & 250,5 & 242,4 & 240,2 & 240,4 & 241,1 & 246,4 & 282,9 & 351,8 & 402,2 & 409,4 & 364,5 \\
\hline 1974 & 309,6 & 299,9 & 297,6 & 340,0 & 323,6 & 299,5 & 311,3 & 315,5 & 305,9 & 303,3 & 303,0 & 302,0 \\
\hline 1975 & 293,4 & 280,8 & 268,8 & 258,0 & 255,5 & 246,3 & 239,5 & 242,9 & 236,7 & 251,0 & 275,2 & 266,2 \\
\hline 1976 & 257,0 & 244,3 & 246,0 & 237,1 & 224,6 & 219,1 & 213,8 & 223,0 & 217,7 & 222,1 & 225,3 & 213,4 \\
\hline 1977 & 212,1 & 209,8 & 206,0 & 198,6 & 193,5 & 189,5 & 196,8 & 211,1 & 239,4 & 260,5 & 268,1 & 263,3 \\
\hline 1978 & 256,9 & 250,9 & 247,7 & 241,6 & 235,4 & 236,4 & 285,6 & 294,1 & 306,2 & 367,1 & 364,7 & 361,6 \\
\hline 1979 & 357,4 & 352,9 & 341,1 & 349,9 & 350,5 & 344,3 & 360,2 & 393,2 & 470,9 & 464,0 & 461,1 & 415,5 \\
\hline 1980 & 406,1 & 375,5 & 348,3 & 338,6 & 329,3 & 319,3 & 324,2 & 334,3 & 328,3 & 363,0 & 345,9 & 310,4 \\
\hline 1981 & 294,6 & 268,9 & 250,7 & 238,2 & 226,7 & 208,1 & 208,4 & 212,7 & 239,7 & 252,0 & 256,0 & 242,5 \\
\hline 1982 & 225,6 & 203,0 & 188,1 & 183,5 & 185,4 & 180,7 & 225,2 & 226,3 & 228,5 & 217,8 & 208,3 & 198,1 \\
\hline 1983 & 187,7 & 183,7 & 188,1 & 222,3 & 218,3 & 202,5 & 240,9 & 255,1 & 315,6 & 310,6 & 295,9 & 283,7 \\
\hline 1984 & 275,8 & 265,7 & 248,2 & 233,7 & 270,9 & 261,3 & 266,5 & 274,5 & 342,6 & 318,4 & 288,9 & 260,1 \\
\hline 1985 & 235,8 & 204,6 & 179,4 & 169,5 & 157,9 & 146,6 & 206,3 & 254,4 & 272,3 & 287,3 & 331,2 & 299,6 \\
\hline 1986 & 257,1 & 226,0 & 213,1 & 223,2 & 235,9 & 257,4 & 284,2 & 311,6 & 335,4 & 322,4 & 434,5 & 499,1 \\
\hline
\end{tabular}

FONTE: IEA, FGV, CEPEA/FEALQ. 
Tabela II - Preços reais mensais do boi magro

\begin{tabular}{lllllllllllllll}
\hline Anos & J & F & M & A & M & J & J & A & S & 0 & N & D \\
\hline 1970 & 1.472 & 1.455 & 1.491 & 1.595 & 1.551 & 1.571 & 1.657 & 1.890 & 1.939 & 1.910 & 2.138 & 2.165 \\
1971 & 2.326 & 2.298 & 2.262 & 2.324 & 2.309 & 2.320 & 2.388 & 2.469 & 2.569 & 2.551 & 2.578 & 2.576 \\
1972 & 2.559 & 2.485 & 2.472 & 2.570 & 2.534 & 2.508 & 2.586 & 2.548 & 2.597 & 2.708 & 2.716 & 2.720 \\
1973 & 2.659 & 2.687 & 2.690 & 2.747 & 2.723 & 2.763 & 2.872 & 3.170 & 3.533 & 3.805 & 4.072 & 3.566 \\
1974 & 3.164 & 3.355 & 3.806 & 3.779 & 3.845 & 3.632 & 3.600 & 3.553 & 3.357 & 3.226 & 3.080 & 3.223 \\
1975 & 3.141 & 2.967 & 2.819 & 2.682 & 2.691 & 2.592 & 2.492 & 2.437 & 2.393 & 2.406 & 2.606 & 2.483 \\
1976 & 2.425 & 2.286 & 2.291 & 2.207 & 2.197 & 2.090 & 2.017 & 1.944 & 1.844 & 1.868 & 1.801 & 1.745 \\
1977 & 1.645 & 1.672 & 1.643 & 1.737 & 1.693 & 1.771 & 1.799 & 1.835 & 1.897 & 2.052 & 2.119 & 2.177 \\
1978 & 2.217 & 2.281 & 2.396 & 2.472 & 2.439 & 2.414 & 2.701 & 2.809 & 2.906 & 3.235 & 3.225 & 3.232 \\
1979 & 3.321 & 3.431 & 3.464 & 3.618 & 3.988 & 3.919 & 3.853 & 4.041 & 4.394 & 4.447 & 4.414 & 4.296 \\
1980 & 4.190 & 4.064 & 3.908 & 3.904 & 3.761 & 3.755 & 3.732 & 3.562 & 3.419 & 3.447 & 3.325 & 3.097 \\
1981 & 2.933 & 2.709 & 2.543 & 2.387 & 2.261 & 2.155 & 2.040 & 1.992 & 1.950 & 1.981 & 1.997 & 1.982 \\
1982 & 1.874 & 1.770 & 1.652 & 1.620 & 1.654 & 1.588 & 1.746 & 1.752 & 2.091 & 1.982 & 1.750 & 1.698 \\
1983 & 1.764 & 1.843 & 1.713 & 2.517 & 2.372 & 2.130 & 2.179 & 2.397 & 2.428 & 2.888 & 2.686 & 2.727 \\
1984 & 2.741 & 2.715 & 2.779 & 2.898 & 2.866 & 2.911 & 2.917 & 2.804 & 3.208 & 3.125 & 2.976 & 2.733 \\
1985 & 2.508 & 2.219 & 1.979 & 1.866 & 1.748 & 1.625 & 1.928 & 2.237 & 2.372 & 2.350 & 2.746 & 2.655 \\
1986 & 2.412 & 2.205 & 2.200 & 2.687 & 3.113 & 3.334 & 3.839 & 4.117 & 4.464 & 4.145 & 4.899 & 5.412 \\
\hline
\end{tabular}

FONTE: IEA, FGV, CEPEA/FEALQ 
Tabela III - Preços reais mensais do bezerro

\begin{tabular}{rrrrrrrrrrrrrr}
\hline Anos & \multicolumn{1}{c}{$\mathrm{J}$} & \multicolumn{1}{c}{$\mathrm{F}$} & $\mathrm{M}$ & $\mathrm{A}$ & $\mathrm{M}$ & $\mathrm{J}$ & $\mathrm{J}$ & $\mathrm{A}$ & $\mathrm{S}$ & \multicolumn{1}{l}{0} & $\mathrm{~N}$ & $\mathrm{D}$ \\
\hline 1970 & 605 & 643 & 671 & 659 & 675 & 707 & 745 & 802 & 826 & 811 & 878 & 901 \\
1971 & 949 & 1.053 & 1.084 & 1.077 & 1.114 & 1.116 & 1.102 & 1.166 & 1.249 & 1.246 & 1.254 & 1.330 \\
1972 & 1.286 & 1.293 & 1.329 & 1.294 & 1.351 & 1.400 & 1.297 & 1.284 & 1.304 & 1.332 & 1.330 & 1.396 \\
1973 & 1.341 & 1.413 & 1.405 & 1.325 & 1.461 & 1.475 & 1.497 & 1.627 & 1.821 & 1.823 & 1.842 & 1.621 \\
1974 & 1.522 & 1.540 & 1.550 & 1.675 & 1.679 & 1.630 & 1.660 & 1.587 & 1.516 & 1.491 & 1.474 & 1.340 \\
1975 & 1.310 & 1.224 & 1.123 & 1.111 & 1.090 & 1.037 & 978 & 926 & 868 & 906 & .971 & 944 \\
1976 & 935 & 921 & 865 & 836 & 820 & 792 & 768 & 732 & 727 & 678 & 687 & 667 \\
1977 & 622 & 663 & 659 & 668 & 652 & 646 & 677 & 710 & 787 & 861 & 867 & 873 \\
1978 & 927 & 987 & 1.050 & 1.087 & 1.090 & 1.097 & 1.285 & 1.398 & 1.468 & 1.552 & 1.563 & 1.595 \\
1979 & 1.619 & 1.700 & 1.797 & 1.913 & 2.176 & 2.196 & 2.237 & 2.633 & 2.590 & 2.521 & 2.439 & 2.471 \\
1980 & 2.339 & 2.274 & 2.140 & 2.185 & 2.101 & 2.120 & 2.230 & 2.143 & 2.100 & 2.049 & 1.973 & 1.873 \\
1981 & 1.641 & 1.460 & 1.380 & 1.303 & 1.249 & 1.149 & 1.107 & 1.055 & 1.024 & 1.052 & 1.043 & 1.018 \\
1982 & 964 & 849 & 784 & 764 & 786 & 758 & 821 & 810 & 978 & 891 & 806 & 746 \\
1983 & 865 & 895 & 801 & 1.156 & 1.097 & 1.025 & 1.191 & 1.321 & 1.414 & 1.411 & 1.297 & 1.246 \\
1984 & 1.274 & 1.381 & 1.459 & 1.482 & 1.590 & 1.622 & 1.649 & 1.662 & 1.764 & 1.702 & 1.601 & 1.464 \\
1985 & 1.350 & 1.216 & 1.079 & 1.018 & 947 & 876 & 1.019 & 1.115 & 1.183 & 1.170 & 1.226 & 1.191 \\
1986 & 1.065 & 1.006 & 1.043 & 1.373 & 1.652 & 1.872 & 2.185 & 2.384 & 2.639 & 2.467 & 2.837 & 2.942 \\
& & & & & & & & & & & & \\
\hline
\end{tabular}

FONTE: IEA, FGV, CEPEA/FEALQ 